\title{
DELINEAMENTOS D-ÓTIMOS: NOVAS PROPOSTAS PARA O AUMENTO DO NÚMERO DE PONTOS DE SUPORTE
}

\section{SILVIO SANDOVAL ZOCCHI}

Engenheiro Agrônomo

Orientadora: Prof. ${ }^{a}$ Dr. $^{a}$ CLARICE G. B. DEMÉTRIO

Tese apresentada à Escola Superior de Agricultura "Luiz de Queiroz", da Universidade de São Paulo, para obtenção do título de Doutor em Agronomia, Área de Concentração: Estatística e Experimentação A gronômica.

P I R A C I C A B A

Estado de São Paulo - Brasil

Outubro - 1998 
Dados Internacionais de Catalogação na Publicação (CIP) DIVISĀO DE BIBLIOTECA E DOCUMENTAÇĀO - Campus "Luiz de Queiroz"/USP

Zocchi, Silvio Sandoval

Delineamento $\mathrm{D}$-ótimos: novas propostas para o aumento do número de pontos de suporte / Silvio Sandoval Zocchi. - - Piracicaba, 1998.

$97 \mathrm{p}$.

Tese (doutorado) - - Escola Superior de Agricultura Luiz de Queiroz, 1998. Bibliografia.

1. Delineamento de experimento 2. Estatistica aplicada 3. Modelo Matemático I. Titulo

CDD 519.5 


\section{DEDICATÓRIA}

Aos meus queridos pais, com eterna gratidão,

dedico com carinho e amor. 


\section{Agradecimentos}

A Prof ${ }^{a}$. Dr ${ }^{a}$. Clarice Garcia Borges Demétrio, a orientação, a amizade e o constante estímulo.

Ao Professor Dr. Anthony Curtis Atkinson, a supervisão e o estímulo durante o período de estudos na "London School of Economics and Political Science".

À Fundação Coordenação de Aperfeiçoamento de Pessoal de Nível Superior (CAPES) a bolsa de estudos (sanduíche) concedida.

Aos Professores e funcionários do Departamento de Matemática e Estatística da ESALQ/USP, o apoio.

Aos colegas de curso o companheirismo e a amizade.

Aos amigos do coração a força, a amizade e o carinho.

Ao Prof. Dr. Pedro Christtofoleti e à Doutoranda Marluce Gonçalves Corteza, a gentileza de terem cedido os dados da Tabela 4.

Ao Dr. Natanael Márcio Itepan, a gentileza de ter cedido os dados da Tabela 1.

A todos que, direta ou indiretamente, colaboraram nesta etapa da minha vida.

A Deus. 


\section{Sumário}

Página

LISTA DE FIGURAS

v

LISTA DE TABELAS vii

RESUMO ix

SUMMARY Xi

1 INTROdUÇÃo E REVISÃo de Literatura 1

2 Material $\quad 7$

2.1 Estudo da influência da radiação gama na emergência da mosca doméstica (Musca domestica) . . . . . . . . . . . . . . 7

2.2 Estudo da toxicidade de uma droga para fetos em desenvolvimento . . 10

2.3 Estudo da produtividade de cebola (Alium cepa) em função da densidade de plantio ......................... 11

2.4 Ensajo de resistência do capim-marmelada (Brachiaria plantaginea) a

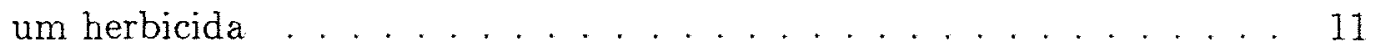

3 MÉtodos 15

3.1 Modelos ......................... 15

3.1 .1 Modelos logísticos multinomiais ............ 15

3.1.2 Modelo logístico de dose e resposta . . . . . . . . . . . 21

3.1.3 Modelos de produtividade em função da densidade de plantio . 23

3.2 Delineamentos ótimos . . . . . . . . . . . . . . . . . . 23

3.2.1 Conceitos básicos ................... . . 24

3.2.2 Critérios de otimização mais comuns e eficiência entre dois de-

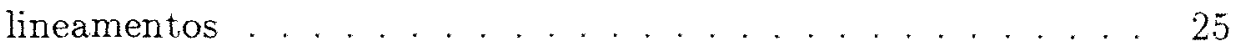


3.2.3 Delineamentos ótimos e "boostrap" . . . . . . . . . . 34

3.2.4 Delineamentos para a detecçāo de falta de ajuste . . . . . . 37

3.3 Teorema da equivalência geral . . . . . . . . . . . . . 48

3.3.1 Modelos de regressão nāo linear multivariada . . . . . . . 52

3.3.2 Modelos logísticos multivariados . . . . . . . . . . 57

3.3.3 Modelos para a deteç̧ão de falta de ajuste . . . . . . . 59

4 Resultados e Discussão 61

4.1 Delineamentos D-ótimos para modelos logísticos multinomiais . . . 61

4.2 Delineamentos ótimos e "boostrap" . . . . . . . . . . . . 67

4.3 Delineamentos para a deteç̧āo de falta de ajuste . . . . . . . . . 74

$\begin{array}{llr}5 & \text { Conclusões } & 88\end{array}$

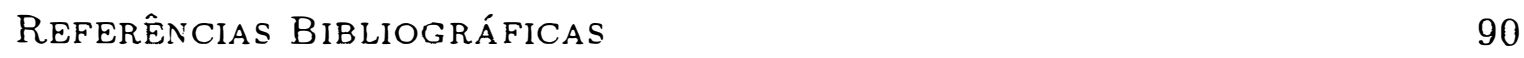




\section{Lista DE FIguras}

Página

1 Respostas hierárquicas no estudo da emergência de moscas: $A=$ morte antes da emergência, $\mathrm{B}=$ morte durante a emergência. . . . . . . . . 9

2 Proporções observadas de controle de dois biotipos, resistente e suscetível, do capim marmelada em função da dose do herbicida haloxyfop.

3 Concentrações médias esperadas para as substâncias $A(-), B(--)$ e $C(\cdots)$ segundo os modelos propostos por (Fedorov, 1972, p.218), $\operatorname{com} \theta_{1}=0,7$ e $\theta_{2}=0,2 \ldots \ldots \ldots \ldots \ldots \ldots \ldots \ldots \ldots \ldots \ldots$

4 Gráfico da função $\psi\left(x, \theta, \xi^{*}\right)(-)$ para o delineamento localmente Dótimo $\xi^{*}$ e da função $E_{\theta} \psi\left(x, \boldsymbol{\theta}, \xi_{E}^{*}\right)(--)$ para o delineamento D-ótimo Bayesiano $\xi_{E}^{*}$

5 Funções de variância $\psi(x, \hat{\theta}, \xi)$, que confirmam a otimalidade do tipo D dos delineamentos Local (-), Bayesiano considerando-se $10 \times \hat{\Sigma}_{1}$ $(--)$ e Bayesiano considerando-se $12 \times \hat{\Sigma}_{1}(--)$, apresentados na Tabela 8

6 Proporções observadas e estimadas (-) de controle de dois biotipos, resistente e suscetível, do capim marmelada, em função da dose do herbicida haloxyfop.

7 Distribuição empírica "bootstrap" marginais dos parâmetros $b, D M_{R}$, $D M_{S}$ and $r$, baseada em 5000 amostras.

8 Funções de variância do valor predito para o delineamento localmente D-ótimo ( . -) e para o delineamento D-ótimo Bayesiano (-) baseado na distribuição "bootstrap" empírica dos parâmetros 
9 Distribuiçōes empíricas "bootstrap" marginais das doses ótimas dos delineamentos localmente D-ótimos baseadas em 5000 amostras "bootstrap".

10 Distribuição empírica dos logaritmos das doses dos delineamentos localmente D-ótimos. . . . . . . . . . . . . . . . . . 75

11 Gráficos de $\psi\left(x, \xi^{*}\right)$ para os delineamentos D-ótimos contínuos de Bayes, para $\tau=0,1(-), \tau=1(\cdots)$ e $\tau=10(\cdots), \operatorname{com} N=12$, para o modelo aumentado construído adicionando-se um polinômio de ordem pequena ao modelo original.

12 Gráficos de $\psi\left(x, \xi^{*}\right)$ para os delineamentos D-ótimos contínuos de Bayes, para $\tau=0,1(-), \tau=1(-)$ e $\tau=10(\cdots)$, com $N=12$, para o modelo aumentado construído adicionando-se termos quadráticos e de produto cruzado às derivadas parciais da resposta em relação aos parâmetros.

13 Gráficos de $\psi\left(x, \xi^{*}\right)$ para os delineamentos D-ótimos contínuos de Bayes, para $\tau=0,1(-), \tau=1(--)$ e $\tau=10(\cdots), \operatorname{com} N=12$, para o modelo aumentado construído aninhando-se o modelo original em um mais geral. 


\section{LISTA DE TABELAS}

Página

1 Número de pupas não abertas $\left(y_{1}\right)$, número de moscas que morreram antes de completar a emergência $\left(y_{2}\right)$ e número de moscas que completaram a emergência ( $\left.y_{3}\right)$, após a exposição a diferentes doses $(x)$ de radiação gama.

2 Números totais de fetos mortos, malformados e normais em função da concentração, em $m g / k g$ por dia, de um solvente industrial dado a ratas prenhes.

3 Produções médias por planta, em $g$, e produtividades, em $\mathrm{kg} / \mathrm{pé}^{2}$, em diferentes densidades de plantio, em plantas/pé $e^{2}$, relativas a um híbrido de cebola. . . . . . . . . . . . . . . . . 12

4 Porcentagens de controle de dois biotipos de capim marmelada (Brachiaria plantaginea) a diferentes doses do herbicida haloxyfop.

5 Critérios de otimização de delineamentos e respectivas funções que devem ser minimizadas para a obtenção de delineamentos ótimos . . 27

6 Versões Bayesianas do critério de otimização D . . . . . . . . . . . 29

7 Distribuição a priori de $\left(\theta_{1} ; \theta_{2}\right) \ldots \ldots \ldots 7$

8 Delineamentos localmente D-ótimos e Bavesianos para a regiào experimental $x \in[0,200]$ e a matriz de variâncias e covariâncias $\hat{\Sigma}_{1}$ multiplicada por 10,11 e $12 \ldots \ldots$

9 Delineamentos D-ótimos local e Bayesiano, considerando-se as estimativas de máxima verossimilhança obtidas para os parâmetros do modelo (56) e a respectiva matriz de variâncias multiplicada por 10 , para os dados da Tabela 2 
10 Estimativas de quadrados mínimos e "bootstrap" (baseada em $B=$ 5000 amostras) dos parâmetros do modelo (9) para a análise dos dados da Tabela 4. (Desvios padrões entre parênteses) . . . . . . . . . 67

11 Delineamentos localmente D-ótimo e Bayesiano D-ótimo baseado na distribuição empírica "bootstrap" de $\boldsymbol{\theta}$. . . . . . . . . . . . . . . . 69

12 Estimativas "bootstrap" das doses dos delineamentos localmente Dótimos e respectivos coeficientes de variação.

13 Delineamentos D-ótimos exatos de Bayes para os três métodos de aumentar o modelos original: (1) adicionar ao modelo original, um polinômio de ordem pequena; (2) adicionar termos quadráticos e de produto cruzado às derivadas parciais da resposta em relação aos parâmetros e (3) aninhar o modelo original em um mais geral.

14 Delineamentos D-ótimos exatos de Bayes, gerados usando o procedimento de transformação iterativa, para os três métodos de aumentar o modelos original: (1) adicionar ao modelo original, um polinômio de ordem pequena; (2) adicionar termos quadráticos e de produto cruzado às derivadas parciais da resposta em relação aos parâmetros e (3) aninhar o modelo original em um mais geral.

15 Delineamentos D-ótimos contínuos, com $N=12$, de Bayes para os três métodos de se aumentar o modelo original: (1) adicionar ao modelo original um polinômio de ordem pequena; (2) adicionar termos quadráticos e de produto cruzado às derivadas parciais da resposta em relação aos parâmetros e (3) aninhar o modelo original em um mais geral. 


\title{
DELINEAMENTOS D-ÓTIMOS: NOVAS PROPOSTAS PARA O AUMENTO DO NÚMERO DE PONTOS DE SUPORTE
}

\author{
Autor: SILVIO SANDOVAL ZOCCHI \\ Orientadora: Prof. ${ }^{a}$ Dr. ${ }^{a}$ CLARICE G. B. DEMÉTRIO
}

\section{RESUMO}

Modelos não lineares de regressão são amplamente usados na Agricultura para análise de resultados provenientes de ensaios de dose e resposta, ensaios de produtividade em função da densidade de plantio, estudos de crescimento etc.

O planejamento desses experimentos, muitas vezes, demandam altos investimentos de tempo e recursos, sendo crítica a escolha dos pontos de suporte (doses, densidades de plantio etc.).

Nesses casos, escolhido um modelo, aconselha-se utilizar a teoria do planejamento ótimo para obter delineamentos ótimos para se estimarem os parâmetros do módelo. No entanto, os delineamentos assim gerados, são dependentes dos valores desses parâmetros e geralmente não possuem um número suficiente de doses diferentes, necessário para se verificar a falta de ajuste do modelo aos dados.

Como solução a esse problema, costuma-se aninhar o modelo em um mais geral, e obter, para esse modelo, delineamentos D-ótimos. Esses delineamentos podem apresentar, no entanto, um número excessivo de pontos. Como alternativa a esse procedimento, as idéias propostas por DuMouchel \& Jones (1994) foram estendidas a modelos não-lineares usando uma distribuição a priori a respeitó dos parâmetros do modelo, gerando delineamentos exatos e contínuos com um pequeno 
número de pontos extras. Em seguida, adaptou-se o Teorema da equivalência geral (Kiefer \& Wolfwitz, 1960) a essa situação, obtendo-se uma forma simples de verificação da otimalidade dos delineamentos gerados. Como ilustração da utilidade da metodologia propiosta, apresenta-se o planejamento de um ensaio de produtividade de uma cultura em função da densidade de plantio.

Como uma segunda alternativa, o presente trabalho propõe o uso do método de reamastragem "bootstrap" para se obter uma distribuição empírica conjunta das doses dos delineamentos ótimos e a partir desta, sugerir delineamentos com o número de pontos de suporte desejado, partindo-se dos resultados de um ensaio preliminar. O planejamento de um ensaio de dose e resposta de resistência do capim marmelada (Brachiaria plantaginea) a um herbicida inibidor da ACCase, a partir de um ensaio preliminar, ilustra a utilidade, simplicidade e generalidade do método proposto.

Ensaios de dose e resposta freqüentemente produzem respostas multicategóricas, sendo que modelos para experimentos desse tipo são descritos em livros como McCullagh \& Nelder (1989) e Agresti (1990, 1996). A literatura existente, no entanto, não aborda o planejamento desses ensaios. Neste trabalho, o Teorema da equivalência geral (Kiefer \& Wolfwitz, 1960) para o critério D de otimização, foi adaptado para modelos logísticos multivariados (Glonek \& McCullagh, 199.5) de dose e resposta, produzindo uma metodologia de planejamento bastante simples. Para ilustrar o procedimento proposto, apresenta-se o planejamento de dois ensaios, um em Entomologia e outro em Biologia. 


\title{
D-OPTIMUM DESIGNS: NEW IDEAS FOR AUGMENTING THE NUMBER OF DESIGN POINTS
}

\author{
Author: SILVIO SANDOVAL ZOCCHI \\ Adviser: Prof. ${ }^{a}$ Dr. ${ }^{a}$ CLARICE G. B. DEMÉTRIO
}

\section{SUMMARY}

Non linear models are widely used in Agriculture to analyse results from dose-response bioassays, yield-density experiments, growth studies etc.

Planning these experiments often requires large amounts of time and resource, being critical the choice of the design points (doses, densities etc.).

In these cases, chosen a model, it is recommended to use the optimum design theory in order to get optimum designs to estimate the model parameters. The generated designs, though, depend upon the parameter values and rarely contain sufficient design points to allow for model checking.

As a common solution to this problem, one can embed the original model in a more general one and generate $\mathrm{D}$-optimum designs to estimate its parameters. This procedure, though, may yield optimum designs with excessively many design points devoted to model checking. The present work extend the ideas of DuMouchel \& Jones (1994) to non linear models and use a flexible prior to generate exact and continuous designs with few extra points. The general equivalence theorem (Kiefer \& Wolfwitz, 1960) is then adapted to this class of models, providing an effective method to generate and check the optimality of designs. The planning of a yield-density experiment demonstrates the method.

As a new strategy based on a prior distribution of the parameters, this work proposes the use of the bootstrap resampling technic to generate an empirical 
joint distribution of the optimum design points and generate, from it, a design with the desired number of points. The planning of a dose-response bioassay for testing a weed (Brachiaria plantaginea) resistance to a herbicide, based on a preliminary assay, demonstrates the facility and utility of the proposed method.

Multicategorical responses frequently occur in dose-response bioassays, that can be analysed using the models presented by McCullagh \& Nelder (1989) and Agresti (1990, 1996). Despite of the existence of such models, there are no methods available in the literature to help planning those assays. Here the general equivalence theorem (Kiefer \& Wolfwitz, 1960) for the criterion D is adapted to this class of models, providing an effective method to generate and check the optimality of designs. Two examples, one on flies, the other on mice, demonstrate the method, which can be easily implemented. 


\section{Introdução e Revisão de Literatura}

Modelos não lineares de regressão são amplamente usados na Agricultura para análise de resultados provenientes de ensaios de dose e resposta, ensaios de produtividade em função da densidade de plantio, estudos de crescimento etc.

O planejamento desses ensaios, em linhas gerais, consta da escolha dos pontos de suporte, por exemplo, doses em um ensaio de dose e resposta, e dos respectivos números de repetições, geralmente realizado baseando-se na experiência prévia do pesquisador, obtida a partir de ensaios preliminares ou da literatura existente.

Esse planejamento é algumas vezes difícil de ser realizado, especialmente se: por alguma limitação de ordem técnica ou financeira, o pesquisador necessite de ensaios com um pequeno número de pontos de suporte e não possa realizar ensaios preliminares. Em Horticultura, por exemplo, ensaios de dose e resposta com herbicidas geralmente demandam altos investimentos de tempo e recursos, sendo crítica a escolha das doses a serem utilizadas.

Nesses casos recomenda-se o uso da teoria do planejamento ótimo de experimentos ou obtenção de delineamentos experimentais ótimos descritos nos livros de Fedorov (1972), Silvey (1980), Pàzman (1986), Atkinson \& Donev (1992), Pukelsheim (1993) e Fedorov \& Hackel (1997). Atkinson (1996) comenta sobre a utilização dos delineamentos ótimos em diversas áreas de aplicação como Biologia, Química e Engenharia. Entende-se por delineamento exato, o conjunto dos diferentes pontos de suporte do ensaio com os respectivos pesos, dados pelo número de repetições de cada ponto dividido pelo número total de pontos. No caso de se considerarem pesos não necessariamente racionais, têm-se os delineamentos denominados aproximados ou contínuos. 
Para a utilização dessa teoria, deve-se inicialmente definir o modelo que deverá ser utilizado para a análise dos resultados do futuro ensaio, e definir claramente seus ojetivos, em função da matriz de informação associada ao modelo escolhido. Diversas funções foram propostas por Brown et al. (1985) para definir critérios para a escolha de um delineamento. $O$ mais freqüentemente usado é o critério $D$, na qual o determinante da matriz de informação ou o seu logaritmo é maximizado, gerando os delineamentos D-ótimos.

Para modelos lineares de regressão, a matriz de informação não depende dos parâmetros do modelo e, conseqüentemente, os delineamentos D-ótimos também não são dependentes dos parâmetros do modelo. Entretanto, para modelos não lineares, os delineamentos D-ótimos dependem diretamente dos parâmetros não lineares do modelo, através da matriz de informação. Logo, escolhidos valores prévios para esses parâmetros, o delineamento D-ótimo obtido será ótimo somente para esse conjunto de valores, sendo, por esse motivo, chamado delineamento localmente Dótimo (Atkinson \& Donev, 1992). Tanto para modelos lineares como para modelos não lineares, porém, os delineamentos produzidos têm poucos pontos de suporte, em geral, em número igual ao número de parâmetros do modelo, não permitindo que se verifique a falta de ajuste. Para modelos de regressão linear simples, por exemplo, o delineamento D-ótimo teria apenas dois pontos de suporte diferentes.

Como estratégia para a obtenção de delineamentos com alguns pontos adicionais, para modelos não lineares, geralmente são utilizadas versões Bayesianas dos critérios de otimização, cujas funções a serem maximizadas são dadas pela esperança da função correspondente ao critério original, em relação aos parâmetros, dada uma distribuição a priori para os mesmos. Uma ampla revisão de literatura a respeito de delineamentos Bayesianos foi apresentada por Chaloner \& Verdinelli (1995).

Um alternativa simples para gerar delineamentos quase D-ótimos com alguns pontos de suporte a mais, proposta por O'Brien (1995), sugere a utilização de um delineamento formado por $r_{1}$ repetiçōes dos pontos do delineamento localmente D-ótimo e $r_{2}$ repetições dos pontos de um delineamento gerado de modo a ter uma 
eficiência alta, previamente escolhida. Escolhidos os valores de $r_{1}$ e $r_{2}$, tal método é bastante fácil de ser implementado, apresentando, porém, o inconveniente de não ser ótimo segundo um critério previamente escolhido.

Como proposta original para a obtenção de delineamentos com pontos de suporte adicionais, pretende-se, a partir dos resultados de um experimento prévio, utilizar a metodologia de reamostragem "bootstrap" (Efron \& Tibishirani, 1993) para gerar uma distribuição empírica dos parâmetros do modelo adotado e gerar delineamentos D-ótimos Bayesianos. Propõe-se, ainda, obter uma distribuição "bootstrap" empírica conjunta dos pontos de suporte dos delineamentos localmente D-ótimos e, a partir desta, sugerir um ou mais delineamentos com o número de pontos de suporte desejado pelo pesquisador, assunto sobre o qual não foram encontradas referências bibliográficas.

Para modelos lineares, contudo, essas idéias não se aplicam podendo-se, alternativamente, aninhar o modelo adotado em um mais geral e gerar delineamentos ótimos para o modelo ampliado (Atkinson, 1972, 1975). Esse procedimento pode, no entanto, trazer como conseqüência indesejada, delineamentos ótimos com um número excessivo de pontos, especialmente se o número de parâmetros do modelo aumentado for muito maior que o número de parâmetros do modelo original.

Para a obtenção de delineamentos D-ótimos exatos para modelos lineares de regressão, com um número adicional pequeno de pontos de suporte, DuMouchel \& Jones (1994) propuseram um procedimento que envolve uma distribuição a priori padrão para os parâmetros do modelo ampliado. Esse procedimento trata, em linhas gerais, da maximização do determinante da matriz de informação a posteriori, obtendo-se os delineamentos D-ótimos de Bayes (denominação adotada neste trabalho para contrastar com os delineamentos Bayesianos). Os autores, no entanto, não mencionam a obtenção de delineamentos contínuos, nem a obtenção de delineamentos para modelos de regressão não lineares e não propõem nenhuma forma de verificação da otimalidade dos delineamentos gerados.

Para verificar se um delineamento contínuo é ótimo segundo um critério de otimização, deve-se utilizar o Teorema da equivalência geral (Kiefer \& Wolfwitz, 
1960), que estabelece a equivalência entre delineamentos contínuos ótimos segundo diversos critérios. Este teorema, de difícil aplicação direta, foi apresentado de forma mais simples por Fedorov (1972) e Atkinson \& Donev (1992), para diversas situações. Para os delineamentos D-ótimos de Bayes, no entanto, o teorema ainda precisa ser adaptado.

Pana os ensaios de dose e resposta com respostas multi-categorizadas, comuns em Entomologia, há também necessidade do desenvolvimento de metodologias de planejamento, o que envolve a adaptação desse teorema de modo que possa ser utilizado de uma forma simples e eficiente. A etapa inicial para esse planejamento é a escolha do modelo, sendo os modelos multinomiais descritos por McCullagh \& Nelder (1989), Agresti (1990), e Agresti (1996), os mais utilizados na prática. Entretanto, os dados multinomiais também podem ser analisados usando-se modelos log-lineares de Poisson, cuja equivalência com os modelos multinomiais foi amplamente discutida por Bishop et al. (1975), McCullagh \& Nelder (1989), Agresti (1990), Lang (1996b) e Agresti (1996). A análise de dados multinomiais usando-se modelos log-lineares de Poisson e o pacote computacional GLIM (Numerical Algorithms Group, NAG, 1986) é apresentada em Aitkin et al. (1989, Cap.5).

Glonek (1996) discute uma classe de funções de ligação que ficam entre a transformação logística multivariada de McCullagh \& Nelder (1989, Cap.6), sistematicamente discutida por Glonek \& McCullagh (1995), e a análise de tabelas de contingência por decomposição log-linear. Essa nova classe de modelos inclui os modelos de Fitzmaurice e Laird (1993) como um caso particular e é útil para analisar dados compostos de várias respostas categorizadas com preditores contínuos ou categorizados.

Os modelos logísticos multivariados propostos por Glonek \& McCullagh (1995) incluem, como casos particulares, os modelos multinomiais descritos por McCullagh \& Nelder (1989), Agresti (1990), e Agresti (1996) e utilizam uma notação geral bastante concisa, que será utilizada no presente trabalho.

O uso de modelos logísticos para dados binários, caso particular dos dados multinomiais, foi extensamente abordado em livros como os de Cox \& Snell 
(1989), Collet (1991) e Morgan (1992). O planejamento de ensaios para esses modelos também foi amplamente discutido por Tsutakawa (1972), Tsutakawa (1980), Chaloner \& Larntz (1989) e Flournoy (1993). Atkinson, Demétrio \& Zocchi (1995) estenderam a idéia aos modelos logísticos binomiais cujas doses do estímulo eram aplicadas a uma mistura de indivíduos pertencentes a diferentes populações quanto à resposta a esse estímulo, e ilustraram o método obtido utilizando os dados de um ensaio com moscas domésticas (Musca domestica) obtidos por Zocchi (1993). Atkinson (1995) apresenta alguns tópicos na obtenção de delineamentos localmente ótimos e ótimos Bayesianos para modelos lineares generalizados, ilustrado através de um exemplo com modelos de regressão logística com duas variáveis explanatórias em que há restrições na região experimental.

Heise \& Myers (1996) propuseram métodos para a obtenção de delineamentos D-ótimos para o modelo de Gumbel (1961) para regressão logística bivariada e adaptaram o teorema da equivalência geral (Kiefer \& Wolfwitz, 1960) para esse caso.

Apesar da grande quantidade de artigos que tratam do planejamento ótimo para modelos logísticos com respostas binomiais, não foram encontrados na literatura artigos considerando a obtenção de delineamentos ótimos para modelos com respostas multinomiais.

Como comentário extra, a maioria dos resultados em otimização de delineamentos experimentais partem do pressuposto que se conheça o modelo estatístico para a análise dos resultados do experimento, antes da realização do mesmo. Para os casos em que diversos modelos podem se ajustar aos dados, Pukelsheim \& Rosenberger (1992) descreveram a obtenção de delineamentos ótimos para a discriminação de diferentes modelos Ponce de Leon \& Atkinson $(1992,1993)$ apresentam o planejamento ótimo para discriminação entre dois modelos lineares generalizados. De uma forma suscinta, destacam-se como objetivos do presente trabalho:

- desenvolver nova metodologia para a obtenção de delineamentos com o número 
desejado de pontos de suporte, a partir de uma distribuiçāo "bootstrap" empírica conjunta dos pontos de suporte dos delineamentos localmente Dótimos, obtida partindo-se dos resultados de um experimento prévio;

- estender a metodologia apresentada por DuMouchel \& Jones (1994) para a obtenção de delineamentos exatos, a modelo não lineares de regressão. Estendê-la para a obtenção de delineamentos contínuos e adaptar o Teorema da equivalência geral (Kiefer \& Wolfwitz, 1960) a essa situação, de modo que se tenha uma forma simples de verificação da otimalidade dos delineamentos gerados;

- adaptar o Teorema da equivalência geral (Kiefer \& Wolfwitz, 1960) apresentado por Fedorov (1972) ao critério D de otimização para modelos logísticos multinomiais de dose e resposta, de modo que se tenha uma forma simples de verificação da otimalidade de delineamentos;

Para ilustrar a metodologia proposta, serão utilizados resultados provenientes de ensaios em diversas áreas da Biologia, descritos na Seção 2. 


\section{MATERiaL}

Nesta Seção, são descritos os experimentos cujos resultados serão utilizados para a obtenção de delineamentos ótimos.

\subsection{Estudo da influência da radiação gama na emergência da mosca doméstica (Musca domestica)}

A necessidade premente de se aumentar a disponibilidade de proteína animal de maneira racional e econômica, deu origem aos modernos sistemas de produção animal. Esses sistemas acarretam um grande acúmulo de esterco, com enorme potencial para a poliferação de moscas.

As moscas são de grande importância médico-veterinária, pois além de transmissoras de vários agentes patogênicos como vírus, rickettsias, bactérias e protozoários, atuam na disseminação de ovos de helmintos e são vetores de ovos da mosca do berne. Em granjas agrícolas, sujam os ovos com suas fezes e regurgitações, obrigando a sucessivas lavagens dos ovos, com risco de quebra e diminuição de sua longevidade. Segundo Costa (1989) os principais muscídeos encontrados nesse meio são a mosca doméstica, Musca domestica (L., 1758), a mosca do estábulo, Stomoxys calcitrans (L., 1759) e a falsa mosca do estábulo, Muscina stabulans (Fallén, 1816).

Para se obter um controle satisfatório desses insetos, o programa de manejo deve integrar métodos culturais, químicos e biológicos, sendo que a prática de qualquer um deles isoladamente pode não ser eficiente. O controle químico isolado, por exemplo, levou ao aparecimento de populações resistentes a inseticidas como o DDT, BHC, organofosforados, carbamatos e piretróides.

O controle biológico dos estágios imaturos da mosca pode ser realizado 
por predadores e parasitóides, necessitando, porém, da sua criação massal, para posterior liberação em áreas problemáticas.

A criação de parasitóides em laboratório, segundo Itepan et al. (1987), é otimizada com a utilização de pupas irradiadas com raios gama. Com o objetivo de verificar se o processo de irradiação aumenta o período de aceitabilidade de pupas de Musca domestica como hospedeira de alguns parasitóides pupais, Itepan (1995) conduziu um ensaio para se avaliar a influência da radiação gama na emergência da mosca doméstica. Esse ensaio foi conduzido no laboratório da Seção de Entomologia do Centro de Energia Nuclear na Agricultura (CENA/USP) e a fonte de radiação gama utilizada foi um irradiador de Cobalto-60, tipo Gammabeam-650, cuja atividade no início dos experimentos foi de $9,8 \times 10^{13} \mathrm{~Bq}(2644 \mathrm{Ci})$.

Nesse estudo, sete frascos contendo, cada um, 500 pupas de moscas com 2 dias de idade, foram expostos a uma dentre várias doses de radiação gama, em Gy. Após um certo periodo de tempo, observou-se em cada frasco, o número $y_{1}$ de moscas que morreram antes da emergência (número de pupas não abertas), o número $y_{2}$ de moscas que morreram antes de completar a emergência e o número $y_{3}$ de moscas que completaram a emergência, do total de $m=500$ pupas. Os resultados são apresentados na Tabela 1.

O objetivo do pesquisador estava no estudo da mortalidade das moscas antes da emergência $y_{1} / m$ e na razão entre as que morreram antes de completar a emergência e o total de moscas que começaram a emergir $y_{2} /\left(m-y_{1}\right)$. Neste caso, as respostas têm uma estrutura claramente hierárquica que é ilustrada na Figura 1.

Embora a criação de moscas seja bastante fácil, este tipo de experimento é bastante trabalhoso e caro devido à utilização de uma fonte de radiação gama repetidas vezes (uma vez para cada frasco). Desta forma, experimentos eficientes teriam um pequeno número de doses distintas, sendo que o número de pupas recebendo cada dose seria menos crítico. 
Tabela 1: Número de pupas não abertas $\left(y_{1}\right)$, número de moscas que morreram antes de completar a emergência $\left(y_{2}\right)$ e número de moscas que completaram a emergência $\left(y_{3}\right)$, após a exposição a diferentes doses $(x)$ de radiação gama.

\begin{tabular}{ccccc}
\hline \multirow{2}{*}{$\begin{array}{c}\text { Dose de radiação } \\
\text { gama, em Gy }\end{array}$} & \multicolumn{3}{c}{ Categorias de resposta } & Número total \\
\cline { 2 - 4 }$x$ & Pupas não abertas & \multicolumn{2}{c}{ Pupas abertas $\left(m-y_{1}\right)$} & de pupas \\
\cline { 2 - 3 } & $y_{1}$ & $y_{2}$ & $y_{3}=m-y_{1}-y_{2}$ & $m$ \\
\hline 80 & 62 & 5 & 433 & 500 \\
100 & 94 & 24 & 382 & 500 \\
120 & 179 & 60 & 261 & 500 \\
140 & 335 & 80 & 85 & 500 \\
160 & 432 & 46 & 22 & 500 \\
180 & 487 & 11 & 2 & 500 \\
200 & 498 & 2 & 0 & 500
\end{tabular}

Etapa 1

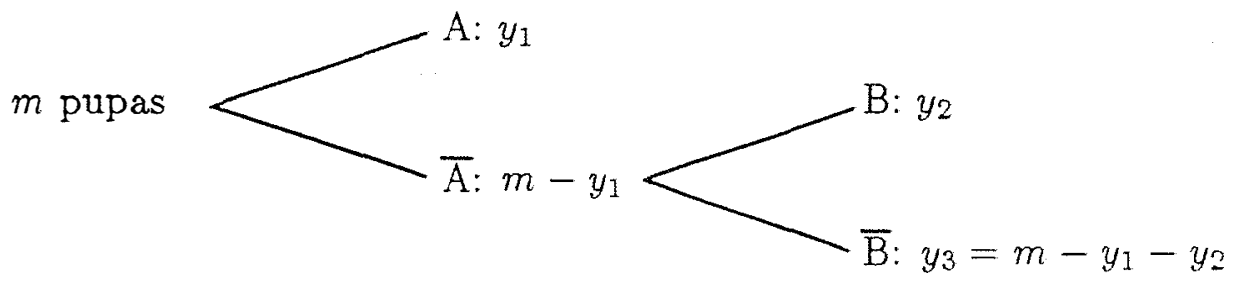

Proporções

of interesse $\quad y_{1} / \mathrm{m} \quad y_{2} /\left(m-y_{1}\right)$

Figura 1: Respostas hierárquicas no estudo da emergência de moscas: $A=$ morte antes da emergência, $B=$ morte durante a emergência. 
Tabela 2: Números totais de fetos mortos, malformados e normais em função da concentração, em $m g / k g$ por dia, de um solvente industrial dado a ratas prenhes.

\begin{tabular}{ccccc}
\hline \multirow{2}{*}{$\begin{array}{c}\text { Concentração } \\
\text { (mg/kg por dia })\end{array}$} & Mortos & Malformados & Normais & Número total \\
\cline { 2 - 4 } & de fetos \\
\hline 0 (controle) & 15 & 1 & 281 & 297 \\
62,5 & 17 & 0 & 225 & 242 \\
125 & 22 & 7 & 283 & 312 \\
250 & 38 & 59 & 202 & 299 \\
500 & 144 & 132 & 9 & 285 \\
\hline
\end{tabular}

Fonte: Price et al. (1987)

\subsection{Estudo da toxicidade de uma droga para fetos em de- senvolvimento}

Estudos com roedores são comumente usados para verificar se certas substâncias são potencialmente perigosas para fetos em desenvolvimento.

Num estudo desse tipo, Price et al. (1987) desejavam saber se o solvente industrial éter dimetil glicol dietileno poderia ser manipulado por mulheres grávidas. Com esse objetivo, realizaram um experimento com ratas (Mus rattus) prenhes, expondo, cada rata, a uma dentre cinco concentrações da droga por um certo período de tempo. Após um determinado período, seus úteros foram abertos e os fetos examinados quanto à presença de deformações, sendo que cada feto podia apresentarse em um dos três seguintes estados ou categorias: morto, malformado ou normal, categorias naturalmente ordenadas, sendo a última (normal) a mais desejada. A Tabela 2 apresenta os resultados deste experimento.

Assim como para o experimento descrito na Seção 2.1, alguém pode questionar a escolha das doses apresentadas, sendo importante, uma discussão a respeito do planejamento de um experimento eficiente. 


\subsection{Estudo da produtividade de cebola (Alium cepa) em} função da densidade de plantio

Como parte dos estudos relativos a uma certa cultura, um Engenheiro Agrônomo muitas vezes está interessado em saber qual é a densidade ideal de plantio para obter a maior produtividade. Com esse objetivo, conduz ensaios onde a cultura é plantada com diferentes densidades de plantio e observando-se a produção final.

Em uma série de ensaios com diversos híbridos de cebola (Alium cepa), descrito e analisado por Mead (1970), procurava-se obter a densidade ideal de plantio para cada hibrido, além de uma função que relacionasse a produtividade com a densidade de plantio, para fins de predição. A Tabela 3 apresenta as produções médias por planta e as correspondentes produtividades, em dez densidades de plantio diferentes, para o primeiro híbrido analisado por Mead (1970). Esse ensaio mostra, aparentemente, um número excessivo de diferentes densidades de plantio, desnecessário para cumprir os objetivos do experimento. Desse modo, um ensaio eficiente teria um número menor de diferentes densidades de plantio.

\subsection{Ensaio de resistência do capim-marmelada (Brachiaria plantaginea) a um herbicida}

O capim-marmelada é uma planta daninha que leva a consideráveis prejuizos em diversas culturas no Brasil. O seu controle, muitas vezes, envolve a aplicação de herbicidas inibidores da acetil-coenzima A carboxilase (ACCase), como o haloxyfop, por vários anos sucessivos. Nas áreas onde esse tipo de controle é utilizado, tem-se detectado o aparecimento de plantas resistentes, isto é, que sobrevivem ao tratamento com herbicidas em doses que normalmente seriam efetivas. Tal fato tem estimulado pesquisadores a estudarem o mecanismo de resistência de gramíneas a herbicidas desse grupo químico (Devine, 1997; Devine \& Eberlein, 1997).

Como parte dos estudos de resistência do capim-marmelada ao herbicida haloxyfop, foi conduzido um ensaio preliminar de dose e resposta, em casa de 
Tabela 3: Produçōes médias por planta, em $g$, e produtividades, em $\mathrm{kg} / \mathrm{pé}^{2}$, em diferentes densidades de plantio, em plantas/pé2 ${ }^{2}$, relativas a um híbrido de cebola.

\begin{tabular}{ccc}
\hline $\begin{array}{c}\text { Densidade de plantio, } \\
\text { em plantas/pé }\end{array}$ & $\begin{array}{c}\text { Produção média } \\
\text { por planta, em } g\end{array}$ & $\begin{array}{c}\text { Produtividade, } \\
\text { em } k g \times 10^{-3} / \text { pé }^{2}\end{array}$ \\
\hline 3,07 & 105,6 & 324,192 \\
3,31 & 89,4 & 295,914 \\
5,97 & 71,0 & 423,870 \\
6,99 & 60,3 & 421,497 \\
8,67 & 47,6 & 412,692 \\
13,39 & 37,7 & 504,803 \\
17,86 & 30,3 & 541,158 \\
21,57 & 24,2 & 521,994 \\
28,77 & 20,8 & 598,416 \\
31,08 & 18,5 & 574,980 \\
\hline
\end{tabular}

Fonte: Mead (1970) 
Tabela 4: Porcentagens de controle de dois biotipos de capim marmelada (Brachiaria plantaginea) a diferentes doses do herbicida haloxyfop.

\begin{tabular}{lcrrrr}
\hline Biotipo & Dose $(x)$ & \multicolumn{5}{c}{ Controle (\%) } \\
\hline \multirow{5}{*}{ Resistente } & 0,5 & 0 & 0 & 0 & 0 \\
& 1 & 0 & 0 & 5 & 0 \\
& 2 & 35 & 40 & 40 & 40 \\
& 4 & 100 & 85 & 80 & 85 \\
Suscetível & 8 & 90 & 90 & 100 & 100 \\
\hline \multirow{5}{*}{} & 0,5 & 95 & 80 & 95 & 90 \\
& 1 & 100 & 100 & 100 & 95 \\
& 2 & 100 & 100 & 100 & 100 \\
& 4 & 100 & 100 & 100 & 100 \\
& 8 & 100 & 100 & 100 & 100 \\
\hline
\end{tabular}

vegetação, inteiramente ao acaso com os tratamentos em esquema fatorial $2 \times 6$ (2 biotipos e 6 doses de herbicida) com 4 repetições. Convém observar que se trata de um experimento preliminar atípico quanto ao número de repetições, geralmente menor. As doses do herbicida, além da testemunha, foram baseadas na dose padrão $d$ indicada pelo fabricante e escolhidas em progressão geométrica: $0,5 d, 1 d, 2 d, 4 d$ e $8 d$, seguindo as recomendações de Seefeldt et al. (1995). Alguns dias após a germinação foi feito o desbaste de modo a deixar casa vaso (unidade experimental) com apenas três plantas e foi feita a aplicação do herbicida.

Após 14 dias, foram atribuídas notas ao controle do capim-marmelada em relação à testemunha, em porcentagem, apresentadas na Tabela 4 e representadas no gráfico da Figura 2.

Observando-se o gráfico para o biotipo resistente, fica evidente o comportamento típico de uma curva de dose e resposta, sempre crescente, com formato sigmoidal e proporção de controle variando de 0 a 1 . No entanto, tal comportamento não é observado para o biotipo suscetível, pois não foram utilizadas, nesse ensaio, 


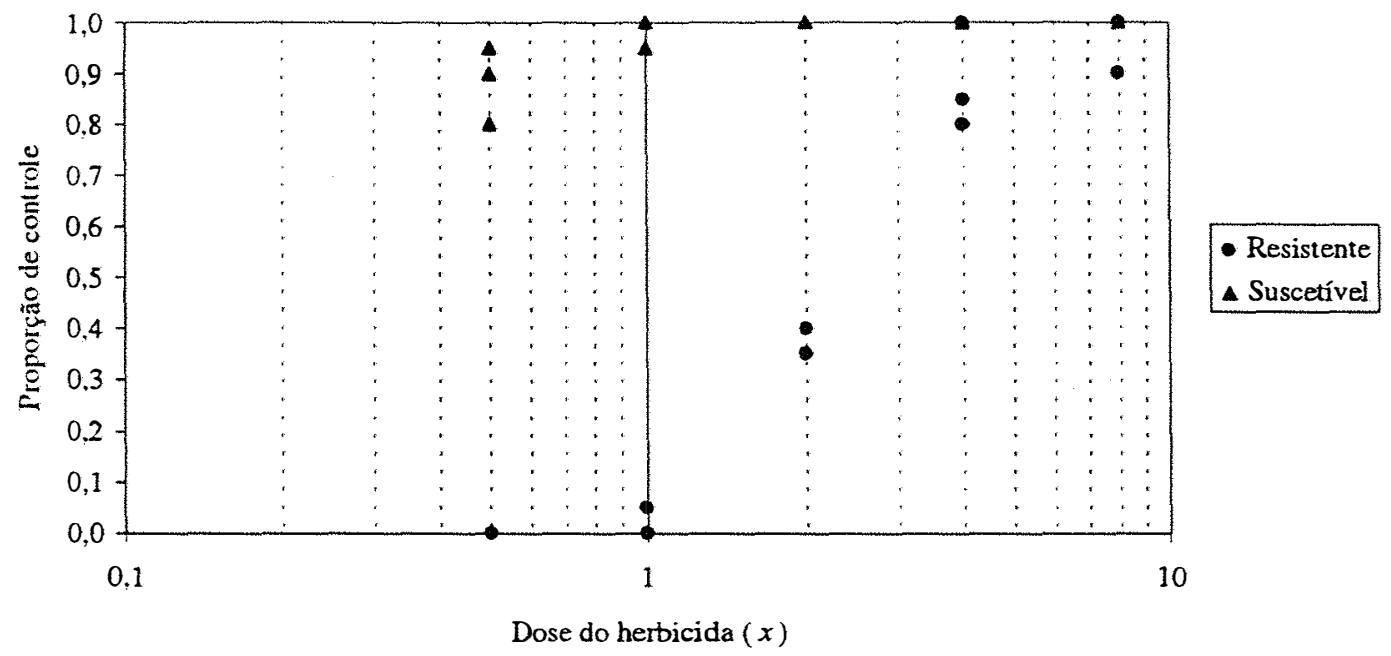

Figura 2: Proporções observadas de controle de dois biotipos, resistente e suscetível, do capim marmelada em função da dose do herbicida haloxyfop. doses inferiores a $0,5 d$, o que seria altamente recomendável para o ensaio definitivo. 


\section{MÉTOdos}

\subsection{Modelos}

Esta Seção apresenta os modelos utilizados para as análises dos dados dos ensaios descritos na Seção 2, além de outros modelos, com a finalidade básica de ilustrar a utilização da metodologia de construção de delineamentos ótimos.

\subsubsection{Modelos logísticos multinomiais}

Esses modelos serão utilizados para as análises dos dados apresentados nas Tabelas 1 e 2. Considere, por exemplo, os dados referentes ao estudo da influência da radiação gama na emergência de moscas domésticas (Seção 2.1). Nesse experimento, os possíveis resultados para cada pupa eram: pupa não aberta, morte durante a emergência da mosca e vida após a emergência, ou seja, cada indivíduo pertencia a uma dentre as $l=3$ categorias. Dada uma amostra de tamanho $m=500$ indivíduos, $y_{1}$ pertenciam à primeira categoria, $y_{2}$ à segunda e $y_{3}$ à terceira. Podese dizer, então, que dado $m$, a resposta $\left(y_{1}, y_{2}, y_{3}\right)$ é uma observação da variável aleatória trinomial $\left(Y_{1}, Y_{2}, Y_{3}\right)$.

Generalizando, seja $Y$ uma variável resposta com $l$ categorias e $Y_{u}$ $(u=1, \ldots, l)$ a variável resposta referente ao número de indivíduos pertencentes à categoria $u$. Seja $\pi_{u}(x)$ a probabilidade de um indivíduo ter resposta $u$ à dose $x$ de estímulo sendo que $\pi_{1}(x)+\cdots+\pi_{l}(x)=1$. Então, pode-se dizer que $\left(Y_{1}, \ldots, Y_{l}\right)$ tem distribuição multinomial com índice $m$ e parâmetros $\left(\pi_{1}, \pi_{2}, \ldots, \pi_{l-1}\right)\left(\pi_{l}=\right.$ $\left.1-\sum_{u}^{l-1} \pi_{u}\right)$.

Em geral, as categorias de resposta estão definidas de uma forma qualitativa, ou não numérica, e podem ser classificadas pela presença ou não de hierarquia 
nas respostas, assim como pela escala de medida. As escalas de medida são basicamente classificadas em McCullagh \& Nelder (1989, p.150) como: nominais, nas quais as categorias podem ser trocadas, não havendo nenhuma ordem natural entre elas, ordinais, nas quais as categorias estão ordenadas como os números ordinais 'primeiro', 'segundo',... de forma que não faz sentido falar em distância ou espaço entre as categorias e intervalares, nas quais as categorias estão ordenadas e a essas categorias estão associados números, de modo que a diferença entre esses números pode ser interpretada como uma medida de separação entre as categorias.

É difícil, no entanto, identificar precisamente as características que distinguem um desses tipos discutidos, das escalas de respostas hierárquicas. Os ensaios descritos nas Seções 2.1 e 2.2 servem para ilustrar este último tipo.

A seguir, são descritos alguns modelos comuns para respostas com escalas nominais, ordinais e hierárquicas e um modelo geral que inclui os anteriores como casos particulares.

Um modelo para respostas com escalas nominais em termos das probabilidades $\pi_{u}(x)$ de resposta a uma certa dose $x$ do estímulo, é dado por McCullagh \& Nelder (1989):

$$
\pi_{u}(x)=\frac{\exp \left(f_{u}^{T}(x) \boldsymbol{\theta}_{u}\right)}{\sum_{h=1}^{l} \exp \left(f_{h}^{T}(x) \boldsymbol{\theta}_{h}\right)} \quad u=1, \ldots, l
$$

onde $\theta_{u}$ é o vetor de parâmetros do modelo associado à u-ésima resposta e $f_{u}(x)$ é um vetor com dimensão $p_{u}$ cujos elementos são funções de $x$. Em geral, $f_{u}^{T}(x) \theta_{u}$ é um polinômio de ordem pequena. Fazendo-se $\boldsymbol{\theta}_{l}=0$, tem-se que:

$$
\log \frac{\pi_{u}(x)}{\pi_{l}(x)}=f_{u}^{T}(x) \theta_{u}, \quad u=1, \ldots, l-1 .
$$

Cada uma dessas $l-1$ equações não redundantes possui um vetor de parâmetros $\theta_{u}$ de dimensão $p_{u}$, de tal forma que $\sum_{u=1}^{l-1} p_{u}=p$ e $p_{l}=1$. Assim, o número total de parâmetros é $p+1$.

Se as categorias estão ordenadas, McCullagh \& Nelder (1989) propōem que se trabalhe com as probabilidades acumuladas de resposta $\gamma_{u}=\sum_{h=1}^{u} \pi_{u}$ e um 
modelo é dado por

$$
\operatorname{logit}\left[\gamma_{u}(x)\right]=\log \frac{\gamma_{u}(x)}{1-\gamma_{u}(x)}=f_{u}^{T}(x) \theta_{u}, \quad u=1, \ldots, l-1,
$$

denominado "modelo de logits acumulados" por Agresti (1990, p.321).

Por outro lado, se houver hierarquia, McCullagh \& Nelder (1989) sugerem que se trabalhe com as probabilidades condicionais de ocorrer resposta $u$ dado que ocorreu resposta $u$ ou superior, ou seja,

$$
\rho_{u}=\frac{\pi_{u}}{\pi_{u}+\cdots+\pi_{l}}
$$

e o modelo sugerido é dado por

$$
\operatorname{logit}\left[\rho_{u}(x)\right]=\log \frac{\rho_{u}(x)}{1-\rho_{u}(x)}=f_{u}^{T}(x) \theta_{u}, \quad u=1, \ldots, l-1 .
$$

onde a parte esquerda dessa equação é chamada "continuation-ratio logit" por Agresti (1990, p.319).

É importante notar que se podem utilizar, nos modelos (2) e (3), outras funções diferentes da logit, como a probit e complemento-log-log dadas por probit $(\cdot)=\Phi^{-1}(\cdot)$, onde $\Phi^{-1}(\cdot)$ é a função inversa da função de distribuição normal acumulada e complemento- $\log -\log (\cdot)=\log [1-\log (\cdot)]$.

Glonek \& McCullagh (1995) e Lang (1996a) apresentam uma notação geral para modelos log-lineares multinomiais, que inclui os casos anteriores como casos particulares. Segundo esses autores, os modelos multivariados de regressão logística são aqueles que se apresentam da seguinte forma

$$
\eta=X \theta
$$

onde $\eta$ é o vetor de preditores lineares, de dimensão $l, X$ é a matriz de dimensôes $l \times(p+1)$, dada por

$$
X=\ominus_{u=1}^{k} f_{u}^{T}(x)=f_{1}^{T}(x) \oplus f_{2}^{T}(x) \ominus \cdots \ominus f_{l}^{T}(x)=\left[\begin{array}{cccc}
f_{1}^{T}(x) & 0 & \cdots & 0 \\
0 & f_{2}^{T}(x) & \cdots & 0 \\
\cdots & \cdots & \cdots & \cdots \\
0 & 0 & \cdots & f_{l}^{T}(x)
\end{array}\right],
$$


onde $f_{u}(x)(u=1, \ldots, l-1)$ são vetores de dimensões $p_{u}$, de funções da covariável $x, f_{l}^{T}(x)=1,0$ são matrizes nulas, $\boldsymbol{\theta}=\left[\boldsymbol{\theta}_{1}^{T} \cdots \boldsymbol{\theta}_{l}^{T}\right]^{T}$ é o vetor de parâmetros, com dimensão $p+1$ e $\oplus$ é o operador soma direta. Ainda em (4), pode-se escrever

$$
\eta=g(\pi)=C^{T} \log (L \pi)
$$

onde $g(\pi)$ é a função de ligação, que representa a transformação logística multivariada $\pi \mapsto \eta, L$ e $C$ são, respectivamente as matrizes de indicadores marginais e de contrastes e $\pi=\pi(x)=\left[\pi_{1}(x) \cdots \pi_{l}(x)\right]^{T}$.

Considere, por exemplo, o seguinte modelo para $l=3$ respostas hierárquicas

$$
\begin{aligned}
& \eta_{1}=\log \frac{\rho_{1}(x)}{1-\rho_{1}(x)}=f_{1}^{T}(x) \theta_{1}=\left[\begin{array}{lll}
1 & x & x^{2}
\end{array}\right]\left[\begin{array}{l}
\theta_{10} \\
\theta_{11} \\
\theta_{12}
\end{array}\right] \\
& \eta_{2}=\log \frac{\rho_{2}(x)}{1-\rho_{2}(x)}=f_{2}^{T}(x) \theta_{2}=\left[\begin{array}{ll}
1 & x
\end{array}\right]\left[\begin{array}{c}
\theta_{20} \\
\theta_{21}
\end{array}\right] \\
& \eta_{3}=0 .
\end{aligned}
$$

Usando-se a notação apresentada em (4) e (5), pode-se reescrevê-lo da seguinte forma

$$
\begin{aligned}
{\left[\begin{array}{l}
\eta_{1} \\
\eta_{2} \\
\eta_{3}
\end{array}\right] } & =\left[\begin{array}{ccccc}
1 & 0 & 0 & -1 & 0 \\
0 & 1 & -1 & 0 & 0 \\
0 & 0 & 0 & 0 & 1
\end{array}\right] \log \left\{\left[\begin{array}{lll}
1 & 0 & 0 \\
0 & 1 & 0 \\
0 & 0 & 1 \\
0 & 1 & 1 \\
1 & 1 & 1
\end{array}\right]\left[\begin{array}{c}
\pi_{1}(x) \\
\pi_{2}(x) \\
\pi_{3}(x)
\end{array}\right]\right\} \\
& =\left[\begin{array}{llllll}
1 & x & x^{2} & 0 & 0 & 0 \\
0 & 0 & 0 & 1 & x & 0 \\
0 & 0 & 0 & 0 & 0 & 1
\end{array}\right]\left[\begin{array}{c}
\theta_{10} \\
\theta_{11} \\
\theta_{12} \\
\theta_{20} \\
\theta_{21} \\
0
\end{array}\right]
\end{aligned}
$$


Note que $\eta_{l}$ representa o contraste nulo $\log \sum_{u=1}^{l} \pi_{u}(x)=\log 1=0$, expressando a exigência $\sum_{u=1}^{l} \pi_{u}(x)=1$. Como $\eta_{l}$ é sempre igual a 0 , pode-se assumir $\theta_{l}=0$. Deve-se notar que, ao invés de impor $\eta_{l}=0$, Glonek \& McCullagh (1995) impuseram a condição equivalente $\eta_{1}=0$.

Uma vez definido o modelo, será visto, em seguida, como ajustá-lo a um conjunto de dados. Seja $m_{i}(i=1, \ldots, n)$ o número total de indivíduos submetidos a uma dose $x_{i}$ e $y_{i}=\left[\begin{array}{llll}y_{i 1} & y_{i 2} & \ldots & y_{i l}\end{array}\right]^{T}$ o vetor de dimensão $l$, de observações da variável aleatória $Y_{i}$, onde $y_{i u}$ é o número de indivíduos pertencentes à $u$-ésima categoria.

Considerando-se apenas uma observação $\boldsymbol{y}_{i}$, e que

$$
Y_{i} \sim \operatorname{Multinomial}\left(m_{i}, \pi\left(x_{i}\right)\right)
$$

o logaritmo da função de verossimilhança é dado por

$$
l\left(\boldsymbol{\theta} ; \boldsymbol{y}_{i}\right)=\log \frac{m_{i} !}{y_{i 1} ! y_{i 2} ! \ldots y_{i l} !}+\boldsymbol{y}_{i}^{T} \log \boldsymbol{\pi}\left(x_{i}\right) .
$$

Antes de se ajustar um modelo de regressão logístico multivariado a um conjunto de dados é necessário expressar $\pi$ como uma função de $\theta$. Inicialmente é necessário obter $\pi$ a partir de $\eta$, o que pode envolver métodos iterativos como o de Newton-Raphson (Glonek \& McCullagh, 1995). Uma vez obtido $\pi$ a partir de $\boldsymbol{\eta}$, o cálculo de $\pi$ a partir de $\theta$ é imediato. Assim, pode-se obter a matriz de derivadas

$$
G(x)=(\partial \pi / \partial \boldsymbol{\theta})=\left(C^{T} D^{-1} L\right)^{-1} X .
$$

Uma vez definidos $(4)$ e (5), a matriz de derivadas $\left(\partial \eta_{i} / \partial \pi_{u}\right)$ é dada por

$$
\frac{\partial \eta}{\partial \pi}=C^{T} D^{-1} L
$$

onde $D=\operatorname{diag}(L \pi)$. Assim, segundo Glonek \& McCullagh (1995), o vetor de escores é igual a

$$
s\left(\boldsymbol{\theta} ; \boldsymbol{y}_{i}\right)=G^{T}\left(x_{i}\right) \oplus_{u=1}^{l} \pi_{u}^{-1}\left(x_{i}\right) \boldsymbol{y}_{i}
$$

e a matriz de informação,

$$
I_{i}(\theta)=m_{i} G^{T}\left(x_{i}\right) \oplus_{u=1}^{l} \pi_{u}^{-1}\left(x_{i}\right) G\left(x_{i}\right) .
$$


Considerando-se $n$ observações independentes

$$
\left(\boldsymbol{y}_{1}, m_{1}, X_{1}\right),\left(\boldsymbol{y}_{2}, m_{2}, X_{2}\right), \ldots,\left(\boldsymbol{y}_{n}, m_{n}, X_{n}\right)
$$

o logaritmo da função de verossimilhança fica igual a

$$
l(\boldsymbol{\theta})=\sum_{i=1}^{n} l\left(\boldsymbol{\theta} ; \boldsymbol{y}_{i}\right)
$$

o vetor de escores igual a

$$
s(\boldsymbol{\theta})=\sum_{i=1}^{n} s\left(\boldsymbol{\theta} ; \boldsymbol{y}_{i}\right)
$$

e a matriz de informação igual a

$$
I(\theta)=\sum_{i=1}^{n} I_{i}(\theta)
$$

A obtenção de estimadores de máxima verossimilhança para o vetor de parâmetros $\theta$ do modelo é feita através da maximização de $l(\theta)$, para $\theta \in \Omega$, ou seja, através da solução do sistema de equações

$$
\frac{\partial l(\theta)}{\partial \theta}=0
$$

onde 0 é um vetor de zeros, com dimensão $p+1$. Em geral, esse sistema não tem solução explícita e precisa ser resolvido por processos iterativos como o método de Newton-Raphson modificado. Nesse método, a $t$-ésima aproximação $\boldsymbol{\theta}^{(t)}$ do vetor de parâmetros $\theta$ é dada por:

$$
\theta^{(t)}=\theta^{(t-1)}+I^{-1}\left(\theta^{(t-1)}\right) s\left(\theta^{(t-1)}\right)
$$

O processo começa pela escolha de valores iniciais para os parâmetros e termina quando $\theta^{(t)}$ diferir de $\theta^{(t-1)}$ por uma quantidade muito pequena préestabelecida. Pode-se, então, obter a matriz estimada de variâncias e covariâncias de $\theta$ através de $I^{-1}$.

Uma vez obtido o vetor $\hat{\theta}$ de estimativas de máxima verossimilhança de $\theta$, uma forma de verificar a adequacidade do modelo é utilizar a estatística "deviance" (McCullagh \& Nelder, 1989, p.174) dada por

$$
G^{2}=2 \sum_{i}\left\{\boldsymbol{y}_{i}^{T} \log \boldsymbol{y}_{i}-\boldsymbol{y}_{i}^{T} \log \left[m_{i} \pi\left(x_{i}\right)\right]\right\}
$$


que tem distribuição assintótica $\chi^{2} \operatorname{com}(l-1) n-p$ graus de liberdade e, portanto, deverá ser aproximadamente igual ao número de graus de liberdade do resíduo quando o modelo for adequado.

\subsubsection{Modelo logístico de dose e resposta}

Diversos modelos não-lineares de dose e resposta têm sido utilizados para a análise de dados provenientes de ensaios do tipo apresentado na Seção 2.4. Dentre os mais utilizados encontram-se os modelos logístico e o de Gompertz, recomendados por Ratkowsky (1990) e Seefeldt et al. (1995), que são bastante flexíveis e apresentam boas propriedades de estimação. Por outro lado, o modelo de Richards (1959), também bastante citado, apresenta propriedades de estimação bastante pobres, como uma considerável curvatura intrínseca, não devendo ser utilizado (Ratkowsky, 1990).

Seguindo essas recomendações, optou-se pelo modelo logístico, dado

por

$$
y=\frac{1}{1+\exp [b(\log D M-\log x)]}
$$

onde $y$ é a proporção de controle da planta daninha, $x$ é a dose aplicada de herbicida, $D M$ é a abscissa do ponto de inflexão ou a dose mediana e $b$ o coeficiente angular no ponto de inflexão. Esse modelo pode ser usado separadamente para os dados relativos a cada um dos biotipos. No entanto, é razoável admitir que haja paralelismo entre as curvas para os biotipos envolvidos, ou seja, que os valores de $b$ sejam iguais para os biotipos. Nesse caso, pode-se reescrevê-lo da seguinte forma

$$
y_{j}=\frac{1}{1+\exp \left[b\left(\log D M_{u}-\log x\right)\right]} \quad j=R, S
$$

onde $y_{R}, y_{S}, D M_{R}$ e $D M_{S}$ são as proporções de controle da planta daninha e as doses medianas para os biotipos resistente e suscetivel, respectivamente.

Para a estimação dos parâmetros de um modelo não-linear de dose e resposta, como o (9), considere que se têm $n$ pares de observaçōes $\left(x_{i} ; y_{i}\right) i=1, \ldots, n$ 
de um modelo não-linear com relação funcional conhecida $\eta$ tal que

$$
y_{i}=\eta\left(x_{i} ; \theta\right)+\epsilon_{i} \quad(i=1, \ldots, n)
$$

onde $E\left[\epsilon_{i}\right]=0, \theta$ é o vetor de dimensões $p \times 1$ de parâmetros do modelo, $\theta \in \Omega$, $\Omega \subset \Re^{p}$.

A estimativa de quadrados mínimos de $\boldsymbol{\theta}$, denotada por $\hat{\boldsymbol{\theta}}$, minimiza a soma de quadrados

$$
S(\theta)=\sum_{i=1}^{n}\left[y_{i}-\eta\left(x_{i} ; \boldsymbol{\theta}\right)\right]^{2}
$$

para $\theta \in \Omega$.

Seja $F(\theta)$ a matriz de dimensões $n \times p$ cuja i-ésima linha é dada por

$$
f^{T}\left(x_{i}, \boldsymbol{\theta}\right)=\frac{\partial \eta\left(x_{i}, \boldsymbol{\theta}\right)}{\partial \boldsymbol{\theta}^{T}}
$$

e a matriz experimental

$$
M(\boldsymbol{\theta})=\sum_{i=1}^{n} f\left(x_{i}, \boldsymbol{\theta}\right) f^{T}\left(x_{i}, \boldsymbol{\theta}\right)=F^{T}(\boldsymbol{\theta}) F(\boldsymbol{\theta}),
$$

que é proporcional à matriz de informação de $\theta$.

Assumindo-se que $\epsilon \sim N\left(0 ; I_{\{n\}} \sigma^{2}\right)$, sendo $\epsilon=\left[\epsilon_{1} \ldots \epsilon_{n}\right]^{T}$, e sob certas condições de regularidade (Seber \& Wild, 1989), $\hat{\theta}$ e $s^{2}=S(\hat{\theta}) /(n-p)$ são estimativas consistentes de $\theta$ e $\sigma^{2}$, respectivamente, e assintoticamente, $\hat{\theta} \sim N(\theta ; \Sigma)$, onde

$$
\Sigma=M^{-1}(\boldsymbol{\theta}) \sigma^{2}
$$

Uma estimativa de $\Sigma$ pode ser obtida através de $\hat{\Sigma}=M^{-1}(\hat{\boldsymbol{\theta}}) s^{2}$ (Seber \& Wild, 1989).

Nesses ensaios, é muitas vezes interessante obter estimativas por ponto e por intervalo para a proporção de controle $y=\eta(x ; \theta)$ da planta daninha para uma certa dose $x$ do herbicida, o que depende da variância

$$
\operatorname{Var}(y)=d(x, \theta) \sigma^{2},
$$

onde

$$
d(x, \boldsymbol{\theta})=f^{T}(x, \boldsymbol{\theta}) M^{-1}(\boldsymbol{\theta}) f(x, \boldsymbol{\theta}) .
$$




\subsubsection{Modelos de produtividade em função da densidade de plantio}

Inúmeros modelos relacionados com curvas de crescimento são utilizados na Agricultura, para quantificar a relação entre a densidade de plantio e a produtividade de uma cultura. Embora alguns deles tenham sido obtidos mecanisticamente, esses modelos podem ser vistos simplesmente como famílias de curvas que têm se ajustado empiricamente bem a diversos conjuntos de dados. Devido à competição entre as plantas por recursos, a produção por planta tende a decrescer com o aumento da densidade de plantio. Por outro lado, a produção por unidade de área, ou produtividade, tende a crescer. Seja $x$ a densidade de plantio, em número de plantas por unidade de área, e y a produtividade. Os modelos utilizados para analisar os dados apresentados na Tabela 2.3 foram os seguintes:

$$
y=x\left(\theta_{1}+\theta_{2} x\right)^{-1}
$$

proposto por Shinozaki \& Kira (1956),

$$
y=x\left(\theta_{1}+\theta_{2} x^{\theta_{3}}\right)^{-1 / \theta_{4}}
$$

proposto por Bleasdale \& Nelder (1960) e

$$
y=x\left(\theta_{1}+\theta_{2} x^{\theta_{3}}\right)^{-1}
$$

proposto por Farazdaghi \& Harris (1968).

A curva assintótica mais comumemnte usada é a (14), que é um caso particular dos modelos mais gerais (15) e (16), iguais ao modelo (14) quando $\theta_{3}=$ $\theta_{4}=1$ e $\theta_{3}=1$, respectivamente. O modelo (16) é um caso especial de (15) quando $\theta_{4}=1$.

A estimação dos parâmetros desses modelos pode ser feita usando-se o método apresentado na Seção 3.1.2.

\subsection{Delineamentos ótimos}

Nesta Seção, será abordado o planejamento ótimo de ensaios, ou seja, a obtenção de delineamentos ótimos, baseados ou não, nos resultados de ensaios preliminares e será adotada, basicamente, a notação de Ponce de Leon (1996). 


\subsubsection{Conceitos básicos}

Seja um conjunto de $m$ covariáveis, denominadas variáveis experimentais e denotadas por um vetor $x=\left[\begin{array}{lll}x_{1} & \ldots & x_{m}\end{array}\right]^{T}$, onde $x \in \Re^{m}$. O vetor $x$ será denominado unidade experimental.

Suponha que os níveis das variáveis experimentais de $\boldsymbol{x}$, para os quais as respostas serão observadas, possam ser escolhidos pelo pesquisador, com a restrição de que estas escolhas sejam realizadas dentro de uma região pré-determinada $\mathcal{X} \subseteq \Re^{m}$, denominada regiāo experimental. Considere que ele esteja interessado na escolha de $N$ unidades experimentais, representada pelo conjunto de vetores $\boldsymbol{x}_{1}$, $\boldsymbol{x}_{2}, \ldots, \boldsymbol{x}_{N}$. Sem perda de generalidade, pode-se representar este conjunto por

$$
\xi_{N}=\left\{\begin{array}{cccc}
\boldsymbol{x}_{1} & \boldsymbol{x}_{2} & \cdots & \boldsymbol{x}_{k} \\
w_{1} & w_{2} & \cdots & w_{k}
\end{array}\right\}
$$

onde $w_{i}=\frac{r_{i}}{N}$, e $r_{i}$ representa o número de repetições para cada unidade experimental $\boldsymbol{x}_{i}(i=1, \ldots, k), \operatorname{com} 1 \leq k \leq N$.

$\mathrm{Na}$ representação $(17), \xi_{N}$ será chamado de delineamento do experimento, as unidades experimentais $\boldsymbol{x}_{1}, \boldsymbol{x}_{2}, \ldots, \boldsymbol{x}_{k}$ serão chamadas de pontos de suporte do experimento e os números $w_{1}, w_{2}, \ldots, w_{k}$, serão chamados pesos associados aos pontos de suporte do experimento.

Pode-se notar que os delineamentos experimentais $\xi_{N}$ têm características de distribuições de probabilidade discretas, sendo geralmente denominados delineamentos exatos. Embora na prática todos os delineamentos sejam desse tipo, pode-se considerar o caso mais geral em que $w_{i} \in[0,1],(i=1, \ldots, k)$ com $\sum_{i} w_{i}=1$, ou seja, quando os pesos associados não são necessariamente racionais da forma $r_{i} / N$. Delineamentos experimentais desse tipo são denominados contínuos ou aproximados, denotados por $\xi$ e têm grande importância na teoria relacionada com o planejamento de experimentos. 
3.2.2 Critérios de otimização mais comuns e eficiência entre dois delineamentos

No planejamento de experimentos que envolvem modelos de regressão, ou seja, na escolha de um delineamento $\xi$, inúmeras são as propriedades em que o pesquisadqr pode estar interessado. Dentre as citadas por Box \& Draper (1975, 1987), destacam-se as seguintes: as variâncias da estimativas dos parâmetros do modelo sejam as menores possíveis; assegurar que o valor ajustado $\eta(\boldsymbol{x}, \hat{\boldsymbol{\theta}})$ em $\boldsymbol{x}$, seja o mais próximo possível do verdadeiro valor $\eta(\boldsymbol{x}, \boldsymbol{\theta})$; seja possível detectar a falta de ajuste e gerar uma distribuição satisfatória da informação na região de interesse.

Essas propriedades desejáveis, são, no entanto, dependentes do modelo previamente escolhido, através da matriz de informação a ele associada. Dado um modelo de regressão não linear (10), foi visto na Seção 3.2.1 que essa matriz é proporcional a (12). Considerando-se um delineamento qualquer $\xi$, pode-se reescrevê-la da seguinte forma

$$
M(\boldsymbol{\theta})=n M(\boldsymbol{\theta}, \xi)
$$

onde

$$
M(\boldsymbol{\theta}, \xi)=\sum_{i=1}^{k} f\left(\boldsymbol{x}_{i}, \boldsymbol{\theta}\right) f^{T}\left(\boldsymbol{x}_{i}, \boldsymbol{\theta}\right) w_{i}=F^{T}(\boldsymbol{\theta}, \xi) W(\xi) F(\boldsymbol{\theta}, \xi)
$$

sendo que $W(\xi)=\oplus_{i=1}^{k} w_{i}$ é a matriz diagonal de pesos associados aos pontos de suporte do delineamento. Assim, a matriz de variâncias e covariâncias de $\hat{\theta}$ é dada por

$$
\Sigma=M^{-1}(\theta) \sigma^{2}=M^{-1}(\theta, \xi) \frac{\sigma^{2}}{n}
$$

e: portanto, a variância de $\hat{\theta}_{j}$ é proporcional ao j-ésimo elemento da diagonal de $M^{-1}(\theta, \xi)$ e a covariância entre $\hat{\theta}_{j}$ e $\hat{\theta}_{k}, j \neq k$, é proporcional ao $(j, k)$-ésimo elemento de $M^{-1}(\theta, \xi)$.

Como o objetivo de planejar experimentos que usem estimadores mais precisos para $\theta$ ou para um subconjunto de $\theta$, o pesquisador pode escolher $\xi$ de modo a minimizar funções dos elementos de $M^{-1}(\theta, \xi)$. Pode, por exemplo, pensar 
em minimizar a variância generalizada de $\boldsymbol{\theta}$, definida como sendo o determinante na matriz de variâncias e covariâncias de $\theta$, proporcional ao determinante de $M^{-1}(\boldsymbol{\theta}, \xi)$. Este critério para a escolha do delineamento experimental é conhecido como criério de otimização $\mathrm{D}$ e os delineamentos gerados utilizando tal critério são denominados D-ótimos. A utilização deste critério pode também ser interpretada em termos da região de confiança para $\theta$ que, supondo a normalidade, independência e aditividade dos erros do modelo, é dada por

$$
(\boldsymbol{\theta}-\hat{\boldsymbol{\theta}})^{T} M(\boldsymbol{\theta}, \xi)(\boldsymbol{\theta}-\hat{\boldsymbol{\theta}}) \leq \delta n
$$

onde $\delta$ é uma constante que depende do nível de significância adotado. O volume do elipsóide delimitado por (19) é inversamente proporcional à raiz quadrada do determinante $|M(\theta, \xi)|$ (o operador $|\cdot|$ denota o determinante de $\cdot$ ). Assim, delineamentos $D$-ótimos, minimizando $\left|M(\boldsymbol{\theta}, \xi)^{-1}\right|=|M(\boldsymbol{\theta}, \xi)|^{-1}$ ou equivalentemente, $-\log |M(\theta, \xi)|$, minimizam também o volume do elipsóide de confiança.

Como critério alternativo, o pesquisador pode escolher delineamentos que minimizam a variância média das estimativas dos parâmetros, ou o traço (soma dos elementos da diagonal principal) da matriz de variâncias e covariâncias de $\theta$, proporcional a $\operatorname{Tr}\left\{M^{-1}(\boldsymbol{\theta}, \xi)\right\}$ (o operador $\operatorname{Tr}\{\cdot\}$ denota o traço da matriz $\cdot$ ). Este critério é denominado critério de otimização $\mathrm{A}$ e os delineamentos que minimizam tal critério são chamados A-ótimos.

Como nova alternativa, o pesquisador pode escolher experimentos com estimadores mais precisos para o valor predito $y=\eta(\boldsymbol{x}, \boldsymbol{\theta})$ de uma resposta a um certo $\boldsymbol{x}$, dado por $\eta(\boldsymbol{x}, \hat{\boldsymbol{\theta}})$, cuja função de variância é proporcional a

$$
d(\boldsymbol{x}, \boldsymbol{\theta}, \xi)=f^{T}(\boldsymbol{x}, \boldsymbol{\theta}) M^{-1}(\boldsymbol{\theta}, \xi) f(\boldsymbol{x}, \boldsymbol{\theta}),
$$

denominada variância padronizada da resposta predita. Como critério de otimização, pode, por exemplo, adotar delineamentos que minimizam o máximo da variância padronizada da resposta predita (20) na região $\mathcal{X}$ do delineamento. Esse critério é denominado critério de otimização $G$ e os delineamentos que maximizam a função correspondente são chamados delineamentos G-ótimos. Uma alternativa aos deli- 
Tabela 5: Critérios de otimização de delineamentos e respectivas funções que devem ser minimizadas para a obtenção de delineamentos ótimos

\begin{tabular}{cc}
\hline Critério & Função \\
\hline $\mathrm{D}$ & $\left|M^{-1}(\boldsymbol{\theta}, \xi)\right|$ \\
$\mathrm{A}$ & $\operatorname{Tr}\left\{M^{-1}(\boldsymbol{\theta}, \xi)\right\}$ \\
$\mathrm{G}$ & $\max _{\boldsymbol{x} \in \mathcal{X}} d(\boldsymbol{x}, \boldsymbol{\theta}, \xi)$ \\
$\mathrm{V}$ & $\frac{\int_{\mathcal{X}} d(\boldsymbol{x}, \boldsymbol{\theta}, \xi) d \boldsymbol{x}}{\int_{\mathcal{X}} d \boldsymbol{x}}$ \\
\hline
\end{tabular}

neamentos G-ótimos é escolher aqueles que minimizam o valor médio de (20) em $\mathcal{X}$, chamados V-ótimos.

A Tabela 5 apresenta a relação dos critérios apresentados até aqui com as respectivas funções que devem ser minimizadas para a obtenção de delineamentos ótimos. Como se pode notar, tais funções dependem do vetor de parâmetros $\theta$ e, portanto, os delineamentos ótimos também dependerão de $\boldsymbol{\theta}$, sendo ótimos somente para o valor de $\boldsymbol{\theta}$ considerado. Por esse motivo, tais delineamentos são comumente chamados delineamentos localmente ótimos.

Dentre os critérios de otimização apresentados, o que tem sido mais utilizado é o critério D. No entanto, um problema relacionado com os delineamentos localmente $\mathrm{D}$-ótimos, é que geralmente possuem um número pequeno de pontos de suporte diferentes, não permitindo que se verifique a falta de ajuste do modelo.

Como solução a esse problema, ao invés de se utilizar um valor prévio $\theta^{0}$ para $\theta$, produzindo-se delineamentos localmente ótimos para $\theta^{0}$, Chaloner \& Verdinelli (1995) sugerem a adoção de uma distribuição a priori para $\boldsymbol{\theta}$. Esta pode ser sugerida, por exemplo, pelos resultados de um ensaio preliminar ou pela experiencia do pesquisador e pode ser incorporada ao critério de otimização tomando-se como novo critério, a esperança da sua função em relação a $\theta$. Escolbido um critério, seja $\Psi\{M(\theta, \xi)\}$ a função que deverá ser maximizada. Então, a nova função $\Psi\{M(\xi)\}$ é 
dada por

$$
\Psi\{M(\xi)\}=E_{\theta} \Psi\{M(\theta, \xi)\}
$$

e os delineamentos que a maximizam são usualmente chamados delineamentos ótimos Bayesianos. Como resultado da incorporação de uma incerteza a respeito de $\theta$, representada pela distribuição a priori de $\theta$, o número de diferentes pontos de suporte do delineamento geralmente aumenta.

Para o critério de otimização $\mathrm{D}$, por exemplo, uma função para a obtenção de um delineamento D-ótimo Bayesiano, é dada por

$$
\Psi_{\mathrm{I}}\{M(\xi)\}=E_{\theta} \log \left|M^{-1}(\boldsymbol{\theta}, \xi)\right|=-E_{\theta} \log |M(\boldsymbol{\theta}, \xi)|
$$

e uma outra possibilidade é dada por

$$
\Psi_{11}\{M(\xi)\}=\log E_{\theta}\left|M^{-1}(\boldsymbol{\theta}, \xi)\right|
$$

Existem, no entanto, outras funções, apresentadas na Tabela 6 , cujas propriedades são comparadas por Atkinson \& Donev (1992, p.217). As vantagens da equação (22) são enfatizadas por Chaloner \& Verdinelli (1995), que a usaram no planejamento de ensaios para modelos logísticos com respostas binárias, caso particular dos modelos logísticos com respostas multinomiais apresentados na Seção 3.1.1.

Por outro lado, para o critério de otimização $G$, uma função para a obtenção de um delineamento G-ótimo Bayesiano, seria

$$
d(\boldsymbol{x}, \xi)=E_{\boldsymbol{\theta}} d(\boldsymbol{x}, \boldsymbol{\theta}, \xi)
$$

Devido à necessidade do cálculo da esperança, a obtenção dos delineamentos Bayesianos pode complicar consideravelmente, dependendo da distribuição escolhida para $\theta$. Se esta for contínua, por exemplo, torna-se necessário o uso de técnicas de integração numérica, que substituem a integral envolvida por uma soma. Uma opção bastante freqüente é utilizar a distribuição normal como distribuição prévia para $\theta$, com média $\theta^{0}$ e matriz de variâncias e covariâncias $\Sigma^{0}$. Seja $\Sigma^{0}=S S^{T}$, onde $S$ é uma matriz triangular, que pode ser obtida através do método de decomposição de Cholesky. Então, se $z$ é um vetor de $p$ variáveis aleatórias normais 
Tabela 6: Versōes Bayesianas do critério de otimização D

\begin{tabular}{cc}
\hline Critério & $\Psi\{M(\xi)\}$ \\
\hline I & $E_{\theta} \log \left|M^{-1}(\boldsymbol{\theta}, \xi)\right|$ \\
II & $\log E_{\theta}\left|M^{-1}(\boldsymbol{\theta}, \xi)\right|$ \\
III & $\log \left|E_{\theta} M^{-1}(\boldsymbol{\theta}, \xi)\right|$ \\
IV & $\log \left\{E_{\theta}|M(\boldsymbol{\theta}, \xi)|\right\}^{-1}$ \\
V & $\log \left|E_{\theta} M(\boldsymbol{\theta}, \xi)\right|^{-1}$ \\
\hline
\end{tabular}

padronizadas independentes, o vetor $T$ de $p$ variáveis aleatórias dado por

$$
T=\boldsymbol{\theta}^{0}+S z
$$

terá a distribuição requerida. Assim, pode-se obter uma amostra dessa distribuição, a partir da geração de amostras de variáveis com distribuição normal padronizada. Seja $T_{1}, T_{2}, \ldots, T_{q}$, uma amostra de tamanho $q$. Então, no lugar de (21), pode-se utilizar

$$
\Psi\{M(\xi)\}=\frac{1}{q} \sum_{j=1}^{q} \Psi\left\{M\left(T_{j}, \xi\right)\right\} .
$$

Os métodos discutidos até aqui assumem que o pesquisador está interessado em obter delineamentos ótimos para todos os parâmetros de $\theta$. No entanto, ele pode estar interessado em obter delineamentos ótimos para se estimarem apenas alguns deles. Seja $\boldsymbol{\theta}^{T}=\left[\begin{array}{ll}\boldsymbol{\theta}_{1}^{T} & \theta_{2}^{T}\end{array}\right]$, onde $\boldsymbol{\theta}_{1}$ é o vetor formado por $p_{1}$ parâmetros de $\boldsymbol{\theta}, \boldsymbol{\theta}_{2}$ é o vetor formado pelos $p_{2}$ parâmetros restantes de $\theta, \mathrm{e} p_{1}+p_{2}=p$.

Considere o modelo de regressão não-linear múltipla

$$
y=\eta(x, \theta)+\epsilon
$$

onde

$$
\begin{gathered}
\eta(\boldsymbol{x}, \boldsymbol{\theta}) \approx f_{1}^{T}(\boldsymbol{x}, \boldsymbol{\theta}) \boldsymbol{\theta}_{1}+f_{2}^{T}(\boldsymbol{x}, \boldsymbol{\theta}) \boldsymbol{\theta}_{2} \\
f_{1}(\boldsymbol{x}, \boldsymbol{\theta})=\frac{\partial \eta(\boldsymbol{x}, \boldsymbol{\theta})}{\partial \boldsymbol{\theta}_{1}}
\end{gathered}
$$


$\mathrm{e}$

$$
f_{2}(\boldsymbol{x}, \boldsymbol{\theta})=\frac{\partial \eta(\boldsymbol{x}, \boldsymbol{\theta})}{\partial \boldsymbol{\theta}_{2}}
$$

Considere, ainda, os seguintes modelos

$$
y=f_{1}^{T}(\boldsymbol{x}, \boldsymbol{\theta}) \boldsymbol{\theta}_{1}+\epsilon
$$

e

$$
y=f_{2}^{T}(\boldsymbol{x}, \boldsymbol{\theta}) \boldsymbol{\theta}_{2}+\epsilon .
$$

Dado um delineamento qualquer $\xi$, seja $F_{1}(\theta, \xi)$ a matriz de dimensões $k \times p_{1}$ cuja $i$-ésima linha é dada por $f_{1}^{T}\left(\boldsymbol{x}_{\boldsymbol{i}}, \boldsymbol{\theta}\right)(i=1, \ldots, k)$ e $F_{2}(\boldsymbol{\theta}, \xi)$ a matriz de dimensões $k \times p_{2}$ cuja $i$-ésima linha é dada por $f_{2}^{T}\left(\boldsymbol{x}_{i}, \boldsymbol{\theta}\right)$. Logo, pode-se escrever que,

$$
F(\boldsymbol{\theta}, \xi) \boldsymbol{\theta}=F_{1}(\boldsymbol{\theta}, \xi) \boldsymbol{\theta}_{1}+F_{2}(\boldsymbol{\theta}, \xi) \boldsymbol{\theta}_{2}
$$

De (18), segue que

$$
\begin{aligned}
M(\boldsymbol{\theta}, \xi) & =\left[\begin{array}{ll}
M_{11}(\boldsymbol{\theta}, \xi) & M_{12}(\boldsymbol{\theta}, \xi) \\
M_{21}(\boldsymbol{\theta}, \xi) & M_{22}(\boldsymbol{\theta}, \xi)
\end{array}\right]=F^{T}(\boldsymbol{\theta}, \xi) W(\xi) F(\boldsymbol{\theta}, \xi) \\
& =\left[\begin{array}{c}
F_{1}^{T}(\boldsymbol{\theta}, \xi) \\
F_{2}^{T}(\boldsymbol{\theta}, \xi)
\end{array}\right] W(\xi)\left[\begin{array}{ll}
F_{1}(\boldsymbol{\theta}, \xi) & F_{2}(\boldsymbol{\theta}, \xi)
\end{array}\right] \\
& =\left[\begin{array}{ll}
F_{1}^{T}(\boldsymbol{\theta}, \xi) W(\xi) F_{1}(\boldsymbol{\theta}, \xi) & F_{1}^{T}(\boldsymbol{\theta}, \xi) W(\xi) F_{2}(\boldsymbol{\theta}, \xi) \\
F_{2}^{T}(\boldsymbol{\theta}, \xi) W(\xi) F_{1}(\boldsymbol{\theta}, \xi) & F_{2}^{T}(\boldsymbol{\theta}, \xi) W(\xi) F_{2}(\boldsymbol{\theta}, \xi)
\end{array}\right] .
\end{aligned}
$$

Então,

$$
M^{-1}(\boldsymbol{\theta}, \xi)=\left[\begin{array}{ll}
A_{11} & A_{12} \\
A_{21} & A_{22}
\end{array}\right]
$$

onde

$$
\begin{aligned}
& A_{11}=\left[M_{11}(\theta, \xi)-M_{12}(\theta, \xi) M_{22}^{-1}(\theta, \xi) M_{21}(\theta, \xi)\right]^{-1} \\
& A_{12}=-A_{11} M_{12}(\theta, \xi) M_{22}^{-1}(\theta, \xi) \\
& A_{22}=\left[M_{22}(\theta, \xi)-M_{21}(\theta, \xi) M_{11}^{-1}(\theta, \xi) M_{12}(\theta, \xi)\right]^{-1} \\
& A_{21}=-M_{11}^{-1}(\theta, \xi) M_{12}(\theta, \xi) A_{22}
\end{aligned}
$$


Suponha que se deseja obter delineamentos D-ótimos para se estimar $\theta_{2}$. Neste caso deve-se obter $\xi$ tal que minimize o determinante de $A_{22}$ ou maximize

$$
\left|M_{22}(\theta, \xi)-M_{21}(\theta, \xi) M_{11}^{-1}(\theta, \xi) M_{12}(\theta, \xi)\right|=\frac{|M(\theta, \xi)|}{\left|M_{11}(\theta, \xi)\right|}
$$

ou equivalentemente,

$$
\log |M(\theta, \xi)|-\log \left|M_{11}(\theta, \xi)\right| .
$$

Analogamente, o delineamento D-ótimo para se estimar $\theta_{1}$ pode ser obtido maximizando-se

$$
\left|M_{11}(\boldsymbol{\theta}, \xi)-M_{12}(\theta, \xi) M_{22}^{-1}(\boldsymbol{\theta}, \xi) M_{21}(\boldsymbol{\theta}, \xi)\right|=\frac{|M(\boldsymbol{\theta}, \xi)|}{\left|M_{22}(\boldsymbol{\theta}, \xi)\right|}
$$

ou equivalentemente,

$$
\log |M(\boldsymbol{\theta}, \xi)|-\log \left|M_{22}(\boldsymbol{\theta}, \xi)\right| \text {. }
$$

Portanto, o delineamento D-ótimo para se estimar $\theta$ é obtido maximizando-se

$$
\begin{aligned}
|M(\theta, \xi)| & =\left|M_{11}(\boldsymbol{\theta}, \xi)\right| \frac{|M(\theta, \xi)|}{\left|M_{11}(\theta, \xi)\right|} \\
& =\left|M_{22}(\boldsymbol{\theta}, \xi)\right| \frac{|M(\theta, \xi)|}{\left|M_{22}(\boldsymbol{\theta}, \xi)\right|}
\end{aligned}
$$

ou

$$
\begin{aligned}
\log |M(\boldsymbol{\theta}, \xi)| & =\log \left|M_{11}(\boldsymbol{\theta}, \xi)\right|+\log \frac{|M(\boldsymbol{\theta}, \xi)|}{\left|M_{11}(\boldsymbol{\theta}, \xi)\right|} \\
& =\log \left|M_{22}(\boldsymbol{\theta}, \xi)\right|+\log \frac{|M(\boldsymbol{\theta}, \xi)|}{\left|M_{22}(\boldsymbol{\theta}, \xi)\right|} .
\end{aligned}
$$

Então, o delineamento D-ótimo para se estimar $\theta$ no modelo (24), pode ser visto, através de (28), como um delineamento intermediário entre o delineamento D-ótimo para se estimar $\theta_{1}$ no modelo (25) e o D-ótimo para se estimar $\theta_{2}$ no modelo (24). Em (29), ele pode ser visto como um delineamento intermediário entre o delineamento D-ótimo para se estimar $\boldsymbol{\theta}_{2}$ no modelo (26) e o D-ótimo para se estimar $\theta_{1}$, no modelo (24). 
Ainda em relação ao delineamento D-ótimo para se estimar $\theta$ no modelo (24) tem-se, a partir de (28), que se $p_{1}>p_{2}$, o maior peso será dado ao delineamento D-ótimo para se estimar $\theta_{1}$ no modelo (25); se $p_{1}=p_{2}$, serão dados pesos iguais aos delineamentos $\mathrm{D}$-ótimos para se estimar $\boldsymbol{\theta}_{1}$ no modelo (25) e $\boldsymbol{\theta}_{2}$ no modelo (24) e se $p_{2}>p_{1}$, o maior peso será dado ao delineamento D-ótimo para se estimar $\theta_{2}$ no modelo (24). A partir de (29), tem-se que se $p_{1}>p_{2}$, o maior peso será dado ao delineamento D-ótimo para se estimar $\boldsymbol{\theta}_{1}$ no modelo (24); se $p_{1}=p_{2}$, serão dados pesos iguais aos delineamentos D-ótimos para se estimar $\boldsymbol{\theta}_{1}$ no modelo (24) e $\boldsymbol{\theta}_{2}$ no modelo (26) e se $p_{2}>p_{1}$, o major peso será dado a.o delineamento $D$-ótimo para se estimar $\boldsymbol{\theta}_{2}$ no modelo (26).

Em certas situações, no entanto, pode-se estar interessado na escolha desses pesos. Considere, então, os novos critérios de otimização, dados por:

$$
p\left\{\frac{\alpha}{p_{1}} \log \left|M_{11}(\theta, \xi)\right|+\frac{1-\alpha}{p_{2}} \log \frac{|M(\theta, \xi)|}{\left|M_{11}(\theta, \xi)\right|}\right\}
$$

e

$$
p\left\{\frac{\alpha}{p_{2}} \log \left|M_{22}(\theta, \xi)\right|+\frac{1-\alpha}{p_{1}} \log \frac{|M(\theta, \xi)|}{\left|M_{22}(\theta, \xi)\right|}\right\}
$$

onde $\alpha(0 \leq \alpha \leq 1)$ é uma constante.

A maximização de (30) leva à obtenção de delineamentos D-ótimos compostos onde $\alpha$ é o peso associado ao delineamento D-ótimo para se estimar $\theta_{1}$ no modelo (25). Como casos particulares tem-se que se $\alpha=0$, o delineamento será D-ótimo para se estimar $\theta_{2}$ em (24); se $\alpha=\frac{1}{2}$, será D-ótimo com iguais interesses em estimar $\boldsymbol{\theta}_{2}$ em (24) e $\boldsymbol{\theta}_{1} \mathrm{em}(25)$; se $\alpha=\frac{p_{1}}{p}$, será D-ótimo para se estimar $\boldsymbol{\theta} \mathrm{em}$ (24); e se $\alpha=1$, será D-ótimo para se estimar $\theta_{1}$ em (25).

A maximização de (31) leva à obtenção de delineamentos D-ótimos compostos onde $\alpha$ é o peso associado ao delineamento D-ótimo para se estimar $\theta_{2}$ no modelo (26). Como casos particulares tem-se que se $\alpha=0$, o delineamento será D-ótimo para se estimar $\theta_{1}$ em (24); se $\alpha=\frac{1}{2}$, será D-ótimo com iguais interesses em estimar $\theta_{1}$ em (24) e $\theta_{2} \mathrm{em}(26)$; se $\alpha=\frac{p_{2}}{p}$, será D-ótimo para se estimar $\theta \mathrm{em}$ (24) e se $\alpha=1$, será D-ótimo para se estimar $\theta_{2}$ em (26). 
Note que os critérios (30) e (31) são equivalentes quando $\alpha=\frac{p_{1}}{p} \mathrm{em}$ (30) e $\alpha=\frac{p_{2}}{p}$ em (31). Nesse caso, também são equivalentes aos critérios (28) e (29).

Delineamentos D-ótimos compostos são discutidos por Atkinson \& Donev (1992, capítulo 21) e por Cook \& Wong (1994). Atkinson \& Bogacka (1997) descrevem um método para se encontrar um valor adequado para $\alpha$, comparandose as eficiências para diversos fins, de delineamentos ótimos para um conjunto de valores de $\alpha$. Os delineamentos $\mathrm{D}$-ótimos compostos para o caso particular em que $\alpha=\frac{1}{2}$, serão denominados delineamentos D-ótimos compostos de interesses iguais. Os critérios envolvidos na obtenção desses delineamentos serão especialmente importantes para a obtenção de delineamentos para a detectar falta de ajuste.

Uma vez definidos os principais critérios de otimização e os respectivos delineamentos ótimos será visto a seguir como medir a eficiência relativa entre dois delineamentos quaiquer $\xi_{1}$ e $\xi_{2}$ associados a um mesmo modelo. Seja $\Psi\{M(\theta, \xi)\}$ a função que deverá ser maximizada para produzir um delineamento ótimo segundo um certo critério. Então, uma medida da eficiência relativa $E f\left(\xi_{1}, \xi_{2}\right)$ do primeiro em relação ao segundo pode ser obtida através de

$$
E f\left(\xi_{1}, \xi_{2}\right)=\frac{\Psi\left\{M\left(\boldsymbol{\theta}, \xi_{1}\right)\right\}}{\Psi\left\{M\left(\boldsymbol{\theta}, \xi_{2}\right)\right\}}
$$

Comumente, no entanto, deseja-se medir a eficiência de um delineamento qualquer $\xi$ em relação ao ótimo $\xi^{*}$, dada por

$$
E f\left(\xi, \xi^{*}\right)=\frac{\Psi\{M(\theta, \xi)\}}{\Psi\left\{M\left(\boldsymbol{\theta}, \xi^{*}\right)\right\}}
$$

e, nesse caso, $0 \leq E f\left(\xi, \xi^{*}\right) \leq 1$.

Para o critério de otimização $D$, a função a ser maximizada para a obtenção do delineamento D-ótimo pode ser definida como $\Psi\{M(\theta, \xi)=|M(\theta, \xi)|$ e, portanto, a eficiência de um delineamento qualquer $\xi$ em relação ao D-ótimo $\xi^{*}$ será dada por

$$
E f_{D}\left(\xi, \xi^{*}\right)=\frac{\Psi\{M(\theta, \xi)\}}{\Psi\left\{M\left(\theta, \xi^{*}\right)\right\}}
$$


Quando o pesquisador deseja comparar as eficiências de delineamentos para diferentes modelos, em relação aos respectivos delineamentos ótimos, surge o problema da dependência das eficiências em relação ao número de parâmetros de cada modelo. Como solução, Atkinson \& Donev (1992) sugerem a utilização de uma medida padronizada de eficiência $\left(D_{e f}\right)$ de um delineamento qualquer em relação ao ótimo, que não depende do número $p$ de parâmetros do modelo, dada por

$$
D_{e f}\left(\xi, \xi^{*}\right)=\left\{\frac{\Psi\{M(\boldsymbol{\theta}, \xi)\}}{\Psi\left\{M\left(\boldsymbol{\theta}, \xi^{*}\right)\right\}}\right\}^{\frac{1}{p}} .
$$

Essa medida, geralmente expressa porcentualmente, é muito importante para saber se delineamentos exatos são aproximadamente ótimos em relação ao delineamento ótimo contínuo.

\subsubsection{Delineamentos ótimos e "boostrap"}

Nesta Seção, será desenvolvida uma nova metodologia para a obtenção de delineamentos com um certo número desejado de pontos de suporte, utilizando a técnica de reamostragem "bootstrap" e os resultados de um ensaio preliminar. Essa metodologia será utilizada no planejamento de ensaios de dose e resposta dos tipos descritos na Seção 2.4, em que é considerada apenas uma covariável $(\boldsymbol{x}=x)$.

Como solução para o problema dos delineamentos localmente $\mathrm{D}$-ótimos dependerem diretamente de $\theta$ e apresentarem poucos ponto de suporte, foi sugerida, na Seção 3.2.2, a utilização de critérios Bayesianos de otimização D como (22). No entanto, a obtenção desses delineamentos envolve um tempo computacional bastante elevado, devido à freqüente necessidade do uso de técnicas de integração numérica. Além disso, na obtenção dos mesmos, a partir dos resultados de um experimento prévio, muitas vezes assume-se que $\theta$ tem distribuição normal com média dada por $\hat{\theta}$ e matriz de covariâncias $\hat{\Sigma}$. Entretanto, os experimentos preliminares normalmente possuem um pequeno número de doses e poucas repetiçôes, sendo questionáveis as hipóteses de normalidade e da aproximação linear assintótica no modelo de regressão não-linear adotado. 
Como alternativa, a técnica de reamostragem "bootstrap" é proposta a seguir, para se estimar a distribuição conjunta de $\theta$ e a partir dela, o delineamento D-ótimo Bayesiano. Apresenta-se, ainda, como se obter uma distribuição empírica dos delineamentos localmente D-ótimos usando-se "bootstrap".

"Bootstrap" é uma técnica computacionalmente intensiva bastante simples e utilizada para se estimar a distribuição amostral de uma estatística. Em linhas gerais, a técnica, aplicada a modelos não-lineares de regressão, consiste em se retirarem $B$ amostras "bootstrap" de tamanho $n$ do conjunto de $n$ pares de observações $\left\{\left(x_{1}, y_{1}\right),\left(x_{2}, y_{2}\right), \ldots,\left(x_{n}, y_{n}\right)\right\}$. A partir de cada uma delas, estima-se 0 vetor de parâmetros do modelo adotado e o correspondente delineamento localmente D-ótimo. Dessa forma, atribuindo-se peso $1 / B$ a cada uma das $B$ estimativas e a cada um dos $B$ delineamentos ótimos, obtêm-se as distribuições empíricas desejadas.

Existem diversas formas de se obter uma amostra "bootstrap". Uma das mais simples, descrita por Efron \& Tibishirani (1993) e adotada neste trabalho, é a de se reamostrarem os pares de valores $\left(x_{i}, y_{i}\right)$. Assim, uma amostra "bootstrap" $\mathrm{x}^{*}$ tem a seguinte forma

$$
\left\{\left(x_{i_{1}}, y_{i_{1}}\right),\left(x_{i_{2}}, y_{i_{2}}\right), \ldots,\left(x_{i_{n}}, y_{i_{n}}\right)\right\}
$$

onde $i_{1}, i_{2}, \ldots, i_{n}$ é uma amostra aleatória, com reposição, dos inteiros 1 até $n$.

Uma forma alternativa é a reamostragem dos resíduos centrados (Efron \& Tibishirani, 1993). Nesse caso, determinam-se a estimativa de mínimos quadrados $\hat{\theta}$ de $\boldsymbol{\theta}$, os resíduos $\hat{\epsilon}_{i}=y_{i}-\eta\left(x_{i}, \hat{\theta}\right)$ e os resíduos centrados $\hat{\varepsilon}_{i}=\left(\hat{\epsilon}_{i}-\sum_{i} \hat{\epsilon}_{i} / n\right)$ para $i=1, \ldots, n$. Nesse caso, uma amostra "bootstrap" tem a seguinte forma

$$
\left\{\left(x_{1}, \eta\left(x_{1}, \hat{\boldsymbol{\theta}}\right)+\hat{\varepsilon}_{i_{1}}\right),\left(x_{2}, \eta\left(x_{2}, \hat{\boldsymbol{\theta}}\right)+\hat{\varepsilon}_{i_{2}}\right), \ldots,\left(x_{n}, \eta\left(x_{n}, \hat{\boldsymbol{\theta}}\right)+\hat{\varepsilon}_{i_{n}}\right)\right\}
$$

onde $i_{1}, i_{2}, \ldots, i_{n}$ é uma amostra aleatória, com reposição, dos inteiros 1 até $n$. Silverman (1986) e Souza (1998, Cap.8) estenderam essa idéia, apresentando uma forma suavizada de "bootstrap" obtida através do ajuste de uma função densidade nãoparamétrica aos resíduos centrados. 
Segundo Efron \& Tibishirani (1993), reamostrar os pares de observaçōes é menos sensível às pressuposições do modelo do que reamostrar os resíduos, razão pela qual este método foi adotado.

Uma outra forma de "bootstrap" para um modelo de regressão nãolinear (Seber \& Wild, 1989 e Ratkowsky, 1983) envolve a pressuposição de normalidade. Nesse caso, após obter a estimativa de mínimos quadrados $\hat{\theta}$ de $\theta$, tomam-se amostras $\left(\epsilon_{1}^{*}, \ldots, \epsilon_{n}^{*}\right)$ da distribuição $N\left(0, s^{2}\right)$ e gera-se, para cada uma delas, uma amostra "bootstrap" da forma:

$$
\left\{\left(x_{1}, \eta\left(x_{1}, \hat{\boldsymbol{\theta}}\right)+\epsilon_{1}^{*}\right),\left(x_{2}, \eta\left(x_{2}, \hat{\boldsymbol{\theta}}\right)+\epsilon_{2}^{*}\right), \ldots,\left(x_{n}, \eta\left(x_{n}, \hat{\boldsymbol{\theta}}\right)+\epsilon_{n}^{*}\right)\right\} .
$$

Uma vez geradas $B$ amostras "bootstrap" do tipo (33), (34) ou (35), obtém-se, para cada uma delas, o vetor $\theta^{* b}(b=1, \ldots, B)$ de estimativas dos parâmetros do modelo considerado. Assim, atribuindo-se peso $1 / B$ a cada uma das $B$ estimativas obtêm-se uma distribuição empírica "bootstrap" para $\hat{\theta}$, a estimativa "bootstrap" $\tilde{\theta}$ de $\boldsymbol{\theta}$, dada por

$$
\tilde{\theta}=\frac{1}{B} \sum_{b=1}^{B} \theta^{* b}
$$

e a estimativa da matriz de variâncias e covariâncias dada por

$$
\tilde{\Sigma}=\frac{1}{B-1} \sum_{b=1}^{B}\left(\boldsymbol{\theta}^{* b}-\tilde{\boldsymbol{\theta}}\right)\left(\boldsymbol{\theta}^{* b}-\tilde{\boldsymbol{\theta}}\right)^{T} .
$$

Logo, utilizando-se a distribuição empírica "bootstrap" de $\theta$ e o critério (22), obtém-se um delineamento D-ótimo Bayesiano. Esses delineamentos, no entanto, podem continuar apresentando o problema de terem poucos pontos de suporte.

A alternativa proposta no presente trabalho é a obtenção da distribuição empírica dos delineamentos localmente D-ótimos e a partir da mesma, obter delineamentos com o número de doses diferentes desejado pelo pesquisador.

Para simplificar a obtenção dessa distribuição convém notar que para os delineamentos localmente $\mathrm{D}$-ótimos, geralmente os pesos $w_{i}$ associados aos valores $x_{i}$, são iguais a $w_{i}=1 / k$. Assim, nesse caso, o delineamento localmente D-ótimo $\xi_{D}$ será escrito da seguinte forma mais simples

$$
\xi_{D}=\left\{\begin{array}{llll}
x_{1} & x_{2} & \cdots & x_{k}
\end{array}\right\} .
$$


Considere a unicidade do delineamento ótimo, ou seja, que para todo $\boldsymbol{\theta} \in \Omega$, onde $\Omega$ é o espaço paramétrico de $\boldsymbol{\theta}$, existe um só delineamento localmente D-ótimo. Essa fato caracteriza o delineamento localmente D-ótimo como uma função de $\boldsymbol{\theta}$, que será denotada por $\xi_{D}(\boldsymbol{\theta})$. Assim, a partir de $\boldsymbol{\theta}^{* 1}, \ldots, \boldsymbol{\theta}^{* B}$, obtém-se $\left\{\xi_{D}\left(\boldsymbol{\theta}^{* 1}\right), \ldots, \xi_{D}\left(\boldsymbol{\theta}^{* B}\right)\right\}$ e portanto, a distribuição empírica "bootstrap" conjunta das doges dos delineamentos localmente $\mathrm{D}$-ótimos (doses ótimas). Seja $\left\{x_{1}^{*}, \ldots, x_{k}^{*}\right\}^{b}(b=1, \ldots, B)$ o conjunto de doses ótimas associada ao delineamento $\xi_{D}\left(\boldsymbol{\theta}^{* b}\right)$. Logo, obtêm-se as estimativas "bootstrap" das doses ótimas, denotadas por $\tilde{x}_{i}^{*}(i=1, \ldots, k)$ e dadas por $\tilde{x}_{i}^{*}=\sum_{b=1}^{B} x_{i}^{* b} / B$.

Falta, porém, estabelecer um método geral para se propor um delineamento geral com $t$ doses distintas e pesos iguais baseado na distribuição conjunta das doses ótimas, gerada usando-se o método "bootstrap". A idéia proposta é a de agrupar todos os $B$ conjuntos de $k$ valores em um único conjunto de tamanho $B k$ e recomendar os percentis

$$
P_{\left\{\frac{100 \times i}{t+1}\right\}} \quad(i=1, \ldots, t),
$$

como as doses para o ensaio definitivo.

Como comentários adicionais, note que a metodologia proposta:

- pode ser utilizada supondo-se outras distribuições a priori dos parâmetros do modelo, diferentes da distribuição empírica "bootstrap";

- pode ser facilmente adaptada a situações em que formas alternativas de técnicas "bootstrap", como o "bootstrap" nos resíduos, são mais indicadas;

- pode ser estendida a outros tipos de delineamentos ótimos.

\subsubsection{Delineamentos para a detecção de falta de ajuste}

Como foi dito nas Seções 1 e 3.2.2, os delineamentos localmente Dótimos geralmente não possuem um número suficiente de pontos de suporte distintos de modo a se poder detectar a falta de ajuste do modelo. Para resolver esse problema, 
Athinson (1972) sugere considerar um modelo mais geral, ou seja, com um número maior de parâmetros, e obter o delineamento localmente D-ótimo para esse modelo aumentado. Como métodos diferentes de construção desse modelo ampliado, sugere:

1. Adicionar ao modelo não linear um polinômio de ordem pequena.

2. Adicionar termos quadráticos e de produtos cruzados às derivadas parciais da resposta em relação aos parâmetros.

3. Aninhar o modelo não linear em um mais geral, que se reduz à forma original para certos valores de alguns parâmetros não lineares.

Para modelos lineares, os três métodos são idênticos. Para modelos não lineares, a principal conseqüência da adoção do primeiro método é gerar delineamentos muito dependentes da região experimental adotada e com tendência a detectar falta de ajuste em partes da região experimental que fornecem pouca informação ao modelo original. O segundo método, por outro lado, é invariante a transformações não lineares dos fatores do modelo. Por esse motivo, Atkinson (1972) sugere a sua adoção, especialmente se o pesquisador tem confiança razoável na adequacidade do modelo original. Um exemplo do terceiro caso é dado por Atkinson \& Bogacka (1997) em que modelos de primeira ordem em cinética química são substituídos por modelos de ordem superior.

Considere que o modelo original tenha $p_{1}$ parâmetros e o modelo ampliado tenha $p=p_{1}+p_{2}$ parâmetros, ou seja, $p_{2}$ parâmetros extras. Então, qualquer que seja o método de ampliação utilizado, tem-se um modelo da forma (24). Assim, de modo a obter delineamentos ótimos para detectar a falta de ajuste, ou seja, ótimos para se estimar o vetor de parâmetros extras $\theta_{2}$ do modelo (24), deve-se maximizar (27). No entanto, o delineamento assim produzido apresenta a grande desvantagem de concentrar todo o esforço experimental em verificar se o modelo original é verdadeiro, ao invés de estimar o vetor de parâmetros $\theta_{1}$ dos parâmetros do modelo original.

Os delineamentos D-ótimos, que maximizam (28), seriam eficientes tanto para estimar $\theta_{1}$ no modelo original como $\theta_{2}$ no modelo ampliado mas, neste 
caso, conforme discutido na Seção 3.2.2, o esforço experimental estaria concentrado na estimação de $\boldsymbol{\theta}_{1}$ ou de $\boldsymbol{\theta}_{2}$ dependendo dos valores de $p_{1}$ e $p_{2}$.

De modo a obter flexibilidade na escolha da importância relativa da estimação de $\theta_{1}$ e da verificação da falta de ajuste do modelo através da estimação de $\boldsymbol{\theta}_{2}$ pode-se usar o critério de otimização D composto (30). Esse critério, no entanto, só pode ser utilizado se o interesse do pesquisador estiver em planejar experimentos com um número de pontos de suporte diferentes maior do que ou igual a $p=p_{1}+p_{2}$. Isto pois, se o número desejado for inferior a $p$, a matriz $M_{11}(\boldsymbol{\theta}, \xi)$ será singular, ou seja, seu determinante será nulo e, nesse caso, (30) não será definida.

O pesquisador, no entanto, muitas vezes está interessado em obter delineamentos com um número de pontos de suporte entre $p_{1}$ e $p=p_{1}+p_{2}$. Como solução, para modelos lineares e delineamentos exatos, DuMouchel \& Jones (1994) propuseram um método para produzir tais delineamentos através da adição de informação a priori a respeito dos parâmetros adicionais. Nesse caso, utilizavam os critérios de otimização usuais, considerando, porém, a matriz de informação a posteriori do delineamento.

A extensão desse método para modelos não lineares é proposta a seguir, considerando-se, inicialmente, o planejamento de ensaios com $n$ pontos de suporte não necessariamente diferentes, ou seja, a escolha de delineamentos exatos do tipo

$$
\xi_{n}=\left\{\begin{array}{cccc}
x_{1} & x_{2} & \ldots & x_{n} \\
\frac{1}{n} & \frac{1}{n} & \ldots & \frac{1}{n}
\end{array}\right\} .
$$

De modo a tornar mais claros os procedimentos a serem expostos, serão adotadas as seguintes notações $F=F\left(\theta, \xi_{n}\right), F_{1}=F_{1}\left(\boldsymbol{\theta}, \xi_{n}\right), F_{2}=F_{2}\left(\boldsymbol{\theta}, \xi_{n}\right)$ e $M=n M\left(\boldsymbol{\theta}, \xi_{n}\right)$. A seguir, será discutida a escolha de uma distribuição a priori para $\theta$.

Supondo que o modelo originalmente proposto seja adequado, espera-se que seus parâmetros $\left(\boldsymbol{\theta}_{1}\right)$ tenham estimativas diferentes de zero e que os parâmetros adicionais $\left(\theta_{2}\right)$ tenham estimativas iguais a zero. No entanto, é difícil prever, de antemão, qual deverá ser o valor da estimativa de $\theta_{1}$. Essa incerteza pode ser expressa através de uma distribuição a priori para $\theta_{1}$, com média arbitrária e variância 
tendendo a infinito. Quanto a $\theta_{2}$, uma distribuição a priori aparentemente adequada seria uma com média zero e variância finita. Uma escolha é considerar $\theta_{2} \sim N\left(0_{\left\{p_{2} \times p_{2}\right\}}, \tau^{2} I_{\left\{p_{2}\right\}}\right)$ (0 representa a matriz nula e 1 , a matriz identidade), assumindo-se, dessa forma, que os parâmetros adicionais sejam independentes e tenham a mesma variância $\tau^{2}$. De modo a tornar essas considerações plausíveis, sugere-se que seja feita uma transformação da matriz $F$ do delineamento, que será descrita mais adiante. $\mathrm{O}$ valor $\tau^{2}=1$ pode ser uma escolha adequada, indicando que não se espera que o efeito de qualquer termo extra do modelo seja muito superior ao desvio padrão residual, considerado igual a um através da transformação de $F$.

Seja $K$ uma matriz de dimensões $p \times p$, dada por

$$
K=\left[\begin{array}{cc}
0_{p_{1} \times p_{1}} & 0_{p_{1} \times p_{2}} \\
0_{p_{2} \times p_{1}} & I_{\left\{p_{2}\right\}}
\end{array}\right]
$$

Assumindo-se a independência entre $\theta_{1}$ e $\theta_{2}$, uma escolha razoável para a distribuição a priori para $\theta$ seria

$$
\theta \sim N(0, V)
$$

onde

$$
V^{-1}=\frac{1}{\tau^{2}} K
$$

A escolha da distribuição a priori apropriada é simplificada se forem estabelecidos certos padrōes a respeito da escala da resposta e dos termos do modelo obtidos por meio de uma tranformação. Essa transformação preliminar, combinada com a centralização de alguns elementos da matriz do delineamento, é necessária de modo a permitir o uso de uma distribuição a priori padrão para $\theta$, que funcione bem em diversas situaçōes.

Seja $F^{*}$ a matriz transformada do delineamento, dada por

$$
F^{*}=F W_{c}
$$

onde $W_{c}$ é a matriz de transformação de dimensões $p \times p$. Essa matriz será descrita mais adiante, onde os resultados de DuMouchel \& Jones (1994) serão esclarecidos e 
estendidos. Por enquanto, assume-se que a matriz do delineamento foi devidamente transformada. Um importante ponto, é que a resposta será também transformada de modo que se possa assumir que a variância residual seja $\sigma^{2}=1$.

$$
\text { Supondo } \sigma^{2}=1 \text { e que }
$$

$$
Y \mid \theta \sim N\left(F^{*} \theta, I\right)
$$

pela regra de Bayes para distribuições normais conjugadas (Box \& Tiao, 1973),

$$
\theta \mid Y \sim N\left(\theta^{*}, V^{*}\right)
$$

onde

$$
\theta^{*}=\left[F^{* T} F^{*}+\frac{1}{\tau^{2}} K\right]^{-1} F^{* T} Y
$$

$\mathrm{e}$

$$
V^{*}=\left[F^{* T} F^{*}+\frac{1}{\tau^{2}} K\right]^{-1}
$$

Delineamentos que minimizam o determinante da matriz a posteriori de variâncias e covariâncias $V^{*}$ ou, de forma equivalente, maximizam o determinante da matriz de informaçāo a posteriori $F^{* T} F^{*}+K / \tau^{2}$, serão chamados delineamentos ótimos de Bayes.

Como extensão do critério de otimização D composto (30) usando-se essa matriz de informação a posteriori, propõe-se a seguinte versão de Bayes para um delineamento qualquer $\xi_{n}$,

$$
p\left\{\frac{\alpha}{p_{1}} \log \left|F_{1}^{T} F_{1}\right|+\frac{1-\alpha}{p_{2}} \log \frac{\left|F^{* T} F^{*}+\frac{1}{\tau^{2}} K\right|}{\left|F_{1}^{T} F_{1}\right|}\right\} .
$$

Esse critério, como será visto mais adiante, não é afetado por diferentes transformações em $F_{1}$.

Como caso particular, considerando-se $\alpha=\frac{1}{2}$ em (39), obtém-se, a versão de Bayes do critério de otimização $D$ de interesses iguais.

Como já vimos, o uso da distribuição a priori informativa assume que os parâmetros extras sejam independentes, com variância comum, e que os parâmetros extras sejam independentes dos parâmetros originais. A seguir, será apresentada e discutida a transformação de $F$ para satisfazer tais condições. 
Já foi assumido, sem perda de generalidade, que $\sigma^{2}=1$. Inicialmente é necessário fazer com que a amplitude de cada termo extra seja 1, isto é, para cada coluna $j$ de $F_{2}, \operatorname{máx}\left\{F_{2 j}\right\}-\operatorname{mín}\left\{F_{2 j}\right\}=1$, e que cada termo extra seja aproximadamente não correlacionado com os termos originais, onde $F_{1}$ e $F_{2}$ são tomados considerando-se o grupo de pontos candidatos ao delineamento (região experimental discreta).

Através da regressāo de $F_{2}$ em relação a $F_{1}$, os termos extras tornamse aproximadamente não correlacionados com os termos originais. Os resíduos $R$ de $F_{2}$ serão, então, reescalados de modo a ter a amplitude desejada. O procedimento proposto é apresentado a seguir.

\section{Procedimento para a transformaçāo da matriz do delineamento}

1. Computar $F_{1 c}$ e $F_{2 c}$, isto é, $F_{1}$ e $F_{2}$ usando os $n_{c}$ pontos candidatos (ou qualquer outra distribuição de referência);

2. Fazer a regressão dos termos extras em relação aos termos originais calculando $B=\left(F_{1 c}^{T} F_{1 c}\right)^{-1}\left(F_{1 c}^{T} F_{2 c}\right)$ e a matriz residual $R=F_{2 c}-F_{1 c} B$

3. Calcular a amplitude de cada coluna de $R$, isto é,

$$
\text { amplitude }\left(R_{j}\right)=\max \left(R_{j}\right)-\min \left(R_{j}\right) \quad\left(j=1, \ldots, p_{2}\right)
$$

onde $R_{j}$ é a $j$-ésima coluna de $R$;

4. Calcular $W_{2 c}=\operatorname{diag}\left\{\operatorname{amplitude}^{-1}\left(R_{1}\right), \ldots\right.$, amplitude $\left.^{-1}\left(R_{p_{2}}\right)\right\}$;

5. Calcular $F_{1}$ e $F_{2}$ usando os $n$ pontos do delineamento;

6. Calcular $F_{2}^{*}=\left(F_{2}-F_{1} B\right) W_{2 c}$;

7. Calcular $F^{*}=\left[F_{1} \vdots F_{2}^{*}\right]=F\left[\begin{array}{cc}I & -B W_{2 c} \\ 0 & W_{2 c}\end{array}\right]$.

Considere, como ilustração desse procedimento, o conjunto de 5 pontos candidatos $\{-1,-0,5,0,0,5,1\}$ e o modelo ampliado dado por $E(Y)=$ 
$\eta(x, \theta)=\theta_{1}+\theta_{2} x+\theta_{3} x^{2}+\theta_{4} x^{3}$, onde os dois últimos termos são os termos extras.

Neste caso, tem-se que:

$$
\begin{aligned}
& f^{T}(x)=\left[\begin{array}{lll}
f_{1}^{T}(x) & \vdots & f_{2}^{T}(x)
\end{array}\right]=\left[\begin{array}{lllll}
1 & x & \vdots & x^{2} & x^{3}
\end{array}\right] \\
& F_{1 c}=\left[\begin{array}{cc}
1 & -1 \\
1 & -0,5 \\
1 & 0 \\
1 & 0,5 \\
1 & 1
\end{array}\right], \quad F_{2 c}=\left[\begin{array}{cc}
1 & -1 \\
0,25 & -0,125 \\
0 & 0 \\
0,25 & 0,125 \\
1 & 1
\end{array}\right] \\
& B=\left[\begin{array}{cc}
5 & 0 \\
0 & 2,5
\end{array}\right]^{-1}\left[\begin{array}{cc}
2,5 & 0 \\
0 & 2,125
\end{array}\right]=\left[\begin{array}{cc}
0,5 & 0 \\
0 & 0,85
\end{array}\right] \text {, } \\
& R=\left[\begin{array}{cc}
1 & -1 \\
0,25 & -0,125 \\
0 & 0 \\
0,25 & 0,125 \\
1 & 1
\end{array}\right]-\left[\begin{array}{cc}
1 & -1 \\
1 & -0,5 \\
1 & 0 \\
1 & 0,5 \\
1 & 1
\end{array}\right]\left[\begin{array}{cc}
0,5 & 0 \\
0 & 0,85
\end{array}\right]=\left[\begin{array}{cc}
0,5 & -0,15 \\
-0,25 & 0,3 \\
-0,5 & 0 \\
-0,25 & -0,3 \\
0,5 & 0,15
\end{array}\right] \text {, }
\end{aligned}
$$

$$
\begin{gathered}
\operatorname{amplitude}\left(R_{1}\right)=0,5-(-0,5)=1, \\
\operatorname{amplitude}\left(R_{2}\right)=0,3-(-0,3)=0,6 \\
W_{2 c}=\left[\begin{array}{cc}
1 & 0 \\
0 & \frac{1}{0.6}
\end{array}\right]
\end{gathered}
$$

e seguindo as etapas 5. e 6 . do procedimento, as linhas de $F_{2}^{*}$ serâo dadas por

$$
\begin{aligned}
f_{2}^{* T}(x) & =\left[f_{2}^{T}(x)-f_{1}^{T}(x) B\right] W_{2 x} \\
& =\left\{\left[x^{2} x^{3}\right]-\left[\begin{array}{ll}
1 & x
\end{array}\right]\left[\begin{array}{cc}
0,5 & 0 \\
0 & 0,85
\end{array}\right]\right\}\left[\begin{array}{cc}
1 & 0 \\
0 & \frac{1}{0,6}
\end{array}\right] \\
& =\left[x^{2}-0,5 \frac{1}{0,6}\left(x^{3}-0,85 x\right)\right]
\end{aligned}
$$


Portanto, seguindo o procedimento proposto, os termos extras devem ser centralizados e ter sua escala mudada para $x^{2}-0,5$ e $\left(x^{3}-0,85 x\right) / 0,6$, respectivamente.

Duas partes do procedimento necessitam de comentários. A primeira diz respeito à mudança de escala. DuMouchel \& Jones (1994) sugeriram, para modelos lineares, que a matriz $F_{1}$ seja transformada de modo a cada termo não constante variar de -1 a 1 . No entanto, será demonstrado que o uso dessa matriz transformada no lugar de $F_{1}$ não afeta os delineamentos gerados usando o critério de otimização D.

Uma vantagem freqüentemente salientada dos delineamentos $\mathrm{D}$-ótimos é a de que eles são invariantes a transformações das variáveis consideradas, o que, no entanto, não é verdade para os delineamentos D-ótimos de Bayes, a não ser que a informação a priori seja simultaneamente transformada.

Considere primeiramente, o delineamento $\mathrm{D}$-ótimo para as variáveis transformadas $F^{*}$ dadas por (38). Este delineamento maximiza

$$
\log \left|F^{* T} F^{*}\right|=\log \left|W_{c}^{T} F^{T} F W_{c}\right|=\log \left|F^{T} F\right|+2 \log \left|W_{c}\right|
$$

de modo que os delineamentos obtidos maximizando-se este critério são os mesmos que os obtidos maximizando-se o não transformado $\left|F^{T} F\right|$.

Considere agora, a matriz de informação a posteriori $F^{* T} F^{*}+K / \tau^{2}$ $\operatorname{com} F^{*}=\left[\begin{array}{ll}F_{1}^{*} & F_{2}^{*}\end{array}\right]$. Essa matriz pode ser escrita da seguinte forma

$$
F^{* T} F^{*}+K / \tau^{2}=\left[\begin{array}{cc}
F_{1}^{* T} F_{1}^{*} & F_{1}^{* T} F_{2}^{*} \\
F_{2}^{* T} F_{1}^{*} & F_{2}^{* T} F_{2}^{*}+I_{\{\mathbf{s}\}} / \tau^{2}
\end{array}\right],
$$

onde o elemento inferior à direita de (41) depende da escala de $F_{1}$ somente através dos resíduos $R$ de $F_{2}$ no passo 2 do procedimento. Uma vez que os resíduos de mínimos quadrados não dependem da escala das variáveis explanatórias, o elemento inferior à direita não é afetado pela transformação de $F_{1}$. Assim, supondo um critério 
da forma (40) no qual a matriz de transformação é dada por

$$
\left[\begin{array}{cc}
W_{1 c} & 0_{\left\{p_{1} \times p_{2}\right\}} \\
0_{\left\{p_{1} \times p_{2}\right\}} & I_{\left\{p_{2}\right\}}
\end{array}\right],
$$

o resultado (40) é novamente assegurado.

No entanto, observando-se (41) vê-se que a transformação de $F_{2}^{*}$ poderá afetar o delineamento resultante.

O segundo ponto importante a respeito do procedimento diz respeito ao conjunto de pontos candidatos a partir dos quais $F_{2}$ é transformado. Sem nenhum comentário, no procedimento descrito, foi proposto o uso da matriz de transformação $W_{2 c}$, que é baseada nos $n_{c}$ pontos candidatos da região do delineamento. Se todos os pontos candidatos são usados no delineamento, então $F_{1 c}=F_{1}$ e $F_{2 c}=F_{2}$,

$$
F_{1}^{T} F_{2}^{*}=F_{1}^{T}\left(F_{2}-F_{1} B\right) W_{2 c}=\left[F_{1}^{T} F_{2}-F_{1}^{T} F_{1}\left(F_{1 c}^{T} F_{1 c}\right)^{-1} F_{1 c}^{T} F_{2 c}\right] W_{2 c}=\mathbf{0}
$$

e a correlação entre os termos originais e os termos extras, como desejado, é zero. Mas isso só ocorrerá no caso particular quando o conjunto de pontos candidatos for igual ao conjunto de pontos de suporte do delineamento.

Em geral, quando os dois conjuntos de pontos não são idênticos, essas correlações serão pequenas. Mas quando $n_{c}>p_{1}$, o uso do procedimento proposto anteriormente pode levar a delineamentos com altas correlações entre os termos extras e os originais. Nesses casos deve-se adotar o procedimento de transformação iterativa proposto a seguir.

\section{Procedimento de transformaçāo iterativa}

1. Maximizar o critério escolhido dado o conjunto de pontos candidatos;

2. Recalcular as matrizes $B$ e $W_{2 c}$ usando o conjunto de pontos de suporte do delineamento gerado no passo 1 , ao invés de usar o conjunto de pontos candidatos;

3. Repetir os passos 1 e 2 até obter a convergência ou até que haja a oscilação entre dois delineamentos com eficiências semelhantes. 
Convém ressaltar que os procedimentos descritos até aqui tratam da transformação da matriz $F$ para a posterior obtenção de delineamentos exatos. A obtenção desses delineamentos, por sua vez, não é uma tarefa muito fácil, exigindo a utilização de algoritmos específicos, como o algoritmo de três fases descrito por Atkinson \& Donev (1992, p.173), apresentado a seguir.

\section{Algoritmo para a construção de delineamentos exatos}

1. Geração aleatória dos primeiros $p_{1}$ pontos do delineamento inicial com $n$ pontos $\left(n>p_{1}\right)$

2. Geração sequencial dos $p_{2}=n-p_{\text {I }}$ pontos restantes do delineamento inicial;

3. Melhora do delineamento inicial por substituição de pontos usando, por exemplo, o algoritmo KL de substituição.

$\mathrm{Na}$ primeira fase são aleatoriamente escolhidos os primeiros $p_{1}$ pontos distintos do conjunto de $n_{c}$ pontos candidatos. Na segunda, $p_{2}=n-p_{1}$ pontos são sequencialmente adicionados ao delineamento inicial, escolhendo, entre os $n_{c}$ pontos candidatos, os que acarretam o maior aumento da função correspondente ao critério desejado.

$\mathrm{Na}$ terceira fase, considera-se a substituição dos pontos $x_{k}$ do delineamento pelos $x_{l}$ da lista de pontos candidatos. A substituição é realizada de modo a levar ao maior aumento da função correspondente ao critério escolhido. Se, por exemplo, deseja-se maximizar o critério $\log \left|F^{* T} F^{*}+K / \tau^{2}\right|$, deve-se substituir $x_{k}$ por $x_{l}$ de modo a maximizar $\log \left|F^{* T} F^{*}-{ }^{*}\left(x_{k}\right) f^{* T}\left(x_{k}\right)+f^{*}\left(x_{l}\right) f^{* T}\left(x_{l}\right)+K / \tau^{2}\right|$.

Os pontos $x_{k}$ e $x_{l}$ considerados para a troca são determinados pelos parâmetros $\mathrm{K}$ e $\mathrm{L}$ tais que $1 \leq k \leq \mathrm{K} \leq n$ e $1 \leq l \leq \mathrm{L} \leq n_{c}-1$. O ponto $x_{k}$ é o que fornece o $k$-ésimo menor decréscimo na função correspondente ao critério adotado entre os $n$ pontos do delineamento e $x_{l}$ o que acarreta o $l$-ésimo maior acréscimo na função coorespondente ao critério adotado, entre os $n_{c}$ pontos candidatos.

$\mathrm{O}$ algoritmo aqui descrito, foi implementado usando-se o sistema computacional GAUSS v.2.0 (Aptech Systems, Inc. 1988). 
Os procedimentos descritos até aqui podem ser facilmente estendidos aos delineamentos contínuos. Nesse caso, a fim de que os termos extras tornemse aproximadamente não correlacionados com os termos do modelo original, faz-se uma regressão ponderada de $F_{2}$ em relação a $F_{1}$ com pesos dados por $W(\xi)$. Os resíduos $R$ de $F_{2}$ são, então, transformados de modo a ter a amplitude desejada. $O$ procedimento resultante é proposto a seguir.

Procedimento para a transformação da matriz do delineamento - delineamentos contínuos

1. Calcular $F_{1 c}, F_{2 c}$ e $W\left(\xi_{c}\right)$, isto é, $F_{1}, F_{2}$ e $W(\xi)$ usando a distribuição para transformação $\xi_{c}$ na região $\mathcal{X}_{c}$. Se essa distribuição é discreta com $n_{c}$ pontos distintos, escreve-se

$$
\xi_{c}=\left\{\begin{array}{llll}
x_{1} & x_{2} & \ldots & x_{n c} \\
w_{1} & w_{2} & \ldots & w_{n c}
\end{array}\right\}
$$

2. Fazer a regressão dos termos extras em relação aos termos originais calculando $B=\left(F_{1 c}^{T} W\left(\xi_{c}\right) F_{1 c}\right)^{-1}\left(F_{1 c}^{T} W\left(\xi_{c}\right) F_{2 c}\right)$ e a matriz residual $R=F_{2 c}-F_{1 c} B ;$

3. Calcular a amplitude de cada coluna de $R$, isto é, calcular $\operatorname{amplitude}\left(R_{j}\right)=\operatorname{máx}\left(R_{j}\right)-\operatorname{mín}\left(R_{j}\right) \quad(j=1, \ldots, s)$ onde $R_{j}$ é a $j$-ésima coluna de $R$;

4. Calcular $W_{2 c}=\operatorname{diag}\left\{\right.$ amplitude ${ }^{-1}\left(R_{1}\right), \ldots$ amplitude $\left.{ }^{-1}\left(R_{s}\right)\right\}$;

5. Calcular $F_{1}$ e $F_{2}$ usando os $n$ pontos do delineamento;

6. Calcular $F_{2}^{*}=\left(F_{2}-F_{1} B\right) W_{2 c}$;

7. Calcular $F^{*}=\left[F_{1}: F_{2}^{*}\right]$.

Note que os comentários feitos em relação aos procedimentos propostos para a delineamentos exatos, são também válidos para os delineamentos contínuos e a versão do critério (39) para um delineamento contínuo $\xi$ é dada por

$$
p\left\{\frac{\alpha}{p_{1}} \log \left|F_{1}^{T} W(\xi) F_{1}\right|+\frac{1-\alpha}{p_{2}} \log \frac{\left|F^{* T} W(\xi) F^{*}+\frac{1}{n \tau^{2}} K\right|}{\left|F_{1}^{T} W(\xi) F_{1}\right|}\right\} .
$$




\subsection{Teorema da equivalência geral}

Nas Seções 3.2.2, 3.2.3 e 3.2.4, foram apresentados diferentes critérios de otimização. No processo computacional de obtenção dos delineamentos ótimos segundo esses critérios, é importante que se tenham formas de verificar se o delineamento obtido é realmente ótimo. Essa verificção, para delineamentos contínuos, pode ser feita utilizando-se o Teorema da equivalência geral de Kiefer \& Wolfwitz (1960). Nesta Seção, esse Teorema será apresentado, inicialmente, de uma forma geral e em seguida, nas Seções 3.3.1, 3.3.2 e 3.3.3, será adaptado para algumas situaçōes específicas de interesse.

$\mathrm{Na}$ teoria que envolve a obtenção de delineamentos contínuos considera-se a minimização da medida geral de imprecisão $\Psi\{M(\xi)\}$, onde $M(\xi)=$ $M(\theta, \xi)$. O teorema da equivalência geral (Kiefer \& Wolfowitz, 1960) estabelece que, sob certas condições, entre elas a diferenciabilidade de $\Psi$, delineamentos que minimizam $\Psi$, também satisfazem a um segundo critério, fornecendo métodos simples para a construção de delineamentos ótimos e verificação da otimalidade de delineamentos.

Esse teorema pode ser visto como uma aplicação do fato de que no mínimo de uma função, sua derivada é igual a zero. No entanto, a função envolvida depende da medida $\xi$ através da matriz de informação $M(\xi)$. Seja a medida $\bar{\xi}$ que coloca massa unitária no ponto $x$ e seja $\xi^{\prime}$ a medida dada por

$$
\xi^{\prime}=(1-\alpha) \xi+\alpha \bar{\xi}
$$

Então,

$$
M\left(\xi^{\prime}\right)=(1-\alpha) M(\xi)+\alpha M(\bar{\xi})
$$

e a derivada $\phi(x, \xi)$, de $\Psi$ na direção $\bar{\xi}$, é dada por

$$
\phi(x, \xi)=\lim _{\alpha \rightarrow 0^{+}} \frac{1}{\alpha}[\Psi\{(1-\alpha) M(\xi)+\alpha M(\bar{\xi})\}-\Psi\{M(\xi)\}] .
$$


Teorema 1. Teorema da equivalência geral. (Kiefer \& Wolfowitz, 1960) As afirmaçōes a seguir são equivalentes:

1. O delineamento $\xi^{*}$ minimiza $\Psi\{M(\xi)\}$;

2. O mínimo de $\phi\left(x, \xi^{*}\right) \geq 0$;

3. A derivada $\phi\left(x, \xi^{*}\right)$ atinge seu mínimo nos pontos de suporte do delineamento.

De modo a estabelecer os teoremas de equivalência segundo vários critérios, é conveniente reescrever a derivada (44) como

$$
\phi(x, \xi)=\Delta(\xi)-\psi(x, \xi)
$$

onde

$$
\begin{aligned}
\Delta(\xi) & =-\operatorname{Tr}\left\{M \frac{\partial \Psi}{\partial M}\right\}, \\
\psi(x, \xi) & =-f^{T}(x) \frac{\partial \Psi}{\partial M} f(x) \\
\Psi=\Psi\{M(\xi)\} & \text { e } M=M(\xi) .
\end{aligned}
$$

Considere o critério de otimizaçāo $\mathrm{D}$ definido por

$$
\Psi\{M(\xi)\}=\log \left|M^{-1}(\xi)\right|=-\log |M(\xi)| .
$$

Então, sabendo-se que para uma matriz não singular $Z, \frac{\partial}{\partial Z} \log |Z|=\left(Z^{T}\right)^{-1}($ Rao \& Toutenburg, 1995, p.321), tem-se que

$$
\begin{aligned}
\frac{\partial \Psi}{\partial M} & =-M^{-1} \\
\psi(x, \xi) & =-f^{T}(x) \frac{\partial \Psi}{\partial M} f(x)=f^{T}(x) M^{-1} f(x), \\
\Delta(\xi) & =-\operatorname{Tr}\left\{M\left(-M^{-1}\right)\right\}=\operatorname{Tr}\left\{I_{\{p\}}\right\}=p \\
\phi(x, \xi) & =p-f^{T}(x) M^{-1} f(x) .
\end{aligned}
$$

Logo, pela primeira afirmação do Teorema 1 , o delineamento $\xi^{*}$ é D-ótimo. Note que a função $\psi(x, \xi)$ é igual à variância padronizada da resposta predita $d(x, \xi)$, dada por $(20)$, e assim, a partir da segunda afirmaçāo do teorema, 
tem-se que $d\left(x, \xi^{*}\right) \leq p$, ou seja, o valor máximo da função padronizada, na região experimental, é igual ao número de parâmetros do modelo adotado. Além disso, pela terceira afirmação, pode-se dizer que o máximo de $d(x, \xi)$ ocorre para os pontos de suporte do delineamento D-ótimo. Assim, estabelece-se um método para se verificar se um delineamento qualquer é D-ótimo. Em seguida será visto um teorema que simplifica ainda mais esse método de verificação.

Teorema 2. Seja $\xi=\left\{\begin{array}{cccc}x_{1} & x_{2} & \ldots & x_{k} \\ w_{1} & w_{2} & \ldots & w_{k}\end{array}\right\}$ um delineamento contínuo qualquer. Então $\bar{d}(\xi)=\sum_{i=1}^{k} d\left(x_{i}, \xi\right) w_{i}=p$, onde $\bar{d}(\xi)$ é a variância média padronizada da resposta predita de $\xi$.

Prova.

$$
\begin{aligned}
\bar{d}(\xi) & =\sum_{i=1}^{k} d\left(x_{i}, \xi\right) w_{i} \\
& =\sum_{i=1}^{k} f^{T}\left(x_{i}\right) M^{-1}(\xi) f\left(x_{i}\right) w_{i} \\
& =\sum_{i=1}^{k} \operatorname{Tr}\left\{f^{T}\left(x_{i}\right) M^{-1}(\xi) f\left(x_{i}\right) w_{i}\right\} \\
& =\sum_{i=1}^{k} \operatorname{Tr}\left\{M^{-1}(\xi) f\left(x_{i}\right) f^{T}\left(x_{i}\right) w_{i}\right\} \\
& =\operatorname{Tr}\left\{M^{-1}(\xi) \sum_{i=1}^{k} f\left(x_{i}\right) f^{T}\left(x_{i}\right) w_{i}\right\} \\
& =\operatorname{Tr}\left\{M^{-1}(\xi) M(\xi)\right\}=\operatorname{Tr}\left\{I_{\{p\}}\right\}=p .
\end{aligned}
$$

A partir dos Teoremas 1 e 2, pode-se reescrever o Teorema 1, para o critério de otimização $\mathrm{D}$, na forma a seguir.

Teorema 3. Teorema da equivalência geral. As afirmações a seguir são equivalentes:

1. O delineamento $\xi^{*}$ maximiza $|M(\xi)|$ (minimiza $\left.\left|M(\xi)^{-1}\right|\right)$, ou seja, é D-ótimo;

2. O delineamento $\xi^{*}$ minimiza o máx $x_{\mathcal{X}} d(x, \xi)$, ou seja, é G-ótimo;

3. $\operatorname{máx}_{\mathcal{X}} d(x, \xi)=p$ 
Segundo o Teorema 3, se um delineamento é D-ótimo, ele também é G-ótimo. Além disso, o máximo da função $d(x, \xi)$ ocorre nos pontos de suporte do delineamento ótimo $\xi^{*}$ e é igual ao número $p$ de parâmetros do modelo adotado.

Atkinson \& Donev, (1992) e Atkinson et al. (1993) apresentam, para outros critérios de otimização, as funções que aparecem no teorema da equivalência geral. Essas funções poderão ser utilizadas para estabelecer a equivalência entre delineamentos ótimos segundo vários critérios. Para o critério de otimização $\mathrm{A}$, por exemplo,

$$
\Psi\{M(\xi)\}=\operatorname{Tr}\left\{M^{-1}(\xi)\right\} .
$$

Então, sabendo-se que para uma matriz não singular $Z$,

$$
\frac{\partial}{\partial Z} \operatorname{Tr}\left\{A Z^{-1}\right\}=-\left(Z^{-1} A Z^{-1}\right)^{T}
$$

(Rao \& Toutenburg, 1995, p.321), tem-se que

$$
\begin{aligned}
\frac{\partial \Psi}{\partial M} & =-M^{-1} M^{-1}, \\
\dot{\psi}(x, \xi) & =f^{T}(x) M^{-1} M^{-1} f(x) \quad \mathrm{e} \\
\Delta(\xi) & =\operatorname{Tr}\left\{M^{-1}\right\} .
\end{aligned}
$$

Para o critério de otimização composto $\mathrm{D}$, cujas funções a serem maximizadas são dadas por (30) e (31), para um certo valor de $\alpha$, obtêm-se, respectivamente

$$
\begin{aligned}
& \psi(\boldsymbol{x}, \boldsymbol{\theta}, \xi)=p\left\{\frac{\alpha}{p_{1}} d_{1}(\boldsymbol{x}, \boldsymbol{\theta}, \xi)+\frac{1-\alpha}{p_{2}}\left[d(\boldsymbol{x}, \boldsymbol{\theta}, \xi)-d_{1}(\boldsymbol{x}, \boldsymbol{\theta}, \xi)\right]\right\} \\
& \psi(\boldsymbol{x}, \boldsymbol{\theta}, \xi)=p\left\{\frac{\alpha}{p_{2}} d_{2}(\boldsymbol{x}, \boldsymbol{\theta}, \xi)+\frac{1-\alpha}{p_{1}}\left[d(\boldsymbol{x}, \boldsymbol{\theta}, \xi)-d_{2}(\boldsymbol{x}, \boldsymbol{\theta}, \xi)\right]\right\}
\end{aligned}
$$

onde,

$$
\begin{aligned}
d(\boldsymbol{x}, \boldsymbol{\theta}, \xi) & =f(\boldsymbol{x}, \boldsymbol{\theta}) M^{-1}(\boldsymbol{\theta}, \xi) f^{T}(\boldsymbol{x}, \boldsymbol{\theta}), \\
d_{1}(\boldsymbol{x}, \boldsymbol{\theta}, \xi) & =f_{1}\left(\boldsymbol{x}, \boldsymbol{\theta}_{1}\right) M_{11}^{-1}(\boldsymbol{\theta}, \xi) f_{1}^{T}\left(\boldsymbol{x}, \boldsymbol{\theta}_{1}\right) \\
d_{2}(\boldsymbol{x}, \boldsymbol{\theta}, \xi) & =f_{2}\left(\boldsymbol{x}, \boldsymbol{\theta}_{2}\right) M_{22}^{-1}(\boldsymbol{\theta}, \xi) f_{2}^{T}\left(\boldsymbol{x}, \boldsymbol{\theta}_{2}\right)
\end{aligned}
$$


$\mathrm{e} \Delta(\xi)=p$

Assim, para verificar se um delineamento qualquer $\xi$ é D-ótimo composto, basta verificar se $\psi(\boldsymbol{x}, \boldsymbol{\theta}, \xi) \leq p, \forall x \in \mathcal{X}$ e $\psi(\boldsymbol{x}, \boldsymbol{\theta}, \xi)=p$ nos pontos de suporte do delineamento.

A seguir será apresentada a extensão para o critério de otimização D envolvendo modelos de regressão não linear multivarida (Fedorov, 1972), que será importante para a obtenção dos delineamentos D-ótimos para os modelos logísticos multinomiais da forma (4).

\subsubsection{Modelos de regressão não linear multivariada}

Freqüentemente é possível observar várias respostas $y_{1}, y_{2}, \ldots, y_{l}$ para cada uma das unidades experimentais $\boldsymbol{x}$. Seja $\boldsymbol{y}=\left[\begin{array}{llll}y_{1} & y_{2} & \ldots & y_{l}\end{array}\right]^{T}$ um vetor de observações do vetor de variáveis aleatórias $\boldsymbol{Y}=\left[\begin{array}{llll}Y_{1} & Y_{2} & \ldots & Y_{l}\end{array}\right]^{T}$. Essas variáveis $Y_{1}, Y_{2}, \ldots, Y_{l}$ podem estar correlacionadas. Considere que a matriz de variâncias e covariâncias de $\left(Y_{1}, Y_{2}, \ldots, Y_{l}\right)$, denominada $V(x)$, seja conhecida. Suponha, ainda, que se conheça

$$
\eta(\boldsymbol{x}, \boldsymbol{\theta})=\left[\begin{array}{c}
\eta_{1}(\boldsymbol{x}, \boldsymbol{\theta}) \\
\eta_{2}(\boldsymbol{x}, \boldsymbol{\theta}) \\
\ldots \\
\eta_{l}(\boldsymbol{x}, \boldsymbol{\theta})
\end{array}\right]
$$

onde $\eta_{u}(x, \theta),(u=1, \ldots, l)$, é a parte sistemática do modelo associado à $u$-ésima variável resposta.

Então, dado um delineamento qualquer

$$
\xi=\left\{\begin{array}{cccc}
\boldsymbol{x}_{1} & \boldsymbol{x}_{2} & \cdots & \boldsymbol{x}_{k} \\
w_{1} & w_{2} & \cdots & w_{k}
\end{array}\right\}
$$

a matriz de informação do estimador de $\theta$ é igual a

$$
M(\boldsymbol{\theta}, \xi)=\sum_{i=1}^{k} \mathcal{F}\left(\boldsymbol{x}_{i}, \boldsymbol{\theta}\right) V^{-1}\left(\boldsymbol{x}_{i}\right) \mathcal{F}^{T}\left(\boldsymbol{x}_{i}, \boldsymbol{\theta}\right) w_{i}
$$

onde

$$
\mathcal{F}(x, \theta)=\left[\begin{array}{llll}
f_{1}(x, \theta) & f_{2}(x, \theta) & \cdots & f_{l}(x, \theta)
\end{array}\right]
$$


e

$$
f_{u}(\boldsymbol{x}, \boldsymbol{\theta})=\frac{\partial \eta_{u}(\boldsymbol{x}, \boldsymbol{\theta})}{\partial \boldsymbol{\theta}}=\left[\begin{array}{c}
\frac{\partial \eta_{u}(\boldsymbol{x}, \boldsymbol{\theta})}{\partial \theta_{1}} \\
\frac{\partial \eta_{u}(\boldsymbol{x}, \boldsymbol{\theta})}{\partial \theta_{2}} \\
\cdots \\
\frac{\partial \eta_{u}(\boldsymbol{x}, \boldsymbol{\theta})}{\partial \theta_{p}}
\end{array}\right], \quad(u=1, \ldots, l)
$$

Nesse caso, a matriz de dispersão do estimador de $\eta(x, \theta)$ é

$$
D(\boldsymbol{x}, \boldsymbol{\theta}, \xi)=\mathcal{F}^{T}(\boldsymbol{x}, \boldsymbol{\theta}) M^{-1}(\boldsymbol{\theta}, \xi) \mathcal{F}(\boldsymbol{x}, \boldsymbol{\theta})
$$

Pode-se, então, definir o delineamento D-ótimo como aquele que maximiza o determinante de (47) e estender o conceito de delineamento G-ótimo para aquele que minimiza o máximo da função

$$
\psi(\boldsymbol{x}, \boldsymbol{\theta}, \xi)=\operatorname{Tr}\left\{V^{-1}(\boldsymbol{x}) D(\boldsymbol{x}, \boldsymbol{\theta}, \xi)\right\}
$$

que é a soma dos elementos de $D$ ponderados pelos elementos de $V^{-1}$.

Como (48) e (49) são dependentes de $\theta$, os delineamentos D e G-ótimos também dependem de $\theta$. Assim, os delineamentos ótimos baseados nesses critérios são ótimos só para o valor a priori de $\theta$, ou seja, são localmente ótimos.

Analogamente ao caso univariado, pode-se considerar uma distribuição a priori para $\theta$, gerando os delineamentos ótimos Bayesianos. No caso do critério de otimalidade $D$, uma função a ser maximizada poderia ser $E_{\theta} \log |M(\theta, \xi)|$ e no caso do critério $\mathrm{G}$, a função a ser minimizada poderia ser o máximo de $E_{\theta} \psi(\boldsymbol{x}, \theta, \xi)$ na regiāo experimental.

Teorema 4. Teorema da equivalência geral (Fedorov, 1972, p.212, 218). As seguintes afirmações são equivalentes:

1. O delineamento $\xi^{*}$ maximiza $|M(\theta, \xi)|$, ou seja, é $D$-ótimo;

2. O delineamento $\xi^{*}$ minimiza $\max _{x \in \mathcal{X}} \psi(\boldsymbol{x}, \theta, \xi)$, ou seja, é G-ótimo;

3. $\psi\left(x, \theta, \xi^{*}\right) \leq p, \forall x \in \mathcal{X}$. 
Corolário. Nos pontos de suporte do delineamento $D$-ótimo, a função $\psi\left(\boldsymbol{x}, \theta, \xi^{*}\right)$ assume seu valor máximo $p$.

Como conseqüência do teorema geral da equivalência e do seu corolário, cujas provas podem ser vistas em Fedorov (1972), tem-se um método simples para se verificar se um delineamento qualquer $\xi$ é $D$-ótimo ou não. Para isso é suficiente verificar se o valor da função $\psi(\boldsymbol{x}, \boldsymbol{\theta}, \xi)$ é igual a $p$ nos pontos de suporte do delineamento $\xi$, e no máximo $p$ nos pontos restantes da região experimental. De forma análoga, para se verificar se um delineamento qualquer $\xi$ é $D$-ótimo Bayesiano, basta verificar se o valor da função $E_{\theta} \psi(\boldsymbol{x}, \boldsymbol{\theta}, \xi)$ é igual a $p$ nos pontos de suporte do delineamento $\xi$, e no máximo $p$ nos pontos restantes da região experimental.

A fim de facilitar o entendimento do Teorema 4, será apresentado, a seguir, o planejamento de um ensaio em Química.

Em experimentos químicos em que são formados vários compostos, freqüentemente deseja-se medir a concentração de cada um deles durante a reação. Considere, por exemplo, uma reação química do tipo $A \rightarrow B \rightarrow C$ em que todas as reações são de primeira ordem. Isto indica que a taxa de reação da substância $A$ é diretamente proporcional à sua concentração com uma constante de proporcionalidade igual a $\theta_{1}$, a taxa de formação de $B$ é proporcional à concentração de $A$ com constante de proporcionalidade $\theta_{1}$, a taxa de decréscimo de $B$ é proporcional à concentração de $B$ com constante de proporcionalidade $\theta_{2}$ e a taxa de formação de $C$ é diretamente proporcional à concentração de $B$ com uma constante de proporcionalidade $\theta_{2}$.

Neste caso, considerando-se que a concentração inicial da substância $A$ é igual a 1, as concentrações médias $\eta_{1}, \eta_{2}$ e $\eta_{3}$, das substâncias $A, B$ e $C$, em função do tempo de reação, podem ser descritas através das seguintes funções (Fedorov, 1972, p.218)

$$
\begin{aligned}
& y_{1}=\eta_{1}(x, \boldsymbol{\theta})=e^{-\theta_{1} x} \\
& y_{2}=\eta_{2}(x, \boldsymbol{\theta})=\frac{\theta_{1}}{\theta_{2}-\theta_{1}}\left(e^{-\theta_{1} x}-e^{-\theta_{2} x}\right) \\
& y_{3}=\eta_{3}(x, \boldsymbol{\theta})=1-\eta_{1}(x, \boldsymbol{\theta})-\eta_{2}(x, \boldsymbol{\theta})=1+\frac{1}{\theta_{2}-\theta_{1}}\left(-\theta_{2} e^{-\theta_{1} x}+\theta_{1} e^{-\theta_{2} x}\right),
\end{aligned}
$$

cujo comportamento típico é apresentado na Figura 3. 


\section{Concentração}

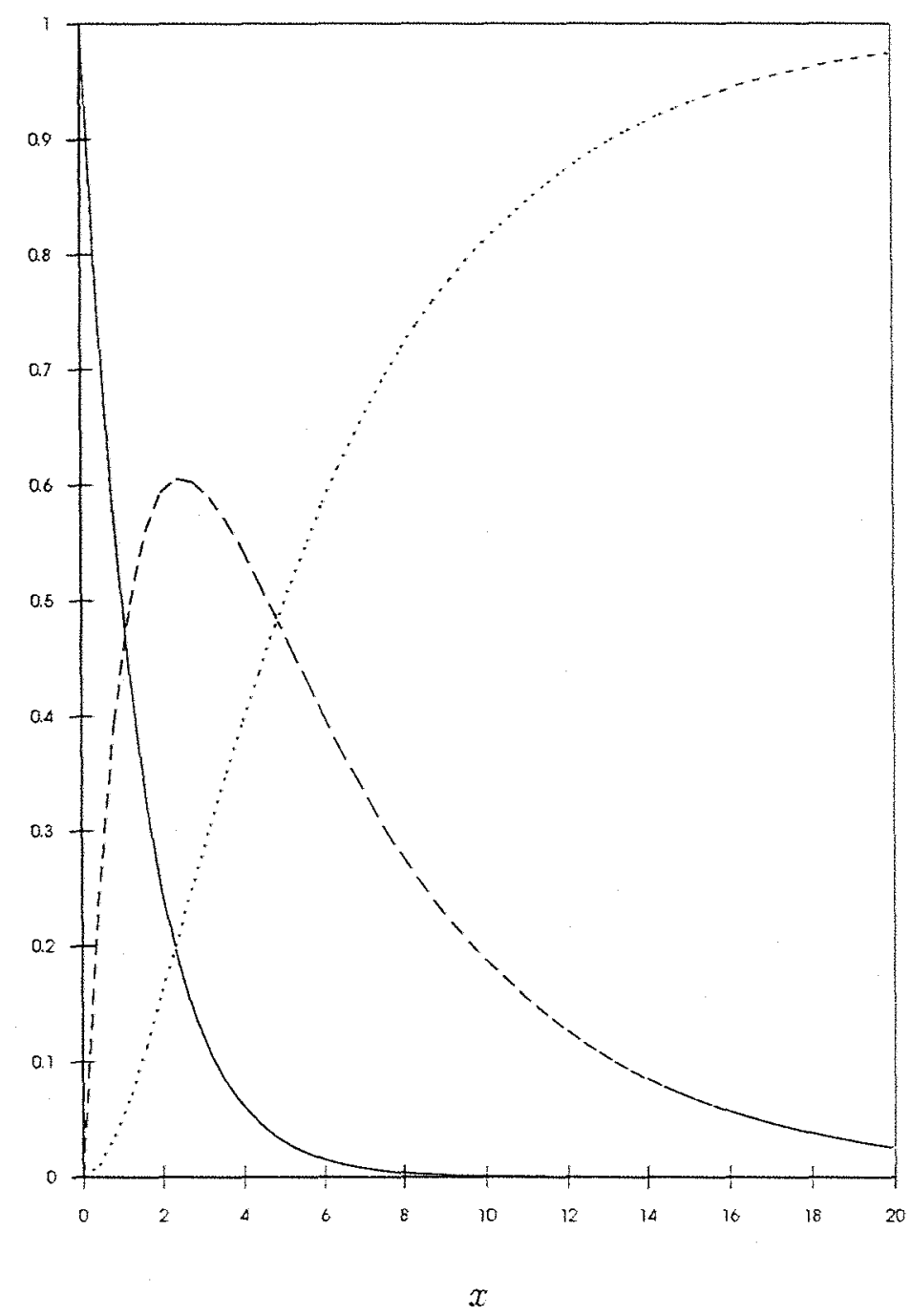

Figura 3: Concentrações médias esperadas para as substanncias $A(-), B(--)$ e $C(\cdots)$ segundo os modelos propostos por (Fedorov, 1972, p.218), $\operatorname{com} \theta_{1}=0,7 \mathrm{e}$ $\theta_{2}=0,2$. 
Suponha que seja possível observar simultaneamente as quantidades $y_{1}$ e $y_{2}(l=2)$ e que as observações tomadas em diferentes pontos sejam independentes. Suponha ainda que os verdadeiros valores dos parâmetros $\theta_{1}$ e $\theta_{2}$ estejam próximos dos valores $\theta_{1}^{o}=0,7$ e $\theta_{2}^{o}=0,2$ e que a matriz de variâncias e covariâncias de $\left(Y_{1}, Y_{2}\right)$ seja igual a

$$
V(x)=\left[\begin{array}{ll}
1 & 1 \\
1 & 4
\end{array}\right]
$$

constante na região experimental considerada. Neste caso,

$$
\mathcal{F}(x, \theta)=\left[\begin{array}{ll}
f_{1}(x, \theta) & f_{2}(x, \theta)
\end{array}\right]
$$

onde

$$
f_{1}(x, \theta)=\left[\begin{array}{c}
-x e^{-\theta_{1} x} \\
0
\end{array}\right]
$$

e

$$
f_{2}(x, \boldsymbol{\theta})=\frac{1}{\left(\theta_{2}-\theta_{1}\right)^{2}}\left[\begin{array}{c}
\theta_{2}\left(e^{-\theta_{1} x}-e^{-\theta_{2} x}\right)+\theta_{1}\left(\theta_{1}-\theta_{2}\right) x e^{-\theta_{1} x} \\
\theta_{1}\left(e^{-\theta_{2} x}-e^{-\theta_{1} x}\right)+\theta_{1}\left(\theta_{2}-\theta_{1}\right) x e^{-\theta_{2} x}
\end{array}\right] \text {. }
$$

O delineamento localmente $\mathrm{D}$-ótimo, que maximiza o determinante de (47) é dado por

$$
\xi^{*}=\left\{\begin{array}{ll}
1,414 & 6,822 \\
0,511 & 0,489
\end{array}\right\}
$$

que apresenta apenas dois pontos de suporte $\left(x_{1}=1,414\right.$ e $\left.x_{2}=6,822\right)$, número insuficiente de pontos para se verificar a falta de ajuste do modelo. Seguindo as sugestões apresentadas na Seção 3.2 .2 e considerando-se a distribuição a priori de $\theta$ apresentada na Tabela 7 , onde $E\left(\theta_{1}\right)=0,7$ e $E\left(\theta_{2}\right)=0,2$, o delineamento D-ótimo Bayesiano é dado por

$$
\xi_{E}^{*}=\left\{\begin{array}{ccc}
1,300 & 4,552 & 18,573 \\
0,424 & 0,372 & 0,204
\end{array}\right\}
$$

Vê-se que apresenta um ponto de suporte a mais do que o localmente ótimo, permitindo, dessa forma, a detecção de falta de ajuste do modelo. Suponha 
Tabela 7: Distribuição a priori de $\left(\theta_{1} ; \theta_{2}\right)$.

\begin{tabular}{cc}
\hline$\left(\theta_{1} ; \theta_{2}\right)$ & $\operatorname{Pr}\left(\theta_{1} ; \theta_{2}\right)$ \\
\hline$(0,4 ; 0,05)$ & 0,3 \\
$(0,4 ; 0,35)$ & 0,2 \\
$(1,0 ; 0,05)$ & 0,2 \\
$(1,0 ; 0,35)$ & 0,3 \\
\hline Total & 1,0 \\
\hline
\end{tabular}

que o pesquisador tenha condições de realizar 5 determinações durante todo o processo. Então, deverá fazer aproximadamente duas $(42,2 \%$ de 5$)$ no tempo $x_{1}=1,300$, duas no tempo $x_{2}=4,552$ e uma no tempo $x_{3}=18,573$.

Através do gráfico da função $\psi\left(x, \theta, \xi^{*}\right)$ para o delineamento localmente D-ótimo $\xi^{*}$, apresentado na Figura 4, observa-se que o seu máximo ocorre para os pontos de suporte de $\xi^{*}$, sendo igual ao número $p=2$, de parâmetros do modelo. Na mesma figura, pode-se ver que o máximo da função $E_{\theta} \psi\left(x, \theta, \xi_{E}^{*}\right)$ ocorre para os pontos de suporte do delineamento D-ótimo Bayesiano $\xi_{E}^{*}$, sendo também igual a $p=2$, porém com um ponto de suporte a mais do que o localmente ótimo. Os delineamentos, são, portanto ótimos segundo os critérios de otimização utilizados.

\subsubsection{Modelos logísticos multivariados}

O Teorema 4, apresentado na Seção 3.3.1, com uma pequena modificação, pode ser utilizado para os modelos logísticos multivariados das formas (4) e (5), descritos na Seção 3.1.1.

Para esses modelos, a matriz de variâncias e covariâncias $V(x)$ de $\left(Y_{1}, \ldots, Y_{k}\right)$ é dada por

$$
V(x)=m\left\{\oplus_{j=1}^{k} \pi_{j}(x)-\pi(x) \pi^{T}(x)\right\}
$$

que tem posto igual a $k-1$ sendo, portanto, singular. Desse modo, não existe a 


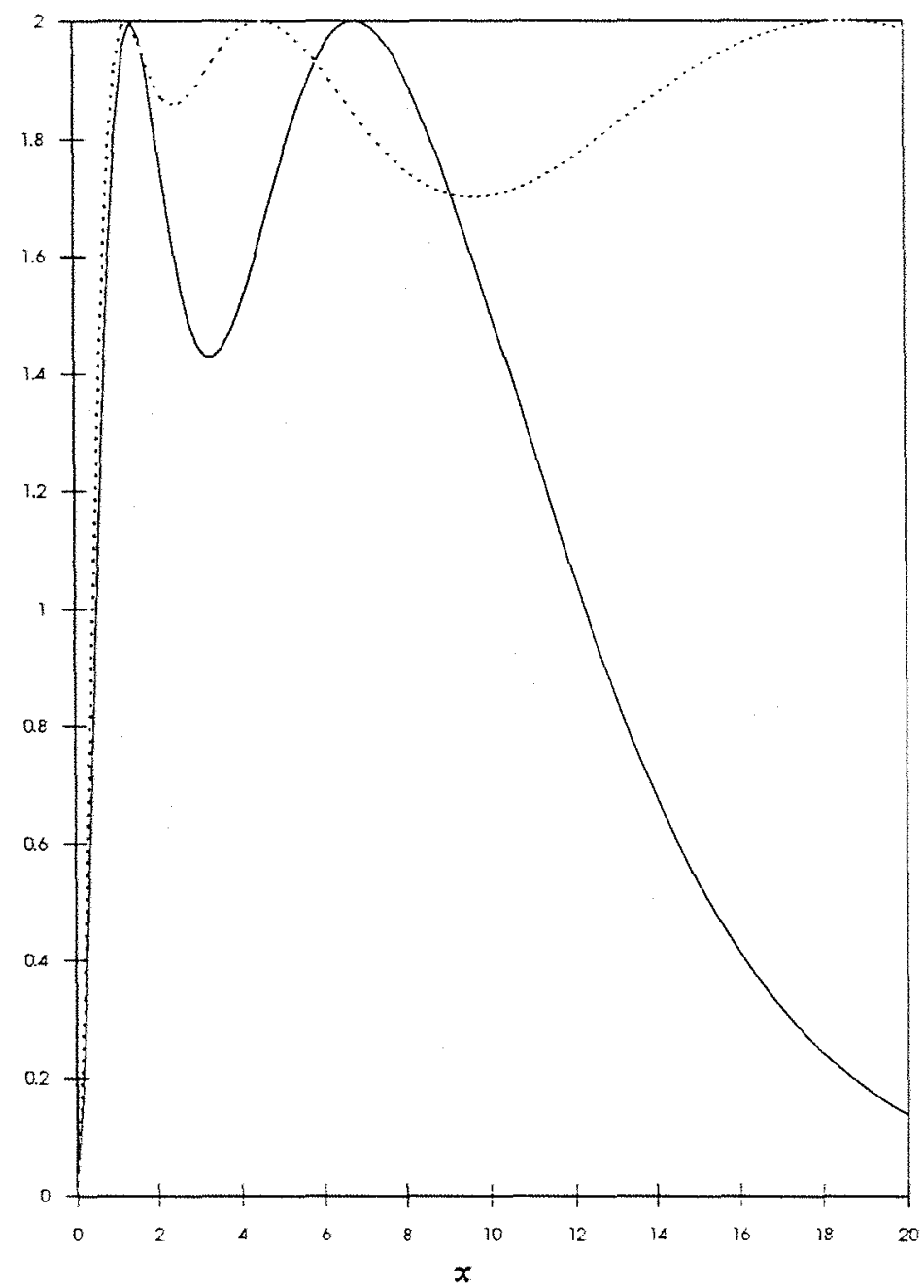

Figura 4: Gráfico da função $\psi\left(x, \theta, \xi^{*}\right)(-)$ para o delineamento localmente D-ótimo $\xi^{*}$ e da função $E_{\theta} \psi\left(x, \theta, \xi_{E}^{*}\right)(--)$ para o delineamento D-ótimo Bayesiano $\xi_{E}^{*}$ 
inversa de $V(x)$ e a função (49) pode ser redefinida por

$$
\psi(x, \boldsymbol{\theta}, \xi)=\operatorname{Tr}\left\{\mathcal{V}^{-1}(x) \mathcal{G}(x) \mathcal{M}^{-1}(\boldsymbol{\theta}, \xi) \mathcal{G}^{T}(x)\right\}
$$

onde $\mathcal{V}(x), \mathcal{G}(x)$ e $\mathcal{M}(\boldsymbol{\theta}, \xi)$ são, respectivamente, as matrizes $V(x), G(x)$ e $M(\theta, \xi)$ sem a última linha e a última coluna, definidas na Seção 3.1.1.

Para os modelos com escala de resposta hierárquica, por exemplo,

$$
\mathcal{M}(\theta, \xi)=\oplus_{j=1}^{k-1} M_{j}(\theta, \xi)
$$

onde

$$
M_{j}(\theta, \xi)=\sum_{i=1}^{n} f_{j}^{T}\left(x_{i}\right) w_{i} \pi_{j}\left(x_{i}\right)\left[1-\rho_{j}\left(x_{i}\right)\right] f_{j}\left(x_{i}\right)
$$

e a função (51) fica reduzida a

$$
\psi(x, \boldsymbol{\theta}, \xi)=\sum_{j=1}^{k-1} \pi_{j}(x)\left[1-\rho_{j}(x)\right] f_{j}(x) M_{j}^{-1}(\boldsymbol{\theta}, \xi) f_{j}^{T}(x) .
$$

Dessa forma, tem-se um método simples para se verificar se um delineamento qualquer é ótimo ou não.

\subsubsection{Modelos para a detecção de falta de ajuste}

Conforme foi dito na Seção 1, um dos objetivos deste trabalho é adaptar o Teorema da equivalência geral de modo que se tenha uma forma simples de verificação da otimalidade de delineamentos para a detecção de falta de ajuste.

Considerando o critério de otimização composto de Bayes (42) para $\alpha=\frac{p_{1}}{p}$, ou seja,

$$
\log \left|F^{* T} W(\xi) F^{*}+\frac{1}{N \tau^{2}} K\right|
$$

tem-se que

$$
\psi(x, \xi)=f^{T}(x)\left[F^{* T} W(\xi) F^{*}+\frac{1}{N \tau^{2}} K\right]^{-1} f(x)
$$

e o Teorema da equivalência, para esse critério, pode ser apresentado na forma a seguir. 
Teorema 5. Teorema da Equivalência. As seguintes afirmações são equivalentes:

1. o delineamento $\xi^{*}$ maximiza (52), os seja, é D-ótimo de Bayes;

2. o delineamento $\xi^{*}$ minimiza máx $x_{\mathcal{X}} \psi(x, \xi)$, ou seja, é $G$-ótimo de Bayes;

3. $\psi\left(x, \xi^{*}\right) \leq \operatorname{Tr}\left\{\left[M\left(\xi^{*}\right)+\frac{K}{N \tau^{2}}\right]^{-1} M\left(\xi^{*}\right)\right\}$

Para outros valores de $\alpha$, no entanto, ainda não se tem uma forma simples de apresentá-lo, que permita a sua aplicação em situações práticas. 


\section{Resultados e Discussão}

\subsection{Delineamentos D-ótimos para modelos logísticos multi- nomiais}

Para ilustrar a generalidade do procedimento proposto para o planejamento de ensaios multinomiais, diferentes modelos da forma (4) e (5) foram considerados para os dados referentes aos ensaios descritos nas Seções 2.1 e 2.2. Com o ajuste desses modelos, obtiveram-se diferentes distribuições prévias, utilizadas para o planejamento de novos ensaios através dos critérios Bayesianos de otimização (Seção 3.2.2) e, a fim de verificar se esses delineamentos eram ótimos, aplicou-se o Teorema da equivalência geral proposto nas Seções 3.3.1 e 3.3.2.

Para os dados da Tabela 1, referentes ao estudo da influência da radiação gama na emergência de moscas domésticas, considerou-se o modelo

$$
\begin{aligned}
& \eta_{1}=\log \frac{\rho_{1}\left(x_{i}\right)}{1-\rho_{1}\left(x_{i}\right)}=\theta_{10}+\theta_{11} x_{i}+\theta_{12} x_{i}^{2} \\
& \eta_{2}=\log \frac{\rho_{2}\left(x_{i}\right)}{1-\rho_{2}\left(x_{i}\right)}=\theta_{20}+\theta_{21} x_{i}
\end{aligned}
$$

que apresentam diferentes números de parâmetros nas duas etapas da hierarquia. Utilizando-se a metodologia de estimação descrita na Seção 3.1.1, obtiveram-se as seguintes estimativas de máxima verossimilhança para os parâmetros: $\hat{\theta}_{10}=$ $-1,935, \hat{\theta}_{11}=-0,02642, \hat{\theta}_{12}=0,0003174, \hat{\theta}_{20}=-9,159$ e $\hat{\theta}_{21}=0,06386$ e a seguinte estimativa para a matriz de variâncias e covariâncias assintóticas das estimativas dos parâmetros, sem a última linha e a última coluna: 


$$
\hat{\Sigma}_{1}=\left[\begin{array}{ccccc}
7,84510^{-1} & -1,26510^{-2} & 4,88910^{-5} & 0 & 0 \\
-1,26510^{-2} & 2,08010^{-4} & -8,18210^{-7} & 0 & 0 \\
4,88910^{-5} & -8,18210^{-7} & 3,27110^{-9} & 0 & 0 \\
0 & 0 & 0 & 2,73410^{-1} & -2,12810^{-3} \\
0 & 0 & 0 & -2,12810^{-3} & 1,70310^{-5}
\end{array}\right] \text {. }
$$

A "deviance" para o modelo (55) foi igual a $G^{2}=7,34$ com 9 graus de liberdade. Comparando-se esse valor com o tabelado $\left(\chi_{\{9 ; 0,05\}}^{2}=16,92\right)$ vê-se que não há evidências de falta de ajuste. Uma vez que o modelo se ajustou bem aos dados, espera-se que o delineamento D-ótimo Bayesiano baseado nas estimativas para o modelo adotado seja muito próximo ao localmente D-ótimo. Então, de modo a aumentar a incerteza em relação às estimativas dos parâmetros e aumentar, assim, o número de pontos de suporte dos delineamentos D-ótimos Bayesianos, multiplicouse a matriz $\hat{\Sigma}_{1}$ por 10,11 e 12. Os delineamentos localmente D-ótimos e D-ótimos Bayesianos resultantes, para a região experimental $x \in[0,200]$, são apresentados na Tabela 8, onde, assegurando-se que o limite inferior da região experimental seja 0 e o superior seja maior do que 149,24 , os delineamentos ótimos não se alteram.

A introdução de incerteza nas estimativas nos parâmetros teve, neste caso, um efeito pequeno no delineamento ótimo. Embora o número de pontos de suporte tenha aumentado com o aumento da constante usada na multiplicação da matriz de variâncias e covariâncias $\hat{\Sigma}_{1}$, os delineamentos D-ótimos Bayesianos e localmente $\mathrm{D}$-ótimos são praticamente indistingüíveis. Por exemplo, quando a matriz de variâncias e covariâncias é multiplicada por 12 , apenas $2 \%$ do esforço experimental se concentra no segundo e terceiro pontos.

A otimalidade dos delineamentos da Tabela 8 pode ser verificada usando-se o Teorema da equivalência geral apresentado na Seção 3.3.2, através do gráfico da função $\psi$ apresentado na Figura 5. Para o delineamento localmente Dótimo e Bayesiano considerando a matriz de variâncias e covariâncias $\hat{\Sigma}_{1}$ multiplicada por 10, há claramente três pontos de máximo, correspondentes aos pontos de suporte de cada delineamento, para os quais o valor da função é igual a 5 , o 
Tabela 8: Delineamentos localmente D-ótimos e Bayesianos para a região experimental $x \in[0,200]$ e a matriz de variâncias e covariâncias $\hat{\Sigma}_{1}$ multiplicada por 10, 11 e 12 .

\begin{tabular}{ccccccccc}
\hline \multirow{2}{*}{ Local } & \multicolumn{8}{c}{ Bayesiano } \\
\cline { 3 - 9 }$x$ & $w$ & $x$ & $w$ & $x$ & $w$ & $x$ & $w$ \\
\hline 0 & 0,203 & 0 & 0,206 & 0 & 0,204 & 0 & 0,198 \\
103,55 & 0,398 & 103,62 & 0,396 & 40,66 & 0,004 & 40,35 & 0,010 \\
149,24 & 0,399 & 149,04 & 0,398 & 103,75 & 0,395 & 84,48 & 0,013 \\
& & & & 149,04 & 0,397 & 104,38 & 0,382 \\
& & & & & & & 149,08 & 0,396 \\
\hline
\end{tabular}

número de parâmetros do modelo. Confirma-se, assim, que os delineamentos obtidos são realmente D-ótimos. Similarmente, o gráfico para o delineamento Bayesiano considerando-se a matriz de variâncias e covariâncias multiplicada por 12 tem cinco pontos de máximo, para os quais o valor da função é 5 . Desta forma, pode-se dizer que o delineamento obtido também é D-ótimo. O gráfico considerando-se a matriz de variâncias e covariâncias $\hat{\Sigma}_{1}$ multiplicada por 11 não foi apresentado devido à sua similaridade com aquele em que $\hat{\Sigma}_{1}$ é multiplicada por 12 .

Os gráficos apresentados para os delineamentos ótimos Bayesianos sugerem, ainda, que muitos delineamentos aproximadamente ótimos podem ser encontrados, devido à forma achatada dos gráficos dessas funções, fato que não é verificado para o delineamento localmente ótimo.

Para os dados da Tabela 1, referentes ao estudo de toxicidade com ratas prenhes considerou-se o seguinte modelo para respostas hierárquicas:

$$
\eta_{j}=\log \frac{\rho_{j}\left(x_{i}\right)}{1-\rho_{j}\left(x_{i}\right)}=\theta_{j 0}+\theta_{j 1} x_{i}, \quad i=1, \ldots, 5 \quad j=1,2,
$$

cujas estimativas de máxima verossimilhança obtidas para os parâmetros, foram: $\hat{\theta}_{10}=-3,248, \hat{\theta}_{11}=0,006389, \hat{\theta}_{20}=-5,702$ e $\hat{\theta}_{21}=0,01737$, e a estimativa da 
$\psi(x, \hat{\theta}, \xi)$

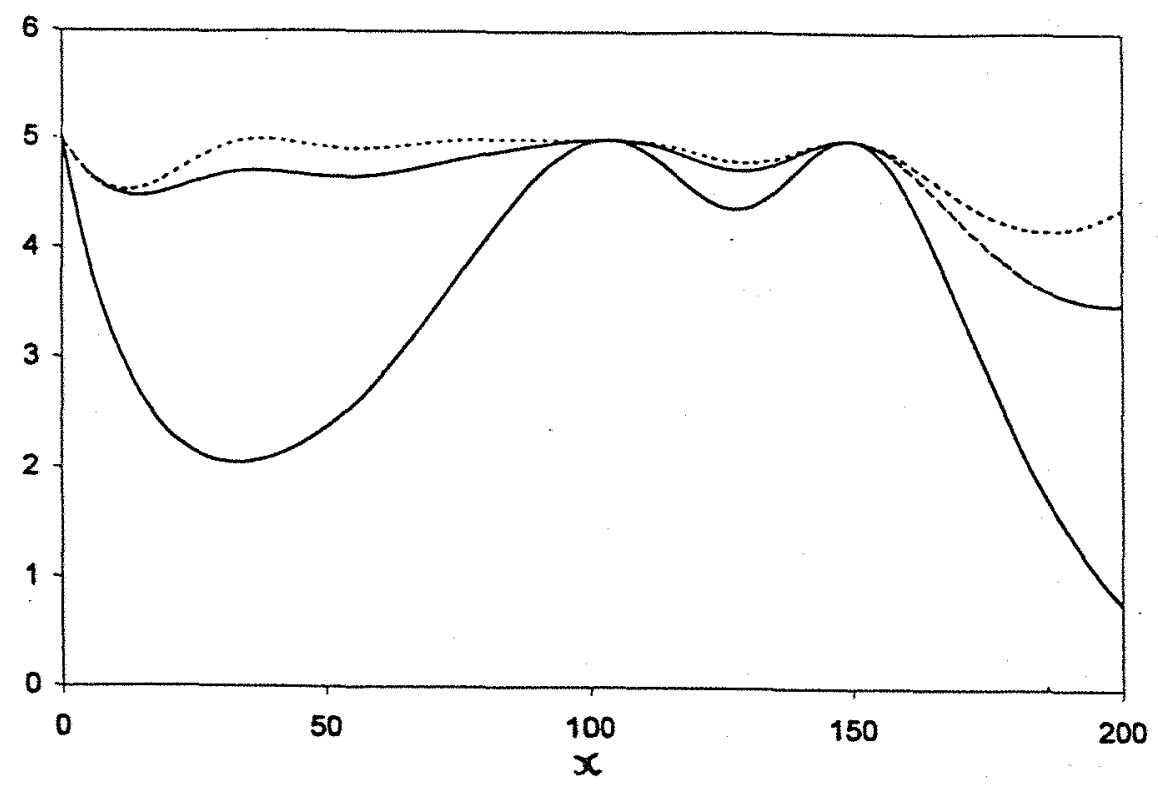

Figura 5: Funções de variância $\psi(x, \hat{\theta}, \xi)$, que confirmam a otimalidade do tipo D dos delineamentos Local (-), Bayesiano considerando-se $10 \times \hat{\Sigma}_{1}(---)$ e Bayesiano considerando-se $12 \times \hat{\Sigma}_{1}(--)$, apresentados na Tabela 8

matriz de variâncias e covariâncias,

$$
\hat{\Sigma}_{2}=\left[\begin{array}{cccc}
2,48610^{-2} & -5,91610^{-5} & 0 & 0 \\
-5,91610^{-5} & 1,89010^{-7} & 0 & 0 \\
0 & 0 & 1,09310^{-1} & -3,68410^{-4} \\
0 & 0 & -3,68410^{-4} & 1,47110^{-6}
\end{array}\right]
$$

Nesse caso, a "deviance" total observada $G^{2}=11,84$, com 6 de graus de liberdade, também não foi superior ao valor tabelado $\left(\chi_{\{6 ; 0,05\}}^{2}=12,59\right)$, não havendo indícios de falta de ajuste do modelo considerado.

Apesar do bom ajuste aparente, deve-se comentar que esta análise trata os resultados dos diferentes fetos da mesma dose, como observações independentes. No entanto, se cada rata prenhe tem um certo número de fetos, pode haver dependência entre diferentes fetos dentro do mesmo grupo de fetos de uma rata. Além disso, para uma dada concentração da droga pode também haver heterogeneidade en- 
Tabela 9: Delineamentos D-ótimos local e Bayesiano, considerando-se as estimativas de máxima verossimilhança obtidas para os parâmetros do modelo (56) e a respectiva matriz de variâncias multiplicada por 10, para os dados da Tabela 2.

\begin{tabular}{ccccc}
\hline Região experimental & \multicolumn{4}{c}{ Delineamento D-ótimo } \\
\cline { 2 - 6 } $\mathcal{X}$ & \multicolumn{2}{c}{ Local } & \multicolumn{2}{c}{ Bayesiano } \\
& $x$ & $w$ & $x$ & $w$ \\
\hline$[0 ; 450]$ & 214,51 & 0,500 & 204,93 & 0,473 \\
& 450,00 & 0,500 & 331,79 & 0,063 \\
& & & 450,00 & 0,464 \\
& 222,60 & 0,406 & 220,78 & 0,406 \\
& 401,35 & 0,380 & 399,63 & 0,378 \\
& 767,91 & 0,214 & 761,49 & 0,216 \\
\hline
\end{tabular}

tre as probabilidades de resposta associadas às ratas prenhes, ou seja, fetos de mesma ninhada terão probabilidades de sucesso mais semelhantes do que fetos de ninhadas diferentes. Este fato, viola as pressuposições da distribuição multinomial, podendo causar superdispersão Agresti (1996, p.219). Para solucionar esse problema, Zhu, Krewski e Ross (1994) e Krewski, Zhu e Fung (1996) propuseram modelos multinomiais que incluem parâmetros de superdispersão, que, como sugestão, poderiam ser utilizados no planejamento ótimo de ensaios.

Os resultados apresentados na Tabela 9 mostram que os delineamentos D-ótimos podem depender da região experimental adotada. Isto acontece para os delineamentos localmente ótimos, se o limite superior da região experimental for menor do que 767,91. Quando, por exemplo, o valor máximo é 450, obtém-se um delineamento localmente ótimo com apenas dois pontos de suporte, que passa a três quando o limite superior da região experimental é maior do que 450. Pode-se ver, ainda, que a incorporação de uma certa incerteza em relação às estimativas dos parâmetros, neste exemplo, teve um efeito pequeno. Os delineamentos localmente 
ótimos e os Bayesianos são praticamente indistinguíveis. Para a região restrita, no entanto, o delineamento Bayesiano tem três pontos de suporte contra os dois do delineamento localmente ótimo, mas apenas $6,3 \%$ do esforço é dedicado ao ponto extra. Os delineamentos Bayesianos D-ótimos foram gerados usando a matriz $\hat{\Sigma}_{2}$ multiplicada por 10. Embora não apresentados, gráficos semelhantes aos da Figura 5, para o modelo (55), comprovam que os delineamentos da Tabela 9 são realmente Dótimos.

De modo geral, os resultados mostraram o aumento do número de pontos de suporte do delineamento com o aumento da incerteza a priori, conforme o desejado.

A seguir serão feitos alguns comentários gerais a respeito dos procedimentos utilizados nesta Seção.

Inicialmente, convém observar que trabalhou-se apenas com o critério de otimização $D$, apropriado se a maior importância é dada à estimação precisa dos parâmetros do modelo. Outros critérios refletiriam outros interesses. Atkinson, Demétrio \& Zocchi (1995), por exemplo, utilizaram um critério que envolvia uma função dos parâmetros de um modelo de regressão logística com resposta binomial envolvendo misturas de indivíduos pertencentes a diversas populações.

Para a obtenção dos delineamentos Bayesianos, usou-se uma distribuição a priori, construída a partir dos resultados de um experimento prévio. No entanto, essas distribuições podem também ser obtidas a partir de informações dadas por pesquisadores ou obtidas em publicações. Em todos esses casos, porém, os procedimentos numéricos são os mesmos apresentados aqui.

O método de incorporação da informação a priori, através da soma da matriz de informação fornecida pelos dados relativos a um experimento prévio à matriz de informação do modelo adotado, descrito por Dykstra (1971) não é indicado no nosso caso. Isto devido ao fato de não se ter total controle da variabilidade do material experimental. No experimento com as pupas de mosca, por exemplo, a emergência dos adultos ocorre de quatro a cinco dias após a formação das pupas e as pupas reagem de formas bastante diferentes à radiação de acordo com suas idades. 
Tabela 10: Estimativas de quadrados mínimos e "bootstrap" (baseada em $B=5000$ amostras) dos parâmetros do modelo (9) para a análise dos dados da Tabela 4. (Desvios padrōes entre parênteses)

\begin{tabular}{lcccc}
\hline Método de estimação & \multicolumn{4}{c}{ Parâmetros } \\
& $b$ & $D M_{R}$ & $D M_{S}$ & $r=\frac{D M_{R}}{D M_{S}}$ \\
\hline Quadrados mínimos & 3,625 & 2,299 & 0,2730 & 8,422 \\
& $(0,2725)$ & $(0,05147)$ & $(0,02143)$ & $(0,7041)$ \\
"Bootstrap" & 3,610 & 2,302 & 0,2719 & 8,4840 \\
& $(0,2588)$ & $(0,04757)$ & $(0,02021)$ & $(0,9396)$ \\
\hline
\end{tabular}

Assim, essa estratégia seqüencial não é apropriada. Se fosse possível realizar o experimento em diversas etapas, sob condiçôes praticamente idênticas, o que raramente acontece em experimentos em Biologia, então tal procedimento seria aconselhado.

Embora os casos apresentados envolvam apenas uma variável com resposta multi-categorizada e uma covariável (dose), a classe de modelos (4) e (5), apresentados na Seção 3.1.1 é muito mais geral, incluindo o caso de várias variáveis multi-categorizadas serem observadas. Em conseqüência, o Teorema da equivalência geral apresentado na Seção 3.3.2 pode ser aplícado a.os casos multivariados em que duas ou mais respostas são observadas.

\subsection{Delineamentos ótimos e "boostrap"}

A metodologia proposta na Seção 3.2 .3 , para a geração de delineamentos com um certo número de pontos de suporte, utilizando a técnica de reamostragem "bootstrap", será ilustrada através do planejamento de um ensaio de dose e resposta com herbicidas, baseado nos resultados (Tabela 4) do ensaio preliminar descrito na Seção 2.4 .

As estimativas dos parâmetros do modelo (9), ajustado aos dados 
da Tabela 4, e respectivos desvios padrões (entre parênteses), são apresentados na Tabela 10. Tais estimativas têm interpretações práticas bastante importantes. $\widehat{D M}_{S}=0,2730$ indica, por exemplo, que para se ter um controle de $50 \%$ do capimmarmelada do biotipo suscetível, deve-se aplicar 0,273 vezes a dose de herbicida recomendada pelo fabricante. Por outro lado, é necessário aplicar 2,299 vezes a dose recomendada para se ter a mesma porcentagem de controle para o biotipo resistente.

Conforme foi visto na Seção 2.4, para se compararem os dois biotipos quanto à resistência a um herbicida, freqüentemente usa-se a potência relativa $\left(r=D M_{R} / D M_{S}\right)$. Para estimá-la reparametrizou-se o modelo (9) em função de $r$, fazendo-se $D M_{R}=r D M_{S}$. No caso em questão, $\hat{r}=8,422$ (desvio padrão igual a 0,7041), ou seja, para se controlar o biotipo resistente é necessário aplicar uma dose de herbicida 8,422 vezes maior do que para se controlar o biotipo suscetível. Esse valor quantifica e comprova a resistência do biotipo denominado resistente.

Além disso, para a dose recomendada pelo fabricante $(x=1)$, por exemplo, as porcentagens previstas de controle para os biotipos resistente e suscetível são dadas, respectivamente, por $4,66 \%$ e $99,1 \%$, o que ressalta a diferença existente entre os dois biotipos analisados.

Uma vez que o modelo escolhido ajusta-se bem aos dados, o que pode ser visualizado na Figura 6, deve-se partir para o planejamento do experimento definitivo, ou seja, escolher as novas doses e o número de repetições de cada uma.

A Tabela 11 apresenta o delineamento localmente D-ótimo baseado nas estimativas dos parâmetros do modelo (9), cuja otimalidade pode ser comprovada através da Figura 8 , uma vez que o máximo da função de variância, igual a 3 (número de parâmetros do modelo adotado), ocorre nos pontos de suporte do delineamento. Note que são recomendadas duas doses inferiores à menor dose utilizada $(x=0,5)$ no ensaio preliminar e que as quatro doses recomendadas possuem pesos iguais, fato bastante comum em delineamentos D-ótimos.

Como uma forma de se elevar o número de doses diferentes utilizou-se a técnica de reamostragem "bootstrap" para se estimar a distribuição conjunta de $\hat{\theta}$ e a partir dela, o delineamento D-ótimo Bayesiano. Neste caso, dispunha-se de quarenta 


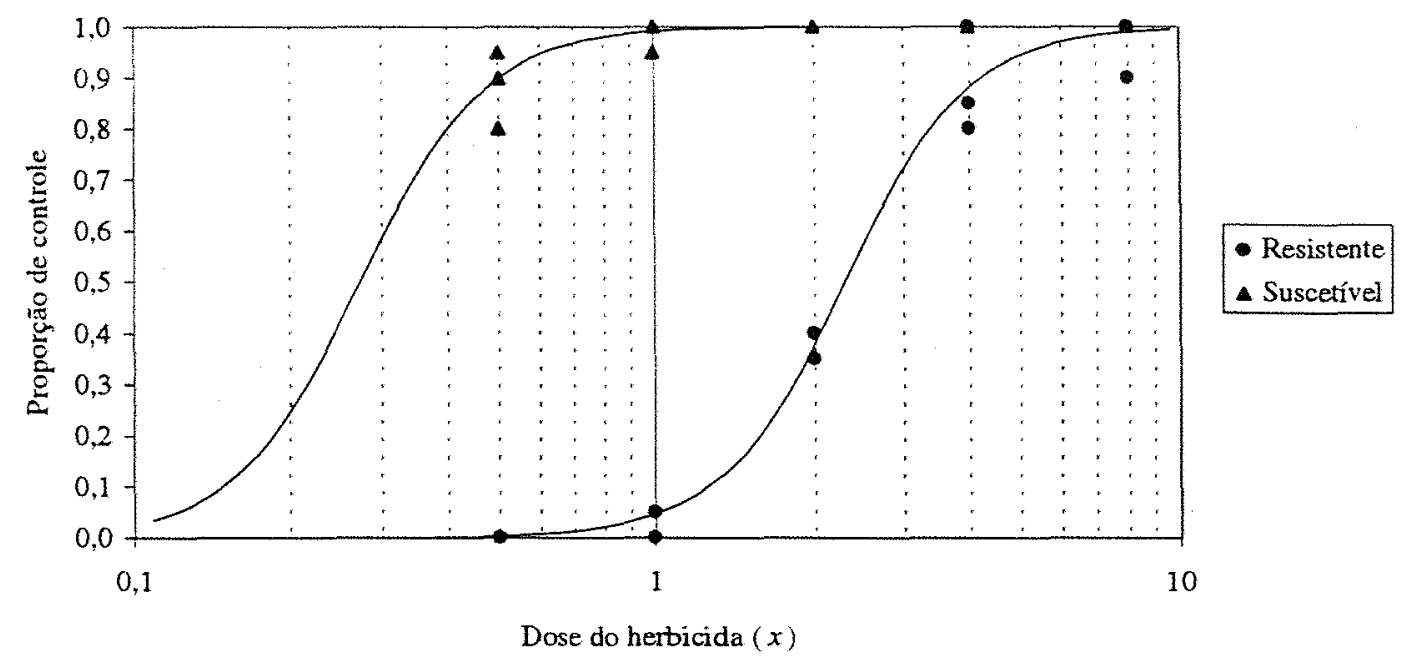

Figura 6: Proporções observadas e estimadas (-) de controle de dois biotipos, resistente e suscetível, do capim marmelada, em função da dose do herbicida haloxyfop.

Tabela 11: Delineamentos localmente D-ótimo e Bayesiano D-ótimo baseado na distribuição empírica "bootstrap" de $\theta$.

\begin{tabular}{cccc}
\hline \multicolumn{3}{c}{ Delineamento } & \multicolumn{2}{c}{ D-ótimo } \\
\multicolumn{2}{c}{ Local } & \multicolumn{2}{c}{ Bayesiano } \\
$x$ & $w$ & $x$ & $w$ \\
\hline 0,216 & 0,250 & 0,221 & 0,234 \\
0,344 & 0,250 & 0,348 & 0,250 \\
1,824 & 0,250 & 1,821 & 0,257 \\
2,899 & 0,250 & 2,848 & 0,259 \\
\hline
\end{tabular}


pares de valores, $\left(x_{i}, y_{i}\right)(i=1, \ldots, 40)$, sendo os vinte primeiros relativos ao biotipo resistente e os restantes, ao biotipo suscetível. Para se obterem as distribuições empíricas conjuntas desejadas, foram retiradas $B=5000$ amostras "bootstrap" de tamanho $n=40$, sendo 20 elementos de cada biotipo, em cada amostra. Observe, na Tabela 10 que as estimativas dos parâmetros do modelo adotado pelo método dos quadrados mínimos e pelo método "bootstrap" são muito semelhantes. No entanto, na Figura 7, nota-se que as distribuições empíricas marginais dos parâmetros do modelo adotado dificilmente poderiam ser consideradas normais, especialmente a do parâmetro $b$ que é multimodal e altamente assimétrica talvez devido à existência de observações influentes. Isto questionaria a suposição de normalidade muitas vezes assumida.

Considerando-se a distribuição empírica "bootstrap" conjunta de $\hat{\theta}$ e maximizando-se a função (22) obtém-se o delineamento D-ótimo Bayesiano apresentado na Tabela 11. Esse delineamento é praticamente igual ao localmente D-ótimo, o que pode ser explicado devido à pequena variância generalizada de $\hat{\boldsymbol{\theta}}$.

Convém notar que o teorema da equivalência geral entre os delineamentos D e G-ótimos Bayesianos continua válido para o caso Bayesiano e a Figura 8 comprova a otimalidade do delineamento D-ótimo Bayesiano, uma vez que o máximo ocorre nos pontos de suporte do delineamento e é igual a 3 , número de parâmetros. Esses delineamentos, no entanto, continuam apresentando o problema de terem poucos pontos de suporte.

Baseando-se nas distribuiçōes empíricas marginais das doses, delineamentos localmente D-ótimos, representada na Figura 9, chegou-se às estimativas "bootstrap" das doses dos delineamentos localmente D-ótimos e respectivos coeficientes de variação, apresentados na Tabela 12. Veja que esse delineamento é muito semelhante ao delineamento localmente D-ótimo apresentado na Tabela 11, mas acrescenta a idéia de dispersão, representada pelo coeficiente de variação, que pode auxiliar o planejamento do ensaio definitivo. Os coeficientes de variação, maiores para as duas menores doses e menores para as duas doses maiores traduzem a necessidade de não se concentrar muito as doses do ensaio definitivo ao redor das duas 


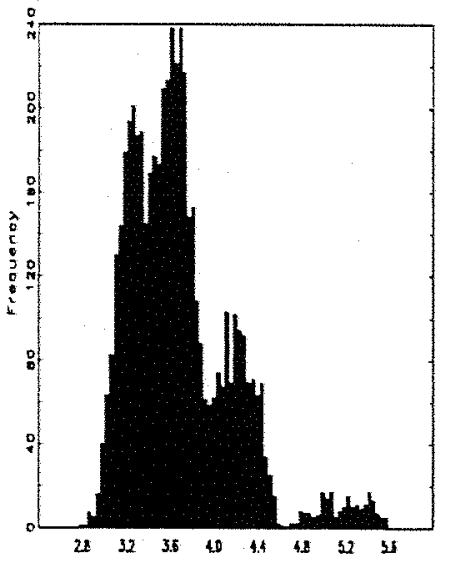

$b$

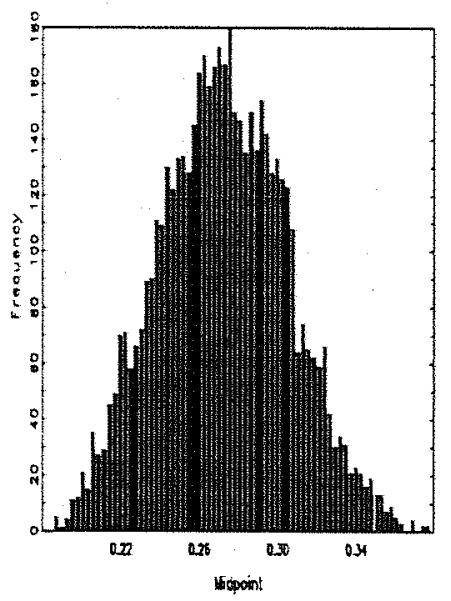

$D M_{S}$

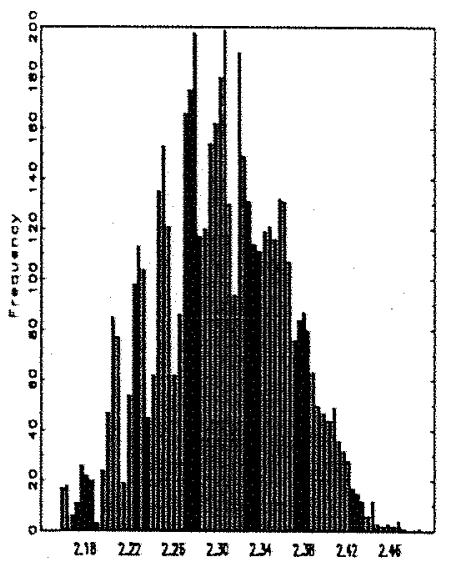

$D M_{R}$

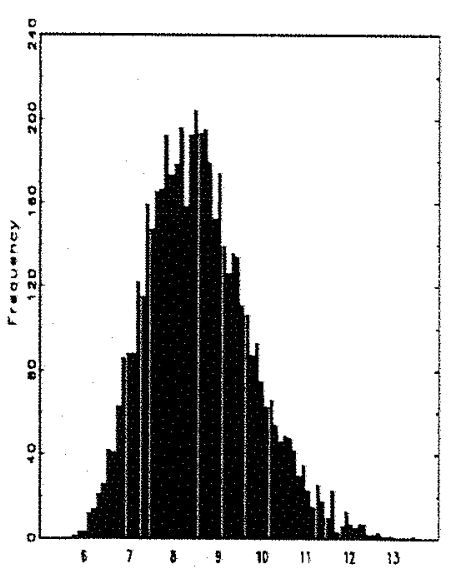

$$
r=D M_{R} / D M_{S}
$$

Figura 7: Distribuição empírica "bootstrap" marginais dos parâmetros $b, D M_{R}$, $D M_{S}$ and $r$, baseada em 5000 amostras. 


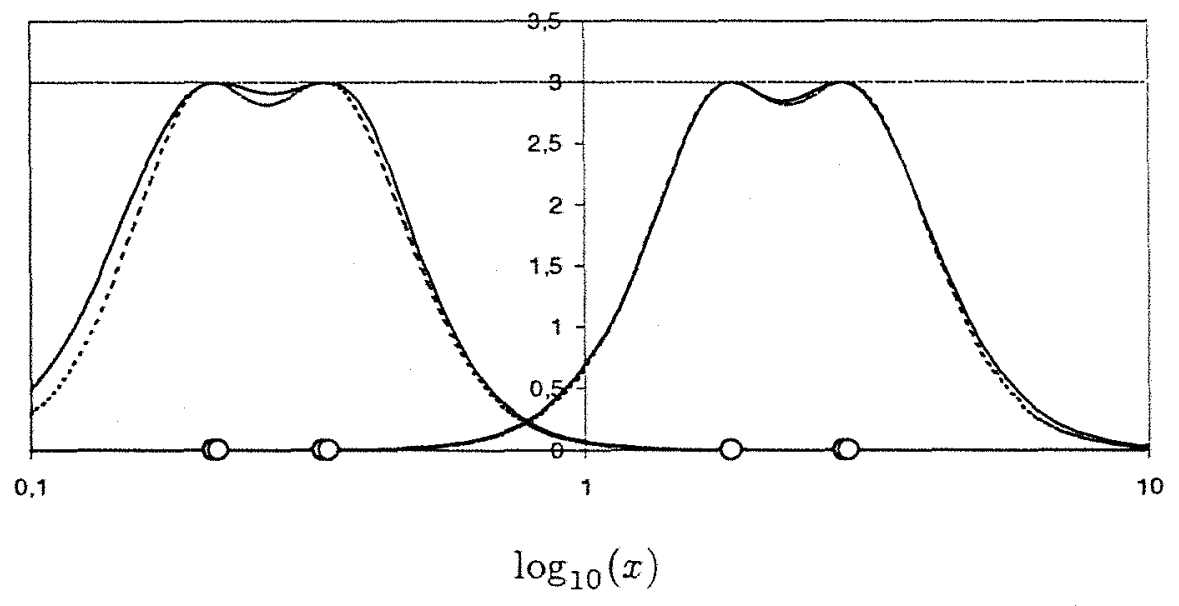

Figura 8: Funções de variância do valor predito para o delineamento localmente $D$ ótimo (- -) e para o delineamento D-ótimo Bayesiano (-) baseado na distribuição "bootstrap" empírica dos parâmetros

primeiras doses e, por outro lado, concentrar as doses restantes ao redor das duas doses mais elevadas.

Agrupando-se todos os $B=5000$ conjuntos de 4 doses ótimas em um único de tamanho 20000, chega-se à distribuição apresentada na Figura 10, que mostra, novamente, que metade das doses para o ensaio definitivo deve estar concentrada ao redor das duas doses superiores e a outra metade mais dispersa ao redor das duas mais baixas.

Supondo que o pesquisador deseja escolher $t=8$ doses para o futuro ensaio, e usando-se (37), tais doses seriam os percentis $P_{11,1}, P_{22,2}, \ldots, P_{88,8}$ do conjunto de 20000 valores, ou seja,

$$
\left\{\begin{array}{llllllll}
0,2114 & 0,2536 & 0,3270 & 0,3710 & 1,808 & 1,836 & 2,715 & 2,924
\end{array}\right\}
$$

com pesos iguais.

Como comentário a respeito do planejamento de ensaios como o descrito nesta Seção, sugere-se, algumas vezes, a adoção de diferentes conjuntos de doses para os diferentes biotipos. Essa sugestão, no entanto, é muitas vezes praticamente inviável, especialmente se o experimento envolve diferentes herbicidas. Isto devido 


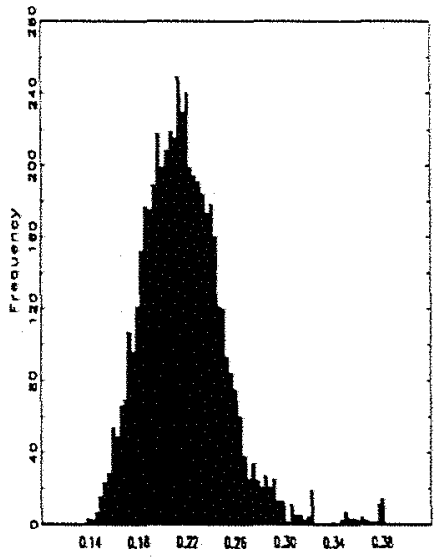

$x_{1}^{*}$

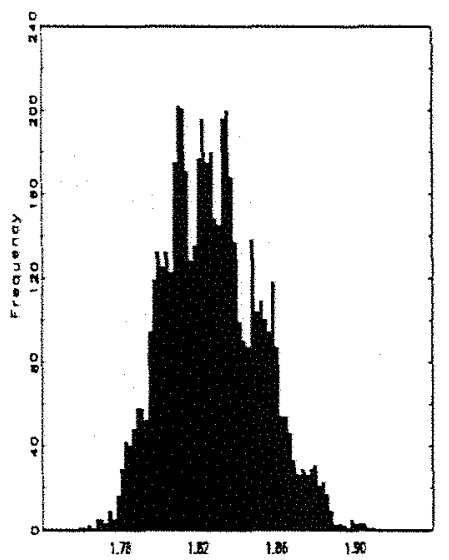

$x_{3}^{*}$

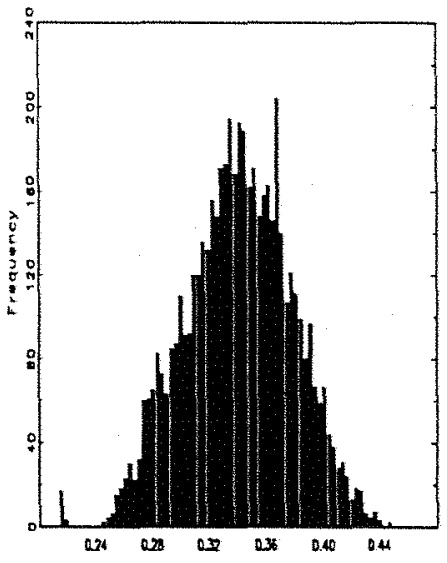

$x_{2}^{*}$

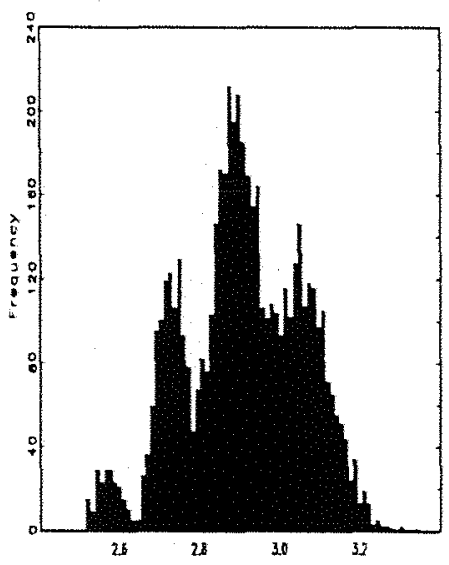

$x_{4}^{*}$

Figura 9: Distribuiçôes empíricas "bootstrap" marginais das doses ótimas dos delineamentos localmente D-ótimos baseadas em 5000 amostras "bootstrap". 
Tabela 12: Estimativas "bootstrap" das doses dos delineamentos localmente Dótimos e respectivos coeficientes de variação.

\begin{tabular}{cc}
\hline$\tilde{x}_{i}^{*}$ & $\begin{array}{c}\text { Coeficiente de } \\
\text { variação (\%) }\end{array}$ \\
\hline 0,218 & 15,7 \\
0,341 & 11,1 \\
1,827 & 1,31 \\
2,906 & 5,13 \\
\hline
\end{tabular}

ao grande trabalho necessário para a cuidadosa lavagem do material envolvido na dosagem e aplicação do herbicida aos vasos.

Convém observar que a análise dos resultados do experimento preliminar junto com os de um definitivo, prática bastante comum em experimentos industriais, não é aconselhável devido à influência de fatores ambientais nos resultados. Desta forma, não se recomenda a utilização do planejamento seqüencial de um ensaio desse tipo.

\subsection{Delineamentos para a detecção de falta de ajuste}

Para ilustrar a metodologia proposta nas Seções 3.2.4 e 3.3.3, para a obtenção de delineamentos ótimos para a detecção de falta de ajuste em modelos não lineares, com um pequeno número adicional de pontos de suporte, será apresentado nesta Seção, o planejamento de ensajos de produtividade em função da densidade de plantio, a partir dos resultados apresentados na Tabela 3.

Para a análise desses dados, considerou-se o modelo (14), proposto por Shinozakj \& Kira (1956), cujas estimativas obtidas de quadrados mínimos para seus parâmetros foram iguais a $\hat{\theta_{1}}=5,496$ e $\hat{\theta_{2}}=1,568$.

Considere, para o planejamento de um novo ensaio baseado nessas estimativas, que a região experimental é dada por $\mathcal{X}=\{3,3,5,4, \cdots, 32,5,33\}$, 


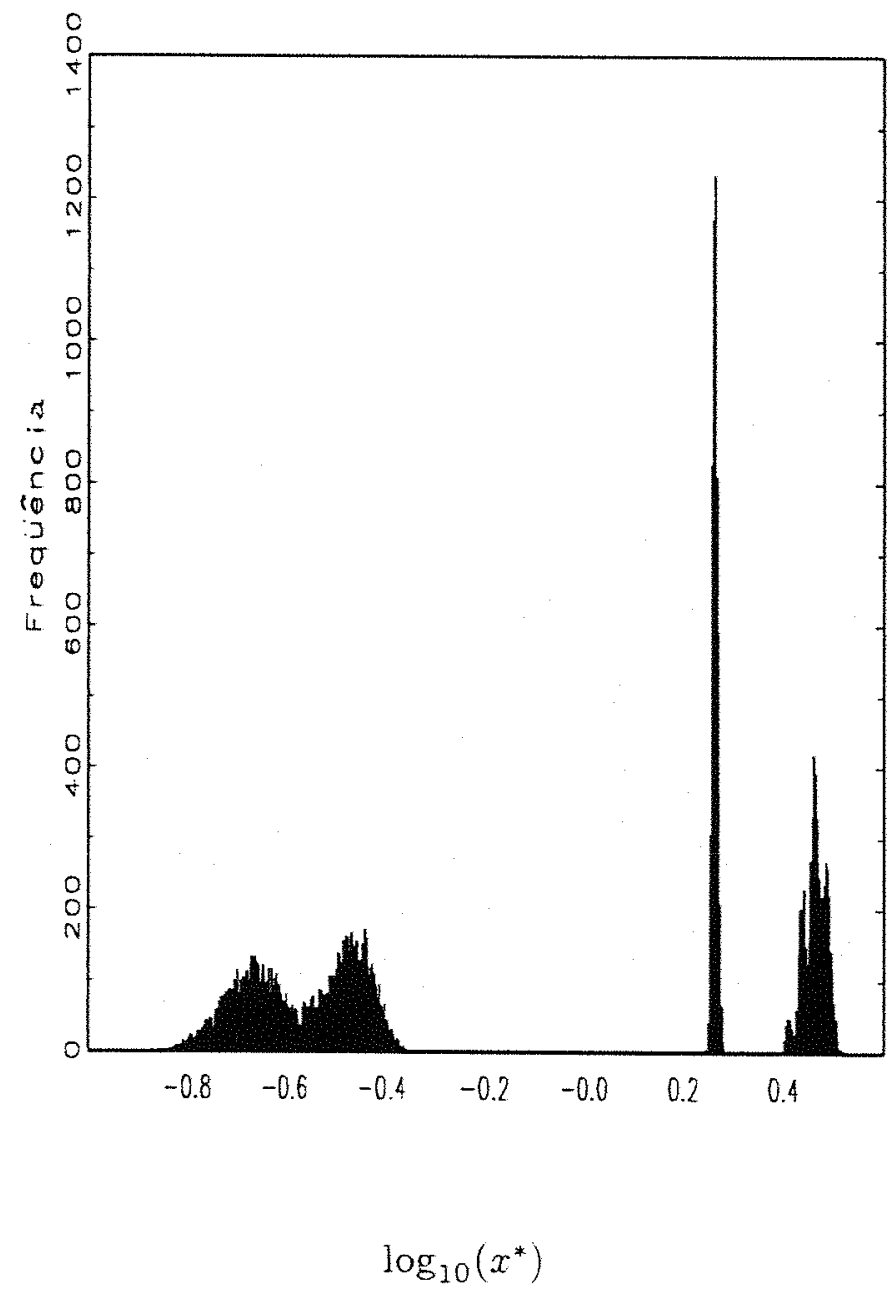

Figura 10: Distribuição empírica dos logaritmos das doses dos delineamentos localmente D-ótimos. 
ou seja, com $n_{c}=61$ pontos, e que o interesse é planejar um experimento com exatamente $N=12$ densidades de plantio, não necessariamente diferentes. O delineamento localmente D-ótimo para estimar $\theta=\left[\begin{array}{ll}\theta_{1} & \theta_{2}\end{array}\right]^{T}$, nesse caso, tem metade dos pontos de suporte iguais a 3 e metade dos pontos iguais a 33 , não permitindo que se verifique a falta de ajuste do modelo. Uma forma de resolver esse problema, segundo as idéias descritas na Seção 3.2.4, seria a ampliação do modelo original (14). Assim, se um polinômio de segunda ordem for adicionado ao modelo não linear (14), tem-se o seguinte modelo

$$
E(Y)=\eta(x, \theta)=x\left(\theta_{1}+\theta_{2} x\right)^{-1}+\theta_{3} x+\theta_{4} x^{2}
$$

com $p_{2}=2$ parâmetros adicionais, e cuja matriz não transformada $F$ do delineamento, teria suas linhas dadas por

$$
f^{T}(x)=\left[\begin{array}{llll}
-x\left(\theta_{1}+\theta_{2} x\right)^{-2} & -x^{2}\left(\theta_{1}+\theta_{2} x\right)^{-2} \quad \vdots \quad x \quad x^{2}
\end{array}\right]
$$

Adicionando-se termos quadráticos e de produto cruzado às derivadas parciais da resposta em relação aos parâmetros $\theta_{1}$ e $\theta_{2}$, as linhas da matriz não transformada $F$ são dadas por

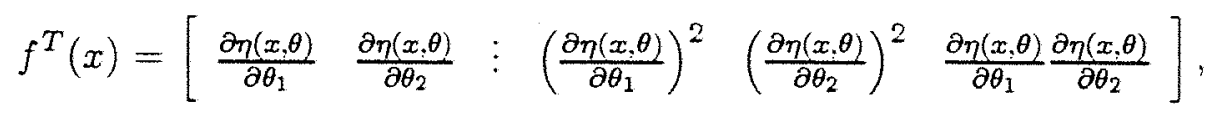

com $p_{2}=3$ termos adicionais, onde $\eta(x, \theta)=\eta(x, \boldsymbol{\theta})=x\left(\theta_{1}+\theta_{2} x\right)^{-1}$.

Utilizando-se o terceiro método, pode-se aninhar o modelo não linear (14) adotado, em um mais geral, como o modelo (15), que é igual ao original para $\theta_{3}=\theta_{4}=1$ e nesse caso, as linhas da matriz não transformada $F$ são

$$
f^{T}(x)=\left[\left.\left.\left.\left.\frac{\partial \eta(x, \theta)}{\partial \theta_{1}}\right|_{\theta_{3}=\theta_{4}=1} \frac{\partial \eta(x, \theta)}{\partial \theta_{2}}\right|_{\theta_{3}=\theta_{4}=1} \quad \vdots \quad \frac{\partial \eta(x, \theta)}{\partial \theta_{3}}\right|_{\theta_{3}=\theta_{4}=1} \frac{\partial \eta(x, \theta)}{\partial \theta_{4}}\right|_{\theta_{3}=\theta_{4}=1}\right]
$$

$\operatorname{com} p_{2}=2$ termos adicionais, onde $\eta(x, \theta)=\eta(x, \theta)=x\left(\theta_{1}+\theta_{2} x^{\theta_{3}}\right)^{-1 / \theta_{4}}$.

Tomando como base esses modelos ampliados e o critério de otimização $\mathrm{D}$ de Bayes, obtiveram-se os delineamentos $\mathrm{D}$-ótimos exatos de Bayes, apresentados nas Tabelas 13 e 14, sem e com o uso do procedimento de transformação iterativa 
proposto na Seção 3.2.4, respectivamente. Como se pode notar, a utilização desse procedimento não levou a praticamente nenhuma alteração nos delineamentos obtidos, com exceção dos delineamentos para $\tau=10$ e o terceiro método de aumento. Introduziu, ainda, o problema de uma possível não convergência do algoritmo de transformação iterativa, levando à oscilação entre dois delineamentos semelhantes. Este fato, por exemplo, foi observado na obtenção do delineamento D-ótimo exato de Bayes de iguais interesses, quando se considerou o segundo método de ampliação do modelo (Tabela 14).

Quanto à comparação entre os delineamentos D-ótimos de Bayes, apresentados na segunda e terceira colunas das Tabelas 13 e 14, com os D-ótimos de iguais interesses de Bayes, apresentados na quarta e quinta colunas das Tabelas 13 e 14, pode-se dizer que também não houve grandes diferenças entre os delineamentos produzidos. Para o primeiro e terceiro métodos de ampliação do delineamento original, tal fato já era esperado, pois $p_{1}=p_{2}=2 \mathrm{e}$, portanto, os delineamentos $\mathrm{D}$ ótimos de interesses iguais e os D-ótimos seriam idênticos. Para o segundo método, a diferença entre o número de termos do modelo aumentado e o número de parâmetros originais é de apenas uma unidade, causando a pequena diferença observada, para $\tau=10$.

A inclusão dos delineamentos para o valor $\tau=10$, diferente do valor $\tau=1$ recomendado, serve apenas para ilustrar que o aumento em $\tau$ geralmente leva a um aumento no número de pontos de suporte e que a eficiência do delineamento em relação ao ótimo para se estimar $\theta_{1}\left(D_{e f_{1}}\right)$, geralmente, diminui. Este fato pode ser observado, nas Tabelas 13 e 14, para os dois primeiros métodos de aumento. De modo contrário, a eficiência do delineamento em relação ao ótimo para se estimar $\theta_{2}\left(D_{e f_{2}}\right)$, geralmente, aumenta. Uma exceção aparente pode ser vista para os delineamentos para o terceiro método de ampliação do modelo, quando praticamente não houve mudanças dos delineamentos obtidos.

Levando-se em conta as mesmas consideraçōes anteriores, porém, com a região experimental dada por $\mathcal{X}=[3,33]$, 
Tabela 13: Delineamentos D-ótimos exatos de Bayes para os três métodos de aumentar o modelos original: (1) adicionar ao modelo original, um polinômio de ordem pequena; (2) adicionar termos quadráticos e de produto cruzado às derivadas parciais da resposta em relação aos parâmetros e (3) aninhar o modelo original em um mais geral.

\begin{tabular}{|c|c|c|c|c|c|c|c|c|}
\hline & \multicolumn{4}{|c|}{ D-ótimo } & \multicolumn{4}{|c|}{ Iguais Interesses } \\
\hline & \multicolumn{2}{|c|}{$\tau=1$} & \multicolumn{2}{|c|}{$\tau=10$} & \multicolumn{2}{|c|}{$\tau=1$} & \multicolumn{2}{|c|}{$\tau=10$} \\
\hline \multirow[t]{5}{*}{ (1) } & & & & $r_{i}$ & $x_{i}$ & $r_{i}$ & $x_{i}$ & $r_{i}$ \\
\hline & 3 & 4 & 3 & 3 & 3 & 4 & 3 & 3 \\
\hline & 14,5 & 4 & 9,5 & 3 & 14,5 & 4 & 9,5 & 3 \\
\hline & 33 & 4 & 22 & 3 & 33 & 4 & 22 & 3 \\
\hline & & & 33 & 3 & & & 33 & 3 \\
\hline$D_{e f_{1}}(\%)$ & \multicolumn{2}{|c|}{85,1} & \multicolumn{2}{|c|}{80,8} & \multicolumn{2}{|c|}{85,1} & \multicolumn{2}{|c|}{80,8} \\
\hline$D_{e f_{2}}(\%)$ & \multicolumn{2}{|c|}{95,0} & \multicolumn{2}{|c|}{96,9} & \multicolumn{2}{|c|}{95,0} & \multicolumn{2}{|c|}{96,9} \\
\hline \multirow[t]{5}{*}{ (2) } & & & & & & & $x_{i}$ & $r_{i}$ \\
\hline & 3 & 3 & 3 & 3 & 3 & 3 & 3 & 3 \\
\hline & 5 & 2 & 5,5 & 3 & 5 & 2 & 5,5 & 3 \\
\hline & 13 & 3 & 14 & 3 & 13 & 3 & 14 & 2 \\
\hline & 33 & 4 & 33 & 3 & 33 & 4 & 14,5 & 1 \\
\hline$D_{e f_{1}}(\%)$ & \multicolumn{2}{|c|}{85,7} & \multicolumn{2}{|c|}{82,1} & \multicolumn{2}{|c|}{85,7} & \multicolumn{2}{|c|}{82,2} \\
\hline$D_{e f_{2}}(\%)$ & \multicolumn{2}{|c|}{95,9} & \multicolumn{2}{|c|}{97,8} & \multicolumn{2}{|c|}{95,9} & \multicolumn{2}{|c|}{97,6} \\
\hline \multirow[t]{6}{*}{ (3) } & & & & $r_{i}$ & $x_{i}$ & $r_{i}$ & $x_{i}$ & $r_{i}$ \\
\hline & 3 & 4 & 3 & 4 & 3 & 4 & 3 & 4 \\
\hline & 11,5 & 4 & 11 & 1 & 11,5 & 4 & 11 & 1 \\
\hline & 33 & 4 & 11,5 & 2 & 33 & 4 & 11,5 & 2 \\
\hline & & & & & & & 12 & 1 \\
\hline & & & 33 & & & & 33 & \\
\hline$D_{e f_{1}}(\%)$ & \multicolumn{2}{|c|}{84,5} & \multicolumn{2}{|c|}{84,6} & \multicolumn{2}{|c|}{84,5} & \multicolumn{2}{|c|}{84,6} \\
\hline$D_{e f_{2}}(\%)$ & \multicolumn{2}{|c|}{96,4} & \multicolumn{2}{|c|}{95,6} & \multicolumn{2}{|c|}{96,4} & \multicolumn{2}{|c|}{95,6} \\
\hline
\end{tabular}


Tabela 14: Delineamentos D-ótimos exatos de Bayes, gerados usando o procedimento de transformação iterativa, para os três métodos de aumentar o modelos original: (1) adicionar ao modelo original, um polinômio de ordem pequena; (2) adicionar termos quadráticos e de produto cruzado às derivadas parciais da resposta em relação aos parâmetros e (3) aninhar o modelo original em um mais geral.

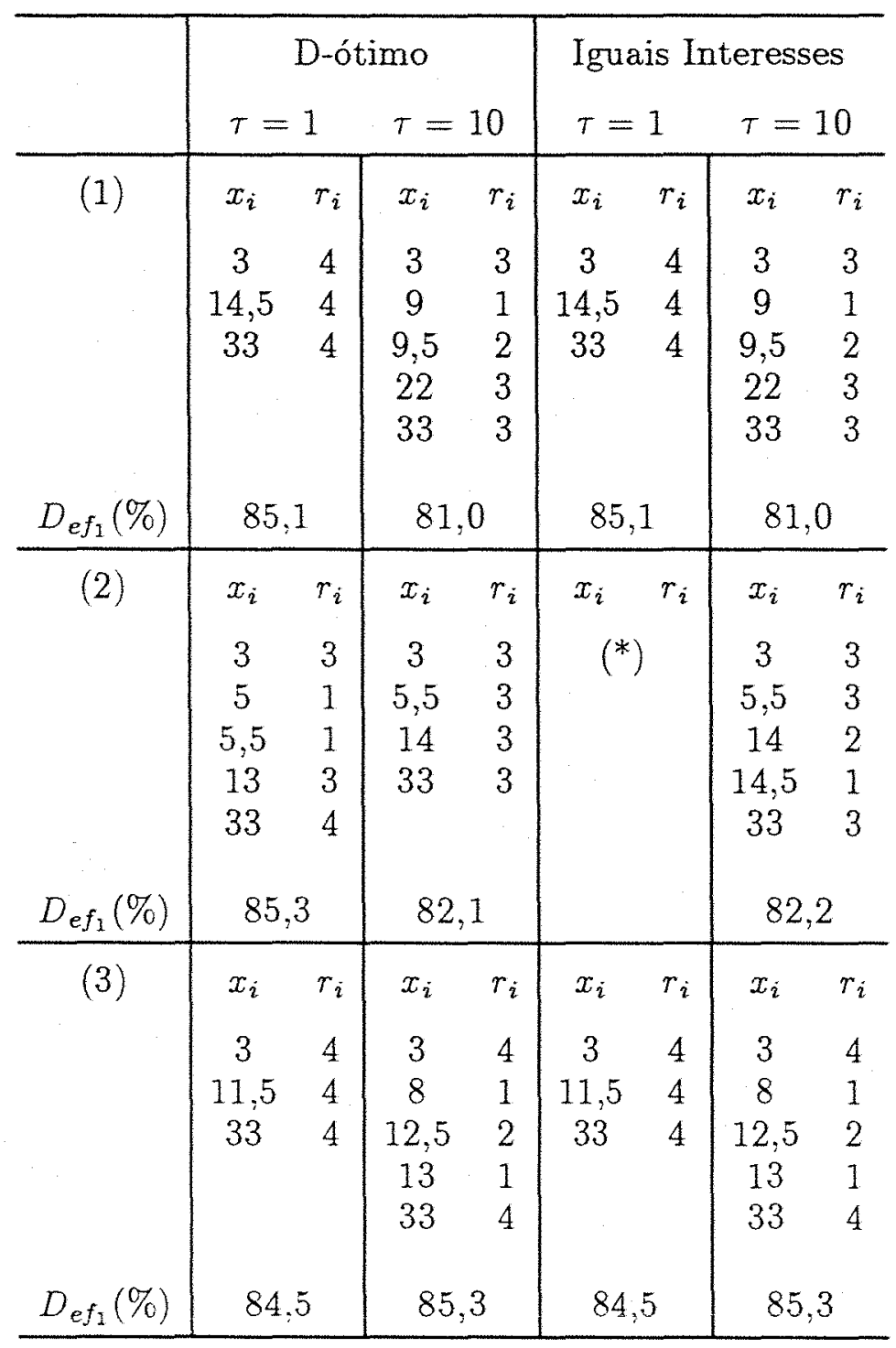

(*) Não houve a convergência do algoritmo proposto, oscilando entre dois delineamentos similares, com eficiências próximas a $85,3 \%$ 


$$
\xi_{c}=\left\{\begin{array}{cccccc}
3 & 3,5 & 4 & \cdots & 32,5 & 33 \\
1 / 61 & 1 / 61 & 1 / 61 & \cdots & 1 / 61 & 1 / 61
\end{array}\right\}
$$

e $N=12$ pontos, o delineamento localmente D-ótimo para se estimarem $\boldsymbol{\theta}_{1}$ e $\boldsymbol{\theta}_{2}$ tem seus pontos distribuídos igualnente nas extremidades ( 3 e 33 ) da região do delineamento. Tal resultado é o mesmo obtido anteriormente, não permitindo, mais uma vez, a deteç̧ão de falta de ajuste do modelo original.

Observando-se a matriz (52), a partir da qual foram baseados os delineamentos D-ótimos de Bayes, podem-se fazer algumas considerações sobre a relação entre esses delineamentos e $N \tau^{2}$. Quando $N \tau^{2} \rightarrow 0$, assume-se que há muita informação a respeito dos parâmetros adicionais, não havendo, portanto, necessidade de estimá-los. Nesse caso, o delineamento D-ótimo de Bayes deve se aproximar do delineamento D-ótimo para se estimarem os $p_{1}$ parâmetros do modelo original, com $p_{1}$ pontos de suporte e todos os pesos iguais a $1 / p_{1}$. Quando $N \tau^{2} \rightarrow \infty$, por outro lado, pode-se admitir que não há nenhuma informação a respeito dos parâmetros adicionais. Assim, o delineamento D-ótimo de Bayes deve se aproximar do delineamento D-ótimo para se estimarem todos os $p=p_{1}+p_{2}$ parâmetros do modelo ampliado, com $p$ pontos de suporte e todos os pesos iguais a $1 / p$. Nos casos intermediários, o delineamento gerado, estaria compreendido entre os dois delineamentos citados, com um número de pontos de suporte entre $p_{1}$ e $p$ com diferentes pesos.

No caso em questão, $N$ é fixo e igual a 12 e assim, a análise resume-se ao exame dos valores de $\tau$ considerados. Na Tabela 15, a escolha do valor bastante pequeno, $\tau=0,1$, conforme esperado, faz com que o delineamento $\mathrm{D}$-ótimo de Bayes seja igual do delineamento $\mathrm{D}$-ótimo para estimar $\boldsymbol{\theta}_{1}$, com apenas $p=2$ pontos de suporte e pesos iguais a $1 / 2$, para todos os métodos de ampliação do modelo original considerados. Com o aumento do valor de $\tau$ para o valor recomendado 1 , observa-se o acréscimo de um ou dois pontos de suporte, gerando delineamentos com número de pontos de suporte diferentes entre $p_{1}=2$ e $p(p=4$ para o primeiro e terceiro métodos de ampliação e $p=5$ para o segundo), cumprindo o objetivo inicial de propor delineamentos com poucos pontos de suporte e capazes de detectar falta de 
Tabela 15: Delineamentos D-ótimos contínuos, com $N=12$, de Bayes para os três métodos de se aumentar o modelo original: (1) adicionar ao modelo original um polinômio de ordem pequena; (2) adicionar termos quadráticos e de produto cruzado às derivadas parciais da resposta em relação aos parâmetros e (3) aninhar o modelo original em um mais geral.

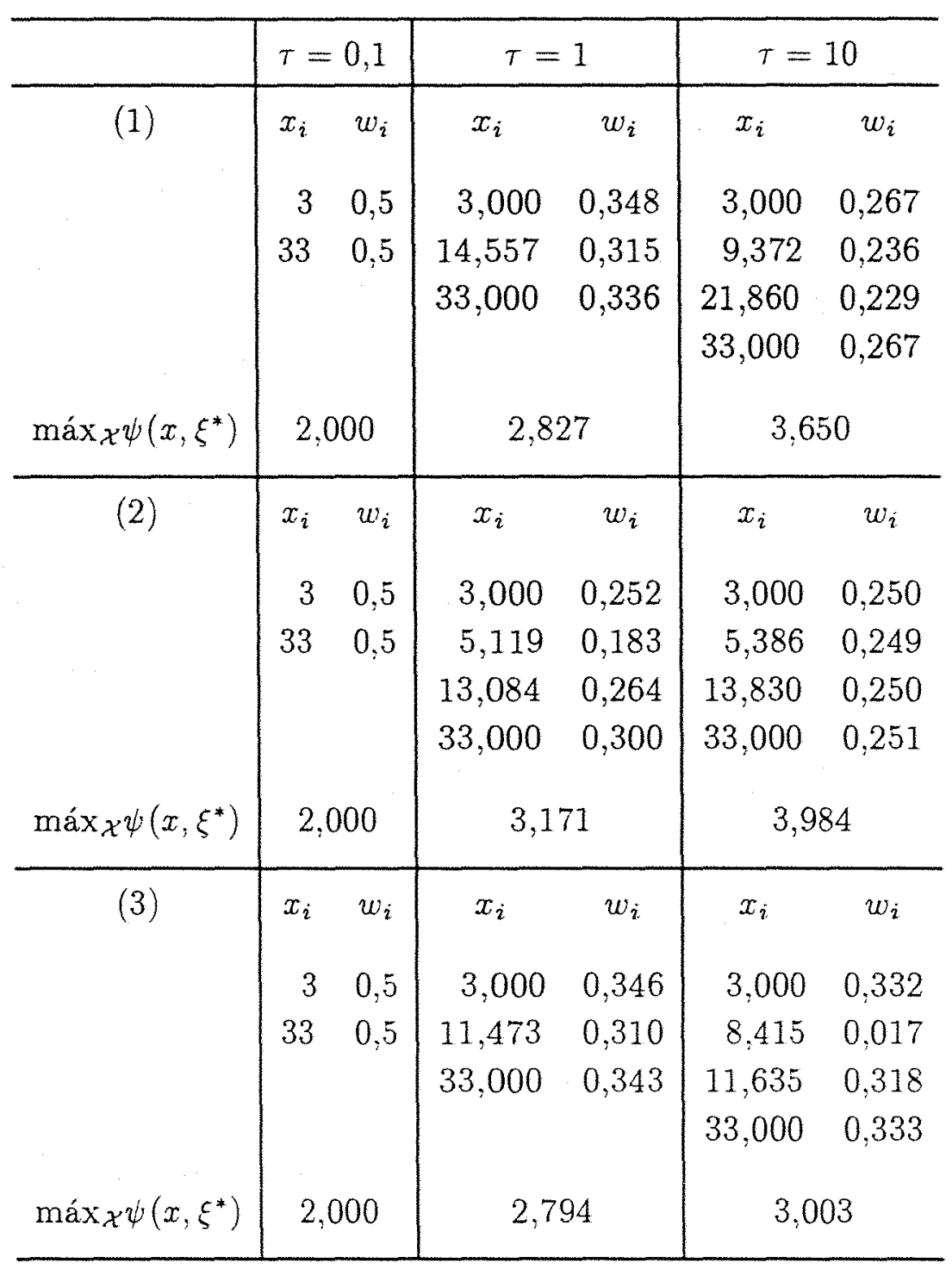


ajuste. No entanto, escolhendo-se $\tau=10$, os delineamentos gerados segundo os métodos 2 e 3 de ampliação do modelo, possuem um número excessivo $(p=4)$ de pontos de suporte.

De modo a verificar se os delineamentos apresentados na Tabela 15 são D-ótimos segundo o critério de Bayes, foram construídos os gráficos apresentados nas Figuras 11, 12 e 13. Para todos esses delineamentos, pode-se observar que os máximos das funções $\psi$ ocorrem para os pontos de suporte desses delineamentos, para a região experimental $\mathcal{X}=[3,33]$ considerada. Assim, de acordo com o Teorema da equivalência geral apresentado na Seção 3.3.3, são todos D-ótimos de Bayes.

Algumas propriedades, ainda não comprovadas, podem ser extraídas a partir dos resultados apresentados na Tabela 15 e dos gráficos apresentados nas Figuras 11, 12 e 13, que poderão ser úteis tanto na verificação da otimalidade como na obtenção de delineamentos com pontos de suporte com iguais pesos. Veja, por exemplo, que em todos os casos, o valor máximo de $\psi$ em $\mathcal{X}$, está sempre compreendido entre $p_{1}$ e $p$ e que, quando o valor máximo de $\psi$ tende a um número inteiro $v$, o delineamento D-ótimo de Bayes tende a um delineamento com $v$ pontos de suporte e pesos iguais a $1 / v$. Essa propriedade pode ser especialmente observada para o delineamento para $\tau=10$ e modelo aumentado, utilizando-se o segundo método de aumento (Tabela 15), com valor máximo 3,984 $\approx 4$, com 4 pontos de suporte com pesos tendendo a 1/4. Para o delineamento para $\tau=10$ e modelo aumentado utilizando-se o terceiro método de aumento, o máximo é igual a 3,003 $\approx 3$; observa-se que esse delineamento é muito próximo de um com 3 pontos de suporte e pesos iguais a $1 / 3$. Note, ainda, que quando o valor máximo tende a $v$ pela esquerda, o número de pontos é igual a $v$ e que quando tende a $v$ pela direita, o número de pontos é igual a $v+1$. Além disso, quanto mais próximo de $v$, pela direita, estiver o valor máximo de $\psi$, maiores serão as dificuldades para a obtenção do delineamento ótimo. Isto devido à função, nesses casos, apresentar-se praticamente constante para certos intervalos da região experimental, sendo difícil determinar numericamente seus pontos de máximo. Este fato aconteceu marcadamente para a obtenção do delineamento ótimo para $T=10$ e o modelo aumentado utilizando-se o terceiro método 
$\psi\left(x, \xi^{*}\right)$

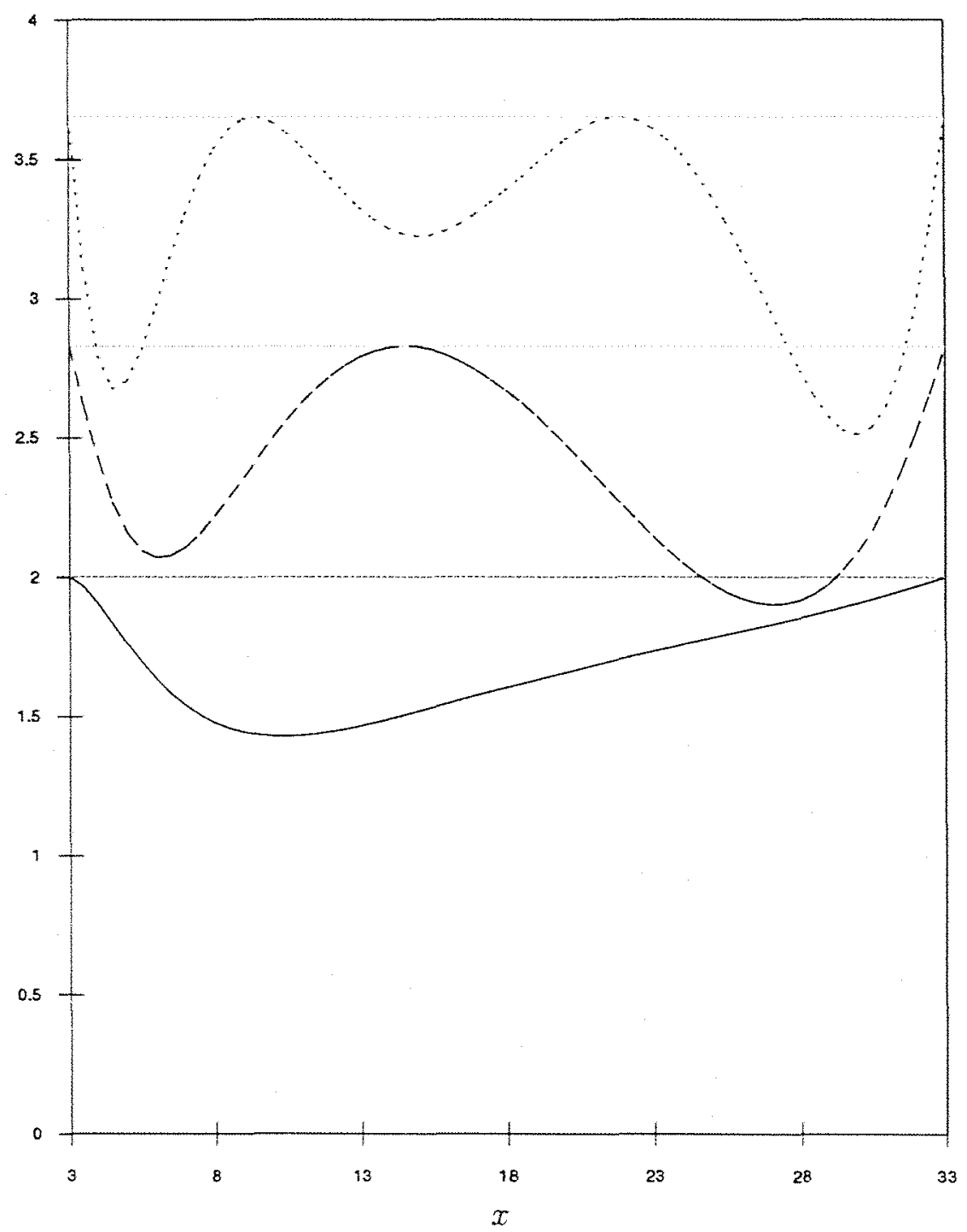

Figura 11: Gráficos de $\psi\left(x, \xi^{*}\right)$ para os delineamentos D-ótimos contínuos de Bayes, para $\tau=0,1(-), \tau=1(-)$ e $\tau=10(\cdots), \operatorname{com} N=12$, para o modelo aumentado construído adicionando-se um polinômio de ordem pequena ao modelo original. 
$\psi\left(x, \xi^{*}\right)$

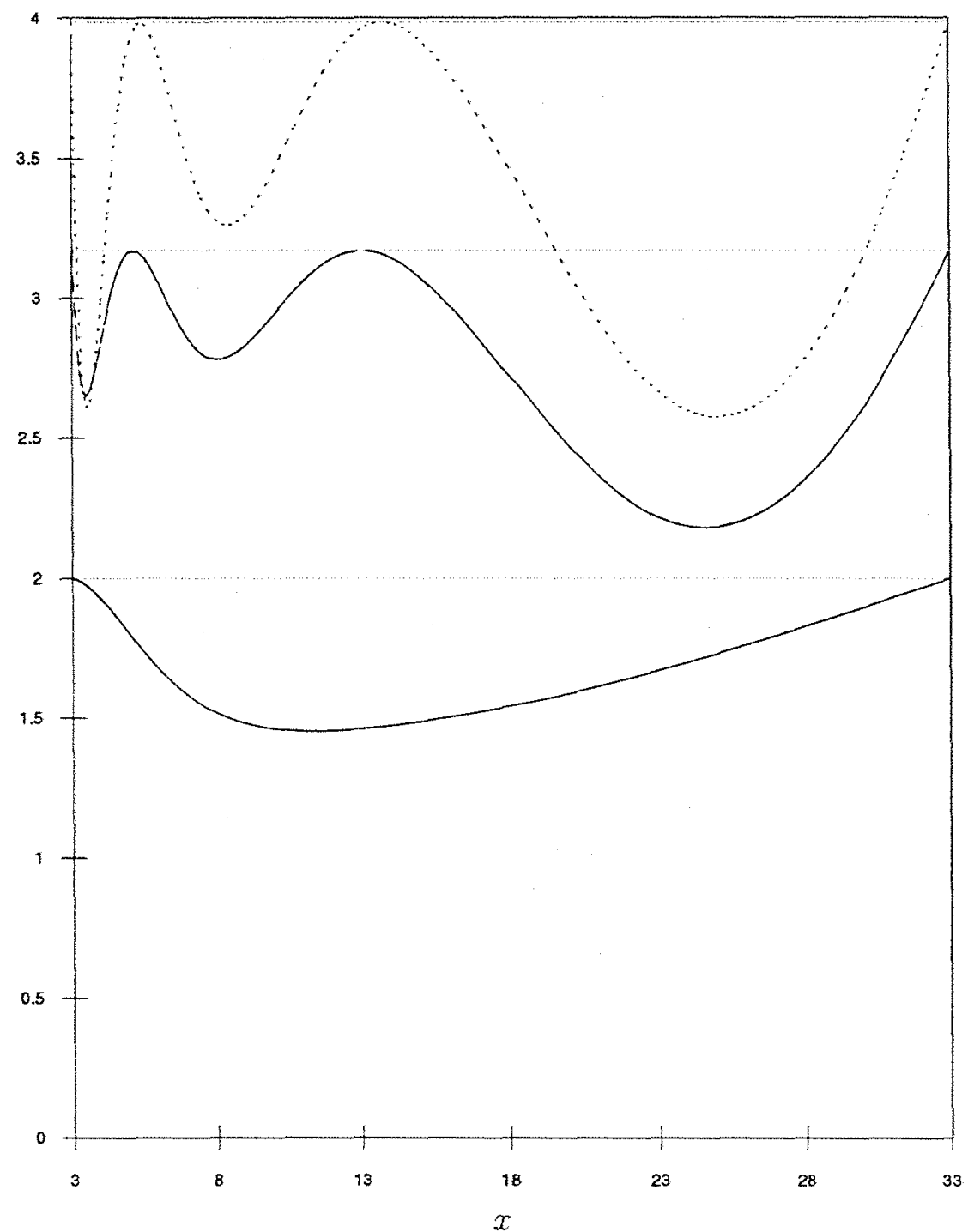

Figura 12: Gráficos de $\psi\left(x, \xi^{*}\right)$ para os delineamentos D-ótimos contínuos de Bayes, para $\tau=0,1(-), \tau=1(-)$ e $\tau=10(\cdots), \operatorname{com} N=12$, para o modelo aumentado construído adicionando-se termos quadráticos e de produto cruzado às derivadas parciais da resposta em relaçāo aos parâmetros. 
$\psi\left(x, \xi^{*}\right)$

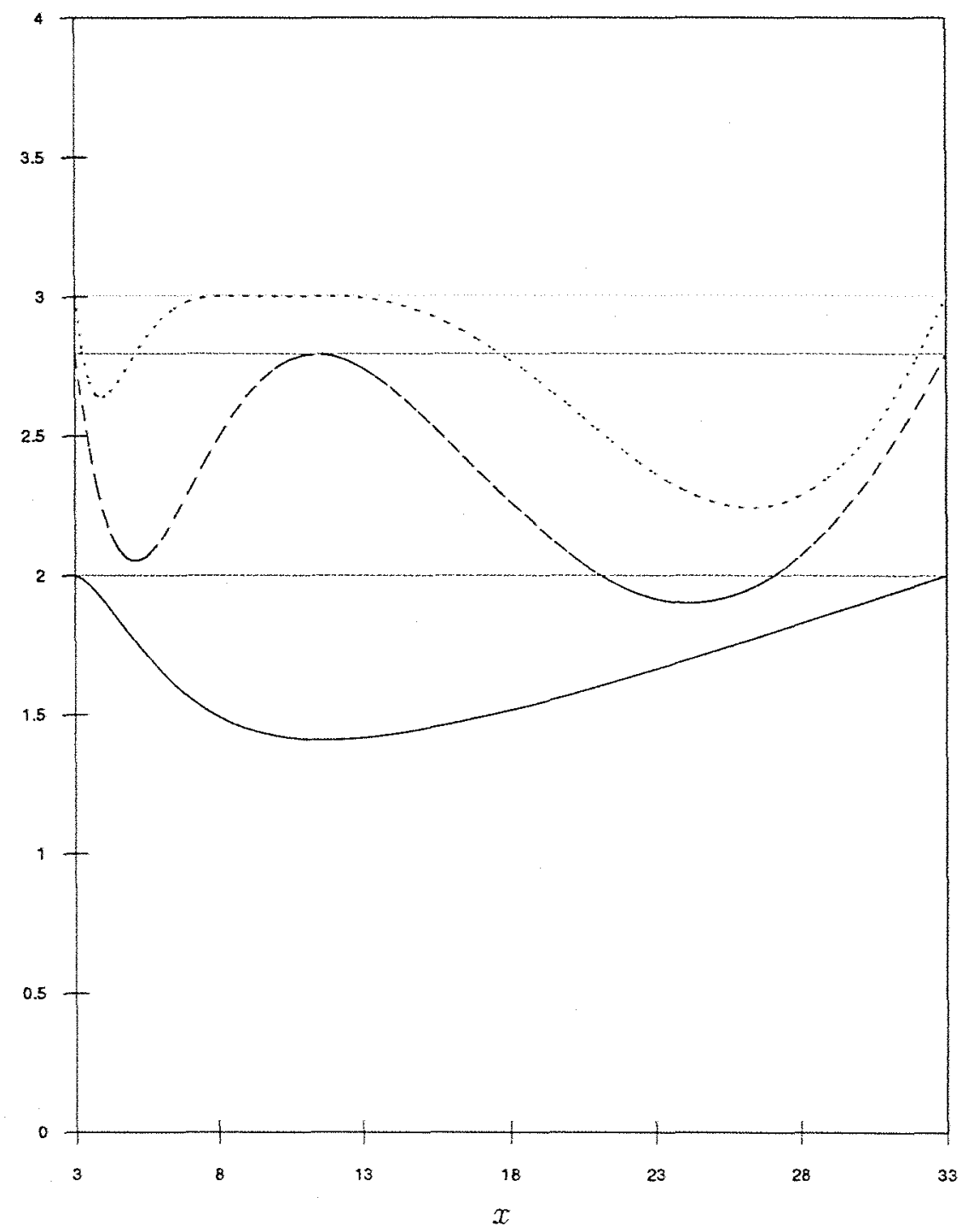

Figura 13: Gráficos de $\psi\left(x, \xi^{*}\right)$ para os delineamentos D-ótimos contínuos de Bayes, para $\tau=0,1(-), \tau=1(--)$ e $\tau=10(\cdots)$, com $N=12$, para o modelo aumentado construído aninhando-se o modelo original em um mais geral. 
de aumento, cujo gráfico da função $\psi$ para o delineamento (Figura 13) apresenta-se praticamente constante para valores de $x$ entre 8 e 13.

Enquanto a otimalidade dos delineamentos contínuos pode ser verificada utilizando-se o Teorema da equivalência geral, para os delineamentos exatos não existem métodos para se verificar se são realmente ótimos, a não ser que seja possivel enumerar todos os possíveis delineamentos na região adotada. No entanto, como método aproximado, pode-se comparar os delineamentos discretos com os ótimos contínuos. Comparando-se a segunda e terceira colunas da Tabela 13 com a terceira e quarta colunas da Tabela 15 observa-se que os exatos são muito próximos aos contínuos ótimos.

Para compará-los, como sugestão, podem ser usadas medidas de eficiência relativa como as descritas na Seção 3.2.2, dos delineamentos discretos em relação ao ótimo contínuo. Uma outra alternativa, é construir os gráficos da função $\psi$ para os delineamentos discretos, sendo que a existência de trechos constantes alertaria o pesquisador sobre a possibilidade de se encontrarem inúmeros delineamentos diferentes com eficiências, em relação ao ótimo, bastante semelhantes.

Para se verificar se os delineamentos exatos de iguais interesses de Bayes apresentados na Tabela 13 são ótimos, pelo menos aproximadamente, um futuro trabalho envolveria o desenvolvimento de formas mais simples para a utilização do teorema da equivalência geral para o critério de otimização composto de Bayes que inclui o de iguais interesses de Bayes para $\alpha=p_{1} / p$.

É importante salientar que há um grande potencial de aplicação da metodologia apresentada, para o planejamento de experimentos na Agricultura, para modelos não lineares de superfícies de resposta. Nesses experimentos, o número de tratamentos formado pela combinação dos níveis das covariáveis envolvidas é geralmente um fator altamente restritivo e a escolha desses níveis é bastante difícil, contando apenas com o conhecimento prévio do pesquisador na área. Nesses ensaios a ampliação do modelo utilizando os métodos apresentados pode levar a um número excessivo de parâmetros adicionais, muito maior do que o número de parâmetros do modelo original. Como conseqüencia, com o uso do critério de otimização $D$ de 
Bayes, os delineamentos ótimos gerados poderiam dar importância excessiva para a estimação dos parâmetros extras do modelo ampliado. Este fato justificaria a adoção dos delineamentos D-ótimos de Bayes compostos de igual interesse e do desenvolvimento de formas mais simples do Teorema da equivalência geral para esse critério. Seria importante, portanto, como futuro trabalho, verificar essas hipóteses levantadas. 


\section{Conclusões}

O Teorema da equivalência geral proposto para modelos logísticos multivariados fornece um método simples de verificação da otimalidade de delineamentos para esses modelos.

A metodologia proposta, do planejamento de ensaios de dose e resposta usando a técnica de reamostragem "bootstrap", apresenta uma série de características desejáveis:

- pode ser facilmente implementada (no presente trabalho optou-se pelo pacote computacional GAUSS (Aptech Systems, Inc. 1988));

- permite a escolha do número de diferentes doses do ensaio definitivo;

- permite obter delineamentos com um número suficiente de doses necessário para se verificar a falta de ajuste do modelo adotado;

- gera gráficos que podem ser de grande valia no planejamento de ensaios por pesquisadores;

- evita o risco de assumir a normalidade assintótica dos parâmetros.

A metodologia proposta para a obtenção de delineamentos com um pequeno número adicional de pontos de suporte, para modelos não lineares, mostrouse eficaz produzindo delineamentos exatos úteis para a deteç̧ão de falta de ajuste.

Embora o procedimento iterativo de transformação da matriz do delineamento elimine a correlação entre os termos extras e os termos originais, foi pequeno o efeito da sua adoção e, em alguns casos, tal procedimento pode levar à 
não convergência. Esses fatos sugerem que esse procedimento iterativo seja melhor estudado ou não utilizado.

A transformação da escala dos termos extras é importante para a incorporação da informação a priori, sendo desnecessária a transformação dos termos originais do modelo, sugerida por DuMouchel \& Jones (1994).

O Teorema da equivalência geral adaptado ao critério de otimização D de Bayes permite que seja verificada, de forma bastante simples, a otimalidade de delineamentos contínuos. 


\section{REFERÊNCIAS BIBLIOGRÁFICAS}

Agresti, A. Categorical data analysis. New York: John Wiley \& Sons, 1990. $558 \mathrm{p}$.

Agresti, A. An introduction to categorical data analysis. New York: John Wiley \& Sons, 1996. 290p.

Aitkin, M.; Anderson, D.; Francis, B.; Hinde, J. Statistical modelling in GLIM. Oxford: Oxford University Press, 1989.

Aptech SYstems, InC. The GAUSS System version 2.0. 26250 196th Place S.E., Kent, Washington: Aptech Systems, Inc, 1988.

Atkinson, A.C. Planning experiments to detect inadequate regression models. Biometrika, v.59, p.275-293, 1972.

Atkinson, A.C. Planning experiments for model testing and discrimination. Math. Oper. Statist., v.6, p.253-67, 1975.

Atkinson, A.C. Some topics in optimum experimental design for generalized linear models. In: INTERNational WORKShOP ON Statistical MODELliNG, Innsbruck, Áustria, 1995. Proceedings. New York: Springer-Verlag; 1995. p.11-18.

Atkinson, A. C. The usefulness of optimum experimental designs. Journal of the Royal Statistical Society, Series B v.58, n.1, p.59-76, 1996. 
Atkinson, A.C.; Bogacka, B. Compound, D- and $\mathrm{D}_{s}$-optimum designs for determining the order of a chemical reaction. Technometrics v.39, n.4, p. $347-356,1997$.

Atkinson, A.C.; Chaloner, K.; Herzberg, A.M.; Juritz, J. Optimum experimental design for properties of a compartmental model. Biometrics, v.49, p.325-337, 1993.

Atrinson, A.C.; Demétrio, C.G.B.; Zocchi, S.S. Optimum dose levels when males and females respond differently. Applied Statistics, v.44, p.213-226, 1995.

Atkinson, A.C.; Donev, A.N. Optimum experimental designs. Oxford: Oxford University Press, 1992. 328p.

Bishop, Y.; FienberG, S.E.; Holland, P. Discrete multivariate analysis. Cambridge: Massachusetts Institute of Technology Press, 1975.

Bleasdale, J.K.A.; Nelder, J.A. Plant population and crop field. Nature, $188,342,1960$.

Box, G.E.P.; Draper, N.R. Robust designs. Biometrika v.62, n.1, p.347-52, 1975.

Box, G.E.P.; Draper: N.R. Empirical model building and response surfaces. New York: Wiley, 1987. 688p.

Box, G.E.P.; TIAO, G.C. Bayesian inference in statistical analysis. New York: Wiley Classics, 1973. 588p. 
Brown, L.D.; Olkin, I.; SACKS, J.; WYNN, H.P. Jack Carl Kiefer collected papers: Design of experiments. New York: Springer-Verlag, 1985.

Chaloner, K.; Larntz, K. Optimal Bayesian designs applied to logistic regression experiments. Journal of Statistical Planning and Inference, v.21, p. 191-208, 1989 .

Chaloner, K.; Verdinelli, I. Bayesian experimental design: a review. Statistical Science, v.10, p.273-304, 1995.

Costa, V.A. Parasitóides (Hymenoptera, Chalcidoidea) de Musca domestica (L., 1758) Stomoxys calcitrans (L., 1759) e Muscina stabulans (Fallén, 1816)(Diptera, Muscidae) em aviários de Echaporã, SP. Piracicaba, SP, Brasil, 1989. 55p. Dissertação (M.S.) - Escola Superior de Agricultura "Luiz de Queiroz"/USP.

Cox, D.; SNell, E.J. Analysis of binary data 2.ed. Londres: Chapman \& Hall, 1989.

DEvine, M.D. Mechanisms of resistance to acetyl-coenzyme A carboxylase inhibitors: a review. Pesticide Science, v.51, p.259-264, 1997.

Devine, M.D.; Eberlein, C.V. Physiological, biochemical and molecular aspects of herbicide resistance based on herbicide resistance based on altered target sites. In: RoE, R.M.; Burton, J.D.; KuHR, R.J. (Ed.), Herbicide activity: toxicology, biochemistry and molecular biology, Amsterdam, Holanda: 1. O. S. Press, 1997. p.159-185.

DuMouchel, W.; Jones, B. A simple Bayesian modification of D-optimal designs to reduce dependence on an assumed model. Technometrics, v. 36 , p. $37-47,1994$. 
DYKstra, O. The augmentation of experimental data to maximize $\left|X^{T} X\right|$. Technometrics, v.13, p.682-688, 1971.

EFRON, B.; TIBSHIRANI, R.J. An introduction to the bootstrap. Londres: Chapman \& Hall, 1993. 436p.

Farazdaghi, H.; Harpis, P.M. Plant competition and crop yield. Nature, v.217, p.289-290, 1968.

Fedorov, V.V. Theory of optimal experiments. Londres: Academic Press, Inc., 1972.

Fedorov, V.V.; Atkinson, A.C. The optimum design of experiments in the presence of uncontrolled variability and prior information. In: DODGE, Y.; FEDOROV, V.V.; WYNN, H.P. (Ed.), Optimal design and analysis of experiments. Amsterdam: North-Holland, 1988, p.327-344.

Fedorov, V.V.; HACKL, P. Model-oriented design design of experiments. New York: Springer Verlag, 1997. 117p.

Fitzmaurice, G.M.; Laird, N.M. A likelihood-based method for analysing longitudinal binary responses. Biometrika, v.80, p.141-151, 1993.

Flournoy, N. A clinical experiment in bone marrow transplantation: estimating a percentage point of a quantal response curve. In: Gatsonis, R.K.C.; Hodges, J.; Singpurwalla, N. (Ed.), Case studies in bayesian statistics. New York: Springer-Verlag, 1993. p.324-336.

GLONEK, G.F.V. A class of regression models for multivariate categorical responses. Biometrika, v.83, p. 15-28, 1996. 
Glonek, G.F.V.; MCCullagh, P. Multivariate logistic models. Journal of the Royal Statistical Society, Series B, v.57, p.533-546, 1995.

GUMBEL, E.J. Bivariate logistic distributions. Journal of the American Statistical Association, v.56, p.335-349, 1961.

Heise, M.A.; MYers, R.H. Optimal designs for bivariate logistic regression. Biometrics, v.52, p.613-624, 1996.

ItePAN, N.M. Aumento no período de aceitabilidade de pupas de Musca domestica L., 1758 (Diptera: Muscidae), irradiadas com raios gama, como hospedeiras de parasitóides (Hymenoptera: Pteromalidae). Piracicaba, SP, Brasil, 1995. 42p. Dissertaçāo (M.S.) - Centro de Energia Nuclear na Agricultura/USP.

Itepan, N.M.; Filho, E.B.; Arthur, V.; Costa, N. Utilização de pupas de Musca domestica (L.,1758) (Diptera: Muscidae) irradiadas com raios gama (60 Co) na criação dos parasitos Spalangia endius (Walker), Muscidifurax raptor (Girault \& Sanders) e Pachycrepoideus vindemiae (Rondani). In: Congresso Brasileiro de Entomologia, Campinas, SP, Brasil, 1987. Resumos. Campinas, 1987.

KIEFER, J.; WOLfowitz, J. The equivalence of two extrema problems. Canadian Journal of Mathemathics, v.12, p.363-366, 1960.

KREWSKI, D.; ZHU, Y.; FUNG, K. Statistical analysis of overdispersed multinomial data from developmental toxicity studies. In: MorGAN, B.J.T. (Ed.), Statistics in toxicology. Oxford: Oxford University Press, 1996. p.151-178.

LANG, J.B. Maximum likelihood methods for a generalized class of log-linear models. The Annals of Statistics, v.24, p.726-752, 1996a. 
LANG, J.B. On the comparison of multinomial and Poisson log-linear models. Journal of the Royal Statistical Society, Series B, v.58, p.253-266, 1996b.

MCCUllagh, P.; Nelder, J.A. Generalized linear models 2.ed. Londres: Chapman \& Hall, 1989. 511p.

MEAD, R. Plant density and crop field. Applied Statistics, v.19, p.64-81, 1970.

Morgan, B.J.T. Analysis of quantal response data. Londres: Chapman \& Hall, 1992. 511p.

Numerical Algorithms Group, NAG The GLIM system release $\mathbf{3 . 7 7}$ manual. Generalized linear iteractive modelling. Wilkinson House, Jordan HillRoad, Oxford OX2 8DR, UK: Numerical Algorithms Group, NAG, 1986.

O'Brien, T.E. Optimal design and lack of fit in nonlinear regression models. In: International Workshop on Statistical Modelling, Innsbruck, Áustria, 1995. Proceedings. New York: Springer-Verlag, 1995. p.201-206.

PÁZMAN, A. Foundations of optimum experimental design. Bratislava, Czechoslovakia: D. Reidel Publishing Company, 1986.

PONCE DE LEON, A.C.M. Introdução à teoria do planejamento de experimentos ótimos. Rio de Janeiro, ABE - Associação Brasileira de Estatística, 1996. 53p.

Ponce de Leon, A.C.M.; Atkinson, A.C. The design of experiments to discriminate between two rival generalized linear models. In: GLIM CONference and International Workshop on Statistical Modelling, 
Munich, 1992. Proceedings. New York: Springer-Verlag, 1992.

Ponce De Leon, A.C.M.; Atkinson, A.C. Designing optimal experiments for the choice of link function for a binary data model. In: MULLER, W.G.; Wynn, H.P.; Zhigljavsky, A.A. (Ed.), Model-oriented data analysis. Heidelberg: Physica, 1993.

Price, C.J.; Kimmel, C.A.; George, J.D.; MarR, M.C. The developmental toxicity of diethylene glycol dimethyl ether in mice. Fundamental and Applied Toxicology, v.8, p.115-126, 1987.

Pukelsheim, F. Optimal design of experiments. New York: John Wiley \& Sons, Inc, 1993. 480p.

Pukelsheim, F.; Rosemberger, J.L. Experimental designs for model discrimination. Journal of the American Statistical Association, v.88, $n .422$, p. $642-649,1993$.

Rao, C.R.; Toutenburg, H. Linear models. New York: Springer-Verlag, 1995. 325p.

Ratkowsky, D.A. Nonlinear regression modeling: A unified practical approach. New York: Marcel Dekker, Inc, 1983. 276p.

RATKowskY, D.A. Handbook of nonlinear regression models. New York: Marcel Dekker, Inc, 1990. 241p.

RICHARDS, F.S.G. A flexible growth function for empirical use. Journal of Experimental Botany, v.10, p.290-300, 1959.

Seber, G.A.F.; WILd, C.J. Nonlinear regression. New York: John Wiley \& Sons, 1989. $768 \mathrm{p}$. 
Seefeldt, S.S.; Jensen, J.E.; Fuerst, E.P. Log-logistic analysis of herbicide dose-response relationships. Weed Technology, v.9, p.218-227, 1995.

ShINOZAKI, K.; KIRA, T. Intraspecific competition among higher plants. VII. Logistic theory of the C-D effect. Journal of the Institute of Polytechnics, Osaka City University, v.D7, p.35-72, 1956.

Silverman, B.W. Density estimation for statistics and data analysis. Londres: Chapman \& Hall, 1986.

SilveY, S.D. Optimal Design. Londres: Chapman \& Hall, 1980. 86p.

SovZA, G.S. Introdução aos modelos de regressão linear e nāo-linear. Brasília: Embrapa, 1998. 489p.

Tsutakawa, R.K. Design of an experiment for bioassay. Journal of the American Statistical Association, v.67, p.584-590, 1972.

Tsutakawa, R.K. Selection of dose levels for estimating a percentage point of a logistic quantal response curve. Applied Statistics, v.29, p.25-33, 1980.

ZhU, Y.; Krewski, D.; Ross, W.H. Dose-response models for correlated multinomial data from developmental toxicity studies. Applied Statistics, v.43, p.583-598, 1994.

Zocchi, S.S. Misturas de modelos logit, probit and complemento-log-log. Piracicaba, SP, Brasil, 1993. 133p. Dissertação (M.S.) - Escola Superior de Agricultura "Luiz de Queiroz"/USP. 